T.C.

MARMARA UNIVERSITY

INSTITUTE FOR GRADUATE STUDIES IN

PURE AND APPLIED SCIENCES

EXOPOLYSACCHARIDE PRODUCTION BY HALOMONAS

STRAINS ISOLATED FROM TURKEY

Hande KAZAK

\author{
THESIS \\ FOR THE DEGREE OF MASTER OF SCIENCE \\ IN \\ BIOENGINEERING \\ SUPERVISOR \\ Assoc. Prof Ebru TOKSOY ÖNER
}

ISTANBUL 2009 
T.C.

MARMARA UNIVERSITY

INSTITUTE FOR GRADUATE STUDIES IN

PURE AND APPLIED SCIENCES

\title{
EXOPOLYSACCHARIDE PRODUCTION BY HALOMONAS STRAINS ISOLATED FROM TURKEY
}

Hande KAZAK

(141103820060174)

\author{
THESIS \\ FOR THE DEGREE OF MASTER OF SCIENCE \\ IN \\ BIOENGINEERING \\ SUPERVISOR \\ Assoc. Prof Ebru TOKSOY ÖNER
}

İSTANBUL 2009 


\section{ACKNOWLEDGEMENTS}

I would like to express my sincere gratitude to my thesis advisor Assoc. Prof. Ebru TOKSOY ÖNER for her continuous guidance, generous support, and valuable advice and for being a pleasure to work with.

I would like to express my sincere gratitude to Prof. Barbara NICOLAUS and Dr. Annarita POLI for their help on the characterization of EPS studies made in Institute of Biomolecular Chemistry of CNR (ICB), Naples, Italy.

I would like to express my gratitude to Prof. Jülide AKBUĞA, the member of my thesis committee, for her time devoted to read and comment on my thesis.

The research presented in this thesis was conducted in the Bioengineering Department of Marmara University and supported by the financial support of The Scientific and Technological Research Council of Turkey (TÜBITTAK) in the framework of the Project "Extremophiles as Sources of Polysaccharides" with project number TBAG-U/122 (104T263).

Many thanks to the Dean of Engineering Faculty, Prof. A. Alp SAYAR, for his support and for giving me opportunity to work in the Biotechnology Laboratories.

I wish to thank all of my friends that have worked with me in the Biotechnology Laboratory for their everlasting support. I am deeply obliged to Özlem ATEŞ, Umut TÜYEL, Bahar GÜRLEYENDAĞ, Faruk KÜÇÜKAŞIK, Deniz KÖŞEBENT, Çağakan ÖZBALCI, Müge SENNAROĞLU BOSTAN and Selim CEYLAN for being very close friends and for their moral support and encouragement throughout this study.

Finally, this study would not been possible without the patience and everlasting support of my family. This thesis is dedicated to my family who has always been there to lend their unending support and love. 


\section{CONTENTS}

PAGE

ACKNOWLEDGEMENTS..................................................................i

CONTENTS .............................................................................................................. ii

ABSTRACT .........................................................................................v

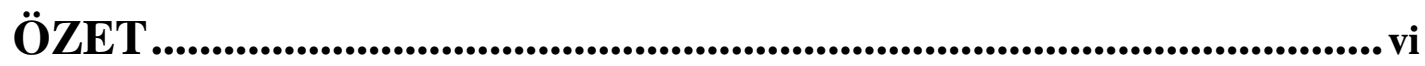

LIST OF SYMBOLS AND ABBREVATIONS................................... vii

LIST OF FIGURES ........................................................................ix

LIST OF TABLES ....................................................................x

PART I. INTRODUCTION AND OBJECTIVES ............................1

PART II. GENERAL BACKGROUND .......................................3

II.1 MICROBIAL BIOPOLYMERS............................................... 3

II.2 EXOPOLYSACCHARIDES............................................................. 4

II.2.1 Biochemistry and Genetics of EPS ................................................4

II.2.2 Rheological Properties of EPS ............................................. 7

II.2.3 Microbial EPS Production Process ....................................9

II.3 IMPORTANT APPLICATIONS OF EPS.................................... 11

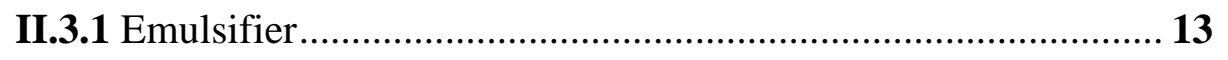

II.3.2 Bioflocculants ................................................................. 15

II.3.3 Heavy Metal Biosorption Ability ......................................................16

II.3.4 EPS in Pharmacy and Medicine.............................................. 17

II.4 EXTREMOPHILES AS SOURCES FOR EPS ........................... 21

II.5 EPS PRODUCTION by Halomonas sp.............................................. 23

PART III. EXPERIMENTAL WORK .........................................25

III.1 MATERIALS

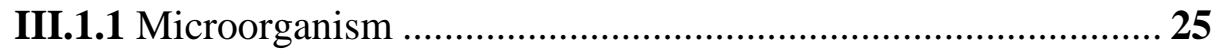

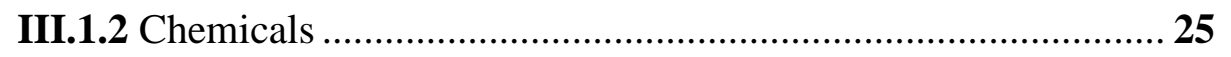

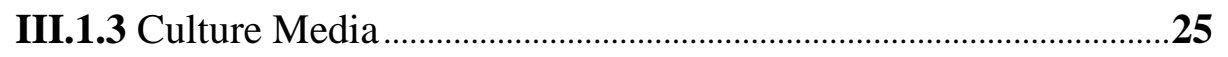

III.1.4. Buffers and Standard Solutions ............................................ 26 
III.1.4.1. Solutions Used in Phenol/Sulfuric Acid Method .... 26

III.1.4.2 Solutions Used in Preparing Stock Culture ............... 26

III.1.4.3 Buffers Used for $\mathrm{pH}$ Adjustment............................. 27

III.2 LABORATORY EQUIPMENT ................................................ 27

III.3 EXPERIMENTAL PLAN AND TECHNIQUES .............................29

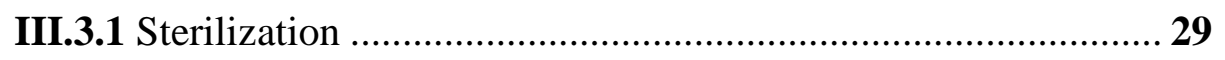

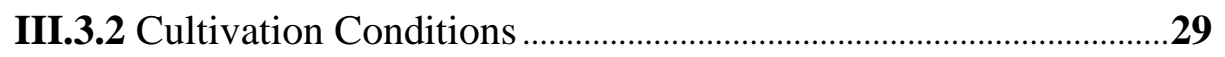

III.3.3 Preparation of Preculture ......................................................... 30

III.3.4 Growth Conditions ..........................................................................30

III.3.4.1 Preculture Growth .................................................. 30

III.3.4.2 Batch Experiments ..........................................................30

III.3.5 Isolation and Purification of EPS ............................................ 30

III.3.6 Statistical Optimization of the Medium .........................................31

III.3.7 EPS Production in Bioreactor...................................................... 31

III.3.7.1 Measurement of Bacterial Growth....................................31

III.3.7.2 Total Carbohydrate Analysis .................................... 32

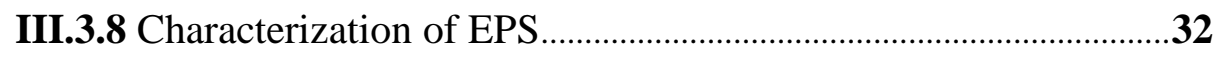

III.3.8.1 Determination of Protein Concentration ................... 32

III.3.8.2 Determination of Quantity and Quality of DNA....... 33

III.3.8.3 Uronic Acid Assay ................................................... 33

III.3.8.4 Rheological Studies............................................................33

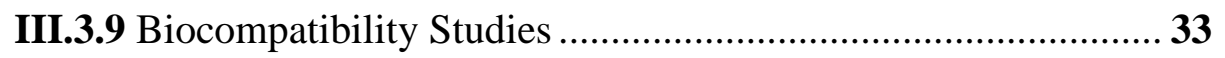

III.3.9.1 Inhibition of Toxic Activity.................................................33

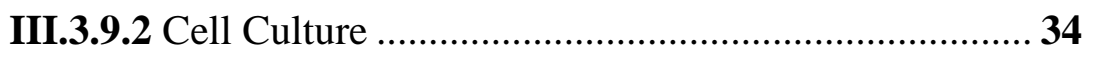

III.3.10 Chemical Characterization of EPS ..................................................35

PART IV RESULTS AND DISCUSSION ……………...............................36

IV.1 OPTIMIZATION OF FERMENTATION CONDITIONS ...........36

IV.1.1 Effect of Different Carbon Sources on Growth And

Exopolysaccharide Production................................................... 36

IV.1.2 Statistical Optimization of the Medium...................................41

IV.2 EPS PRODUCTION IN BIOREACTOR ........................... 45

IV.3 CHARACTERIZATION of EPS ................................................ 48

IV.4 BIOCOMPATIBILITY STUDIES ………………………………...... 


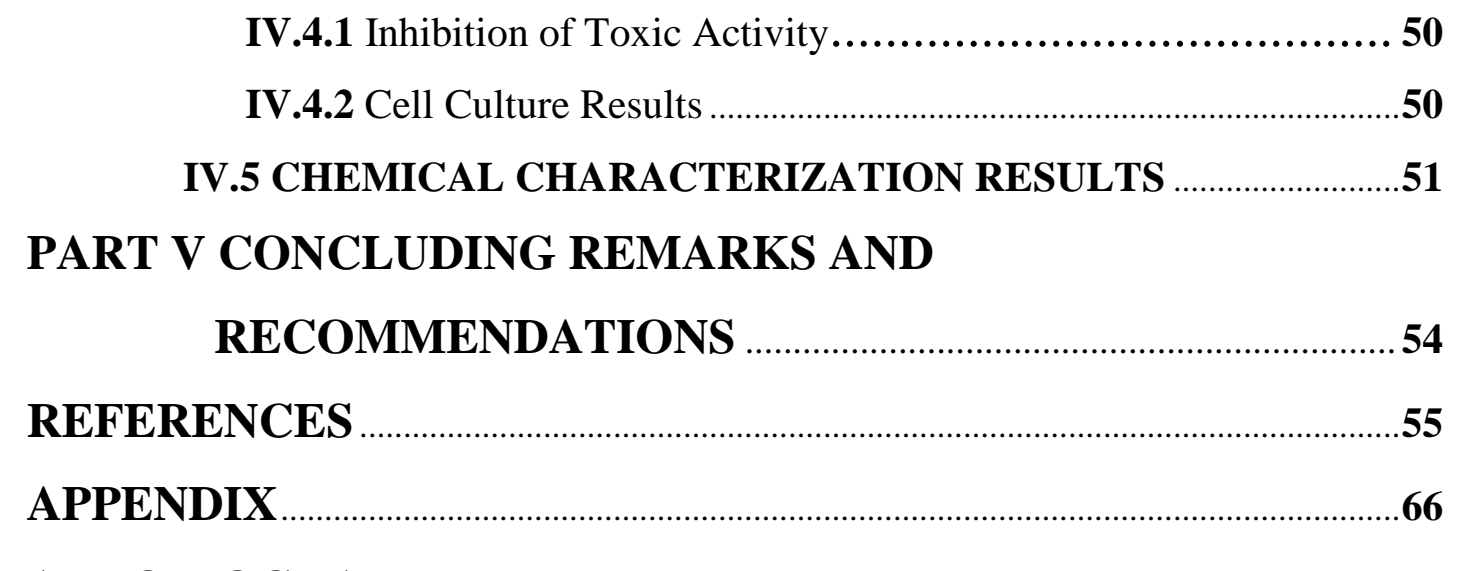

AUTOBIOGRAPHY .....................................................................................70 


\section{ABSTRACT}

\section{EXOPOLYSACCHARIDE PRODUCTION BY HALOMONAS STRAINS ISOLATED FROM TURKEY}

Biopolymers are superior to petrochemical-derived polymers in several aspects that embrace biocompatibility, biodegradability, and both environmental and human compatibility. During recent years, a variety of biopolymers have become available for use in many applications that are not only compatible with human lifestyle but also are friendly to the environment. Due to their many interesting physicochemical and rheological properties with novel functionality, the microbial exopolysaccharides (EPS) act as new biomaterials and find wide range of applications in many industrial sectors like textiles, detergents, adhesives, microbial enhanced oil recovery (MEOR), wastewater treatment, dredging, brewing, downstream processing, cosmetology, pharmacology, and food additives. Xanthan, dextran and pullulan are examples of microbial polysaccharides with a considerable market due to their exceptional properties. Biopolymers with properties superior to the commercial ones could not preserve their functions under industrial process conditions like extremes of temperature, salinity or $\mathrm{pH}$. Hence, most research is focused on the identification of EPS producing extremophiles with the idea that as these microorganisms survive environmental extremes of desiccation, temperature, pressure, salinity, acidity, heavy metals, and radiation, it is to be expected that their biopolymers will also have some unique properties to adapt to such extreme conditions.

Considering the widespread use of microbial polysaccharides in various industrial applications, production of EPS by Halomonas sp AAD6 bacteria isolated from Çamaltı Saltern Area in Izmir was used within the scope of this study. The fermentation conditions were optimized for high-yield biopolymer production by this microorganism. Also within the scope of this study, this novel exopolysaccharide was produced under controlled bioreactor conditions, purified with high yield and chemically characterized.

Key Words: Extremophiles, Halophilic microorganisms, Exopolysaccharide production January, 2009

Hande KAZAK 


\section{ÖZET}

\section{TÜRKIYE'DEN IZOLE EDILLEN HALOMONAS SUŞLARINDAN EKZOPOLISSAKKARITT ÜRETIMI}

Biyopolimerler, biyouyumluluk, biyobozunurluk, çevre ve insana uyumluluk gibi bir çok açıdan petrokimyasal türevli polimerlere göre daha üstün olmalarından dolayı doğal ve çevreye dost birçok uygulamada yaygın olarak kullanılabilir duruma gelmişlerdir. Yeni biyomalzemeler olarak kabul edilen mikrobiyal ekzopolisakkaritler (EPS), farklı fizikokimyasal ve reolojik özellikleri sayesinde tekstil, deterjan, tutkal, petrol ve türevleri atıklarının mikrobiyal yıkımı, atıksu arıtma, kozmetik, ilaç ve gıda gibi çok farklı endüstriyel sektörlerde uygulama alanı bulmuş biyopolimerlerdir. Dekstran, ksantan ve pullulan gibi çok geniş pazara sahip mikrobiyal ekzopolisakkaritlerden daha üstün özelliklere sahip olduğu düşünülen biyopolimerlerin bu özelliklerini, endüstriyel uygulamaların gerektirdiği ekstrem sıcaklık, tuzluluk ve pH koşullarında koruyamadıkları görülmüştür. Bu sebeple, ekstrem ortamlarda yaşayabilen ekstremofilik mikroorganizmaların ürettiği biyopolimerlerin karakterizasyonu çok önem kazanmıştır.

Mikrobiyal polisakkaritlerin çeşitli endüstriyel alanlardaki yaygın kullanımı da göz önünde bulundurularak, İzmir Çamaltı Tuzlası'ndan izole edilen Halomonas sp. AAD6 halofilik bakteri izolatı ile polisakkarit üretimi bu çalışma kapsamında araştırılmıştır. Bu doğrultuda, Halomonas sp. AAD6 mikroorganizmasının üretim koşulları optimize edilmiştir. Kontrollü biyoreaktör koşullarında üretilen polisakkarit saflaştırılmış ve karakterizasyonu yapılmıştır.

Anahtar Kelimeler: Ekstremofiller, Halofilik mikroorganizmalar, ekzopolisakkarit üretimi

Ocak, 2009

Hande KAZAK 


\section{LIST OF SYMBOLS AND ABBREVATIONS}

\begin{tabular}{|c|c|}
\hline Da & : dalton \\
\hline g & : gram \\
\hline h & : hour \\
\hline kDa & : kilodaltons \\
\hline $\mathbf{L}$ & : liter \\
\hline $\mathbf{M}$ & : Molar \\
\hline $\min$ & : minute \\
\hline Мpa & : Mega Pascal \\
\hline nm & : Nanometers \\
\hline rpm & : Round per minute \\
\hline $\mathbf{U}$ & : Unit \\
\hline vvm & : volume air/volume medium/min \\
\hline $\mathbf{v} / \mathbf{v}$ & : Volume per volume \\
\hline $\mathbf{w} / \mathbf{v}$ & : Weight per volume \\
\hline $\mathbf{X}$ & : Microbial biomass concentration \\
\hline $\mathbf{X}_{\mathbf{0}}$ & : Initial microbial biomass concentration \\
\hline$\mu$ & : Specific growth rate \\
\hline$\mu_{\max }$ & : Maximum specific growth rate \\
\hline$\mu \mathbf{L}$ & : Micro liters \\
\hline$\mu \mathrm{g}$ & : Micro grams \\
\hline BSA & : Bovine Serum Albumin \\
\hline CPS & : Capsular polysaccharides \\
\hline DCW & : Dry cell weight \\
\hline DMSO & : Dimethyl sulfoxide \\
\hline DNA & : Deoxy ribonucleic acid \\
\hline DNS & : 3,5-dinitrosalicylic acid \\
\hline EPS & : Exopolysaccharide \\
\hline FBS & : Fetal Bovine Serum \\
\hline GRAS & : Generally Recognized As Safe \\
\hline
\end{tabular}


HPAE-PAD : High Performance Anion Exchange Chromatography with Pulsed Amperometric Detection

\begin{tabular}{|c|c|}
\hline LAB & : Lactic Acid Bacteria \\
\hline $\mathbf{L D}_{\mathbf{5 0}}$ & : Median Lethal Dose \\
\hline LPS & : Lipopolysaccharides \\
\hline MEOR & : Microbial Enhanced Oil Recovery \\
\hline OD & : Optical density \\
\hline PAC & : Polyaluminum Chloride \\
\hline PBS & : Phosphate Buffered Saline \\
\hline PGA & : Poly Glutamic Acid \\
\hline PHA & : Polyhydroxyalkanoates \\
\hline PHB & : Poly(3-hydroxybutyrate) \\
\hline PVP & : Polyvinyl-pyrrolidone \\
\hline RNA & : Ribonucleic Acid \\
\hline RSM & : Response surface methodology \\
\hline SMCs & : Smooth Muscle Cells \\
\hline sp. & : Species \\
\hline TFA & : Trifluoroacetic Acid \\
\hline TLC & : Thin Layer Chromatography \\
\hline UV & : Ultraviolet \\
\hline
\end{tabular}




\section{LIST OF FIGURES}

Page

Figure II.1 Schematic representation of pathways involved in sugar fermentation via glycolysis to lactate and/or other acids and biosynthesis of exopolysaccharides (EPS) from intracellular sugar nucleotides (EPSa) and extracellular EPS biosynthesis

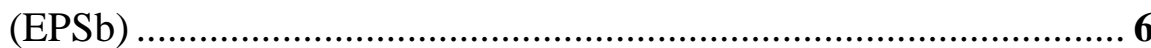

Figure II.2 Factors influencing the rheological characteristics of biopolymeric aqueous solutions 8

Figure II.3 Downstream process flowsheet for isolation and purification of pullulan......

Figure IV.1 The interaction of sucrose and $\mathrm{NaCl}$ on maximum biomass yields by shake flask cultures of Halomonas sp AAD6 strain

Figure IV.2 Time Course of Growth and EPS Production of Halomonas sp AAD6 46

Figure IV.3 Biocompatibility results of EPS 51

Figure IV.4.a TGA thermogram of the EPS from Halomonas sp. AAD6 53

Figure IV.4.b Fourier transform-infrared spectroscopy spectrum of the EPS from Halomonas sp. AAD6 


\section{LIST OF TABLES}

Page

Table II.1 Industrial production of principal exopolysaccharides ......................... 10

Table II.2 Food applications for complex microbial EPSs ................................. 13

Table II.3 Criteria for the pharmaceutical utilization of polysaccharides............... 18

Table IV.1 The Effect of Carbon Sources (1\% (w/v)) in the Minimal Medium on Growth and EPS Production

Table IV.2 Maximum Biomass yields by shake flask cultures of Halomonas sp AAD6 strain grown in different media. Coded values were used during the calculations. The real values in $\mathrm{g} / \mathrm{l}$ are given in parenthesis. Intermediate values are calculated assuming linear interpolation 42

Table IV.3 EPS yields in different phases in bioreactor cultivations 


\section{PART I}

\section{INTRODUCTION AND OBJECTIVES}

Biopolymers produced by diverse groups of microorganisms are rapidly emerging as a new and industrially important source of polymeric materials, which are gradually becoming economically competitive with natural gums produced by a variety of microbes (W.F. Fett, 2000).

Biopolymers are superior to petrochemical-derived polymers in several aspects that embrace biocompatibility, biodegradability, and both environmental and human compatibility. Due to their many interesting physicochemical and rheological properties with novel functionality, the microbial exopolysaccharides (EPS) act as new biomaterials and find wide range of applications in many industrial sectors like textiles, detergents, adhesives, microbial enhanced oil recovery (MEOR), wastewater treatment, dredging, brewing, downstream processing, cosmetology, pharmacology, and food additives (Martinez-Cánovas et al., 2004; Iyer et al., 2006). Xanthan, dextran and pullulan are examples of microbial polysaccharides with a considerable market due to their exceptional properties.

Biopolymers with properties much better than the commercial ones could not preserve their functions under industrial process conditions like extremes of temperature, salinity or $\mathrm{pH}$ (Lee et al., 2002). Hence, most research is focused on the identification of EPS producing extremophiles with the idea that as these microorganisms survive environmental extremes of desiccation, temperature, pressure, salinity, acidity, heavy metals, and radiation, it is to be expected that their biopolymers will also have some unique properties to adapt to such extreme conditions.

Since 1991, EPS producing extremophilic microorganisms have been isolated from deep-sea hydrothermal vents characterized by extreme pressure and temperature, high concentrations of $\mathrm{H}_{2} \mathrm{~S}$ and heavy metals. These include some 
Bacteria such as Alteromonas macleodii sub sp. fijiensis, Vibrio diabolicus, Alteromonas infernos (Raguénès et al., 1997; Roger et al., 2004) and Thermotoga maritima (Rinker et al., 2000) and Archaea such as Thermococcus litoralis (Rinker et al., 2000). EPS producing bacteria from marine Mediterranean shallow vents have also been described (Maugeri et al., 2002; Schiano Moriello et al., 2003). Hypersaline environments are also known to harbor a variety of EPS producing strains such as moderately halophilic bacteria of the genus Halomonas (Bouchotroch et al., 2000), Halomonas maura (Arias et al., 2003), Halomonas alkaliphila, strain CRSS (Poli et al. 2004), Halomonas ventosae and Halomonas anticariensis (Mata et al., 2006), Halomonas cerina (González-Domenech et al., 2008), Aphanocapsa halophytica (Matsunaga et al., 1996), haloalkalophilic Bacillus sp. I-450 (Kumar et al., 2004).

With the ultimate goal of finding EPS with novel and valuable properties, halophilic microorganism isolated from Çamalti Saltern area in Turkey, Halomonas sp. AAD6, was investigated in terms of its carbon source requirements for EPS production. EPS production was investigated both in shake flask cultures and under controlled bioreactor conditions and it is reported along with the chemical and rheological characterization of the polymer. 


\section{PART II}

\section{GENERAL BACKGROUND}

\section{II.1. MICROBIAL BIOPOLYMERS}

The last 50 years have been marked by the astounding growth in the use of plastics and polymers to provide packaging for safer foods, lighter weight and longer lasting appliances, safer cars, and an increased general level of convenience in all manner of applications. These advantages have created a global industry providing 350 billion pounds per year of materials valued at over $\$ 250$ billion. Yet the vast majority of these materials are based upon the extraction and processing of fossil carbon, typically oil and gas, leading ultimately to increases in greenhouse gases in the atmosphere and the accumulation of persistent plastic materials in the environment.

During recent years, a variety of biopolymers have become available for use in many applications that are not only compatible with human lifestyle but also are friendly to the environment. In nature, biopolymers often play important roles in maintaining cell viability by conserving genetic information, by storing carbonbased macromolecules, by producing either energy or reducing power, and by defending an organism against attack from hazardous environmental factors (Lee et al., 2002).

Biopolymers are superior to petrochemical-derived polymers in several aspects that embrace biocompatibility, biodegradability, and both environmental and human compatibility. They include various polysaccharides, polyamides (proteins and poly$\gamma$-glutamic acid ( $\gamma$-PGA)), nucleic acids (DNA and RNA), polyesters (polyhydroxyalkanoates, PHAs), polyphosphates, and polyisoprenoids (natural rubber). Today, some of these biopolymers are produced by bacterial fermentation and are used commercially in a wide range of applications such as foods, pharmaceuticals, plastics and agriculture. Not only refined carbohydrates but also agricultural and dairy byproducts can be used as substrates for the production of these biopolymers by fermentation processes. Some important biopolymers, for example cellulose and starch, are obtained directly from plant materials. Hence, it is 
unnecessary to produce these by fermentation due to the higher production costs, except for certain materials such as bacterial cellulose which has been produced by fermentation and used for specialty applications (Lee et al., 2002).

\section{II.2. EXOPOLYSACCHARIDES}

Exopolysaccharide (EPS) is a term first used by Sutherland (1972) to describe high molecular weight carbohydrate polymers produced by many marine bacteria. Since that time, EPS also has been used to indicate more broadly defined extracellular polymeric substances (Nichols et al., 2005).

Exopolysaccharides exist in a wide variety of unique and often complex chemical structures and they are believed to provide self-protection against antimicrobial substances, antibodies and bacteriophages and/or afford adherence to other bacteria, animal and plant tissues or inert surfaces, thus forming biofilms. They are also proving to have interesting bioactive functions and an extensive range of potential applications in industry, pharmacy, agriculture and various other areas.

During the past 50 years, a considerable number of bacterial EPSs have been described, but few have achieved great commercial success due either to their being unable to offer better properties than those already on the market or to difficulties in finding new practical applications (Mata et al., 2006).

\section{II.2.1. Biochemistry and Genetics of EPS}

Microbial polysaccharides can be present as constituents of cell walls, as part of lipo-polysaccharides (LPS), often referred to as O-antigens, as capsular polysaccharides (CPS) covalently associated with the cell surface, or secreted as exopolysaccharides (EPS) into the extracellular environment. Cell-associated polysaccharides like CPS and LPS are of considerable medical importance since they contribute to the virulence of their producers (Yoshida et al., 2003; Boels et al., 2001).

EPSs are long-chain polysaccharides consisting of branched, repeating units of sugars or sugar derivatives. These sugar units are mainly glucose, galactose and rhamnose, in different ratios. They are secreted into their surroundings during growth and are not attached permanently to the surface of the microbial cell. This distinguishes them from the structurally similar capsular polysaccharides, which do remain permanently attached to the surface of the cell. EPSs from microbial sources can be classified into two groups: homopolysaccharides (e.g. cellulose, dextran, 
mutan, alternan, pullulan, levan and curdlan) and heteropolysaccharides (e.g. gellan and xanthan). Homopolysaccharides consist of repeating units of only one type of monosaccharide (D-glucose or D-fructose) and can be divided into two major groups: glucans and fructans. By contrast, heteropolysaccharides have repeating units that demonstrate little structural similarity to one another. The molecular mass of these polymers ranges between $4.0 \times 10^{4}$ and $6.0 \times 10^{6}$ Da. Heteropolysaccharides are constructed from multiple copies of oligosaccharides, which contain between three and eight residues. Two or more different monosaccharides are usually present in each repeating unit and show different linkage patterns (Welman et al., 2003).

Bacterial polysaccharides have been proposed to protect cells from desiccation or other environmental stresses, including immune responses, and also to enhance the colonization of various ecological niches.

Since bacterial polysaccharides have various rheological properties, they are of industrial interest (Akçelik et al., 2002; Stingele et al., 1999). And because the interest in EPS has increased over the last decade in industry, several EPS structures have been elucidated (Stingele et al., 1996; Stingele et al., 1999).

Different classes of EPS can be distinguished based on the mechanism of biosynthesis and the precursors required. The first class comprises the extracellularly produced homopolysaccharides like dextran, levan, and mutan. The polymerization reaction in these cases proceeds via extracellular glycosyltransferases, which transfer a monosaccharide from a disaccharide to a growing polysaccharide chain (Fig. II.1). The other categories comprise homo- and hetero-polysaccharides with (ir)regular repeating units that are synthesized from intracellular sugar nucleotide precursors (Fig. II.1). Some of these sugar nucleotides serve as precursors for EPS biosynthesis. However, they are also involved in the biosynthesis of several cell wall components and can therefore be considered essential for growth. 


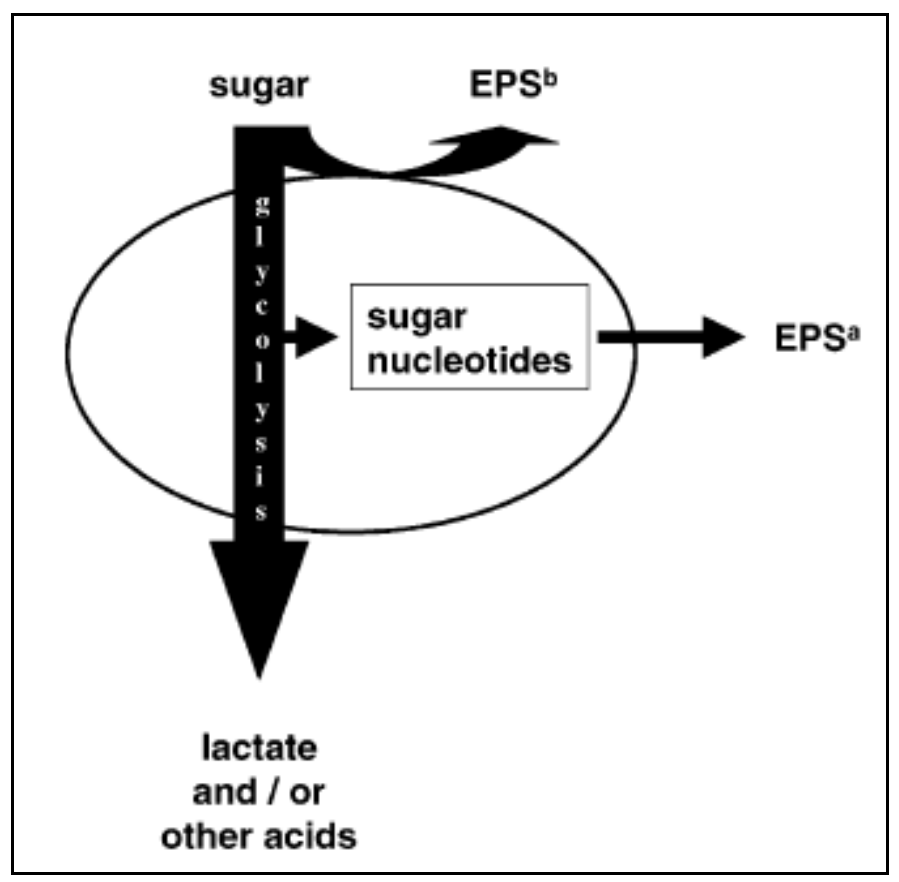

Figure II.1 Schematic representation of pathways involved in sugar fermentation via glycolysis to lactate and/or other acids and biosynthesis of exopolysaccharides (EPS) from intracellular sugar nucleotides (EPSa) and extracellular EPS biosynthesis (EPSb) (Boels et al., 2001).

While investigation of polysaccharide gene clusters in gram-negative bacteria began over 20 years ago, research on those of gram-positive microorganisms has advanced only lately. Recent reports include the characterization of genes involved in polysaccharide biosynthesis from the pathogens Staphylococcus aureus and Streptococcus pneumoniae (Kolkman et al., 1997; Lin et al., 1994; Morona et al., 1997) and from the food microorganisms Streptococcus thermophilus and Lactococcus lactis (Stingele et al., 1996; van Kranenburg et al., 1997). The general organization of these clusters seems to be conserved: a central region with similarity to glycosyltransferase genes is flanked by two regions exhibiting similarity to genes involved in polymerization and export, and a putative regulatory region can be found at the beginning of each cluster. Even though this organization is not always conserved among genes involved in O-antigen synthesis, their homology points to similar biosynthetic pathways. The repeating unit is first assembled by the sequential transfer of sugar residues onto a lipophilic carrier by specific glycosyltransferases. Unlike the other glycosyltransferases, the first glycosyltransferase does not catalyze aglycosidic linkage but transfers a sugar-1-phosphate onto a lipophilic anchor, such as undecaprenylphosphate. Subsequently, the completed repeating unit is exported 
and polymerized. In the case of cell surface polysaccharides, it is anchored to a cell envelope component while secreted polysaccharides are released (Stingele et al., 1999).

The mechanisms involved in assembly, polymerization and translocation across the outer membrane in Gram-negative bacteria follow a similar pathway to that of some capsule EPSs in Escherichia coli groups 1 and 4 (Rahn et al., 1999) and Klebsiella pneumoniae (Arakawa et al., 1995) and of extracellular polysaccharides, including those produced by Erwinia spp. (Bugert et al., 1995), Methylobacillus sp. strain 12S (Yoshida et al., 2003), Rhizobium spp. (Reuber et al., 1993) and Xanthomonas campestris (Katzen et al., 1998). Undecaprenol-pyrophosphate-linked oligosaccharide repeating units are formed at the cytoplasmic face of the inner membrane, transported through this membrane by a Wzx-protein-dependent process, and then polymerized by a mechanism involving a Wzy protein. Some of the polysaccharide-biosynthesis gene clusters have been cloned and sequenced, and found to form long operons with similarities in their genetic organization. In general, the first three genes, which are necessary for high-level polymerization and surface assembly, are conserved in the abovementioned micro-organisms; the genes are wza (encoding an outer-membrane protein), wzb (encoding an acid phosphatase) and wzc (encoding an inner-membrane tyrosine autokinase). It has been suggested that this high level of conservation is the result of lateral transfer events occurring between some of these species. The rest of the genes included in the operon encode glycosyltransferases and components of a Wzy-dependent polymerization system (Arco et al., 2005).

\section{II.2.2. Rheological properties of EPS}

There is great diversity in the composition and structure of EPSs, which results in different properties (Levander et al., 2002).

The rheological behaviour of polysaccharide solutions and the influence of physical or chemical factors on the rheological properties are important because they offer informations on the bioprocess, the biopolymer quality, the relations between microstructure and physical properties, textural analysis. Rheological characteristics depend on a large number of factors, as observed in Figure II.2. 


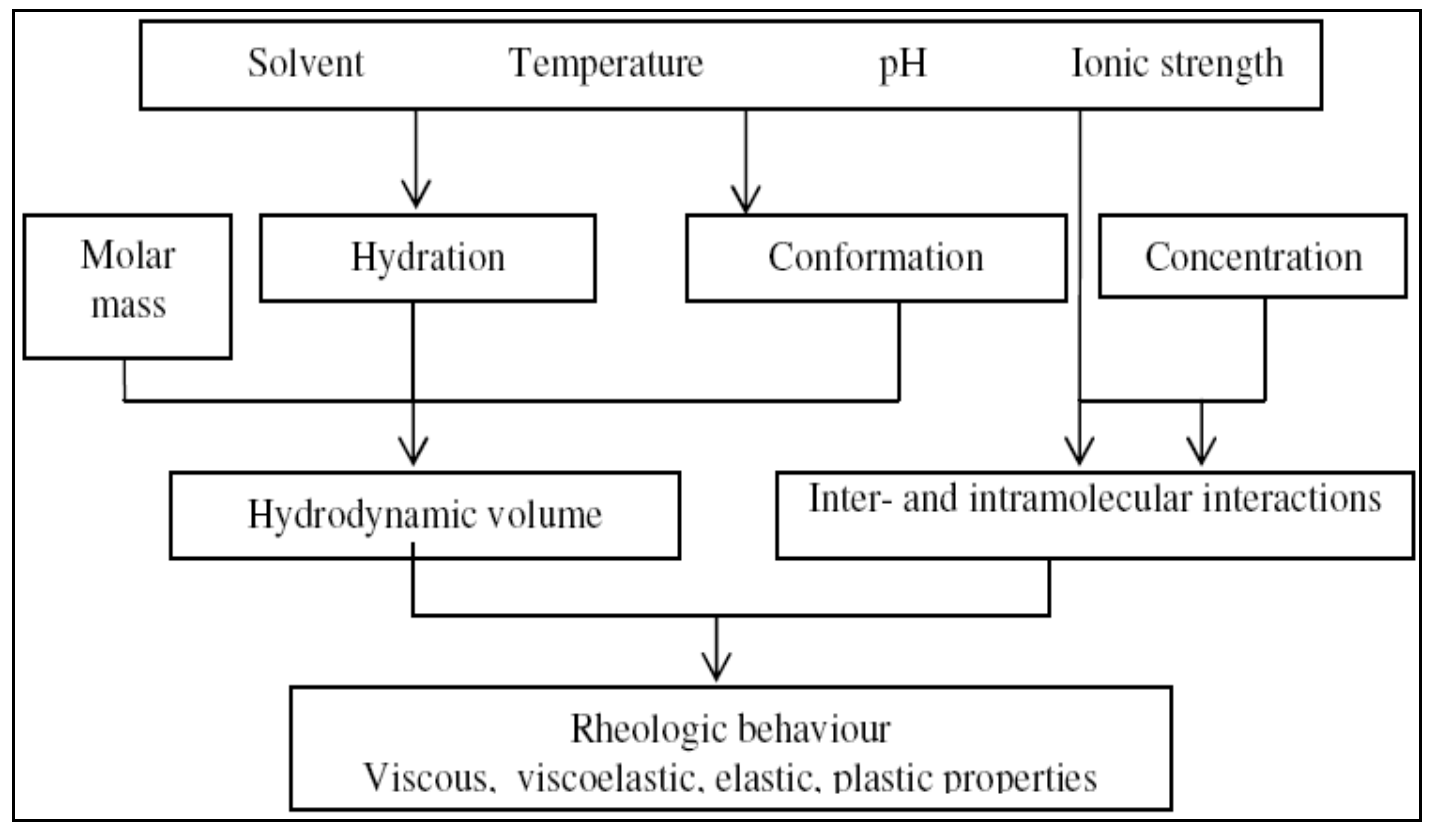

Figure II.2 Factors influencing the rheological characteristics of biopolymeric aqueous solutions (Mironescu, 2003)

For example, if the polysaccharide is a polyelectrolyte, viscosity can be controlled through electrostatic repulsion, ionic strength or addition of divalent and polyvalent cations (making possible the formations of gel through ionic bounds).

The molecules size influences the rheological behaviour at various shear stresses.

For the rheological analysis of EPS, two measuring systems are recommended: parallel plate and cone-plate geometries. Using these geometries, steady state and oscillatory (or dynamic) measurements can be performed; the first one type of analyses gives information on the flow behaviour of polysaccharides and the second one characterises the viscoelastic behaviour (Mironescu, 2003).

Lambo-Fodje et al. (2007) studied the rheological properties of an exopolysaccharide from Pediococcus damnosus 2.6. They compared the rheological behaviour of the EPS to that of a commercial cereal $\beta$-glucan $\left(0.359 \times 10^{6} \mathrm{~g} \mathrm{~mol}^{-1}\right)$. The maximum storage modulus, $G^{\prime}{ }_{\text {max }}$ for EPS solution was lower than that for the cereal $\beta$-glucan at all concentrations, while the relaxation time was higher. And this EPS displayed viscoelastic properties typical of a macromolecular solution with structural entanglements and thus, could be used as a thickener in industrial applications.

El-Tayeb et al. (2007) determined the shear stress (culture viscosity) using various concentrations of purified biopolymer produced by Pseudomonas sp. UBF 2 
at increasing shear rates. Its shear stress increased according to the decrease of the shear rate. However, the degree of the increase was not linear and declined at higher shear rates, suggesting that the biopolymer showed characteristics of a typical nonNewtonian pseudoplastic fluid. Its shear stress also increased in solutions with higher biopolymer concentration.

\section{II.2.3. Microbial EPS Production Process}

Many microorganisms produce exopolysaccharides as an extracellular or cell surface-attached material in the form of amorphous slime. In microorganisms, EPSs may be associated with virulence in some cases, and these molecules are believed to be produced by the bacteria as means of protection against hostile conditions, such as desiccation, osmotic stress, low temperature and bacteriophage infection (Hugenholtz et al., 2000; Lee et al., 2002).

EPSs play a major structural role in the formation of biofilms, in which various prokaryotic and eukaryotic microorganisms grow while attached to solid-liquid interfaces. Several of these microbial polysaccharides are now widely accepted industrial products, while others are in various stages of development (Lee et al., 2002; Sutherland, 1998).

At present, very few EPSs are available commercially, but the number and their applications are gradually increasing (Lee et al., 2002). While dextran was the first microbial polysaccharide to be commercialized and to receive approval for food use, several such polymers now have a variety of commercial uses (Sutherland, 2002).

Some of the microbial polysaccharides such as xanthan (the EPS from Xanthomonas campestis $p v$. campestris) are already well established by modern biotechnology and have a sizable market. Others such as pullulan posseses potentially useful chemical and physical properties, and consequently are receiving much attention from industrial areas. Microbial EPSs are promising substitutes for traditional plant polysaccharides because of their unique and superior physical properties (Lee et al., 2002).

The EPSs can be produced on agar plates or in liquid culture (Yang et al., 2001).

Production of most microbial polysaccharides involves growth in stirred tank fermenters using media with glucose or sucrose as the carbon and energy source. Synthesis is often favoured by high C:N ratios. Because of the high viscosity of the 
fermentation broths, efficient mixing and aeration are required together with considerable energy input (Sutherland, 2002).

The most used cultivation systems are batch, fed-batch and continuous. Some examples of industrial cultivation systems for polysaccharide production are shown in Table II.1.

Table II.1. Industrial production of principal exopolysaccharides (Mironescu, 2003)

\begin{tabular}{|c|c|c|c|}
\hline Exopolysaccharide & $\begin{array}{l}\text { Cultivation } \\
\text { System }\end{array}$ & Cultivation Conditions & $\begin{array}{l}\text { Cultivation } \\
\text { Medium }\end{array}$ \\
\hline Alginate & Continuous & $\begin{array}{l}30^{\circ} \mathrm{C} \text {; pH 7.2; Aeration (oxygen } \\
\text { in excess does not stimulate the } \\
\text { synthesis of EPS); Agitation. }\end{array}$ & $\begin{array}{l}\text { Carbon source: } \\
\text { sucrose }(20 \mathrm{~g} / \mathrm{l}) \text {; } \\
\text { Higher } \\
\text { production speed } \\
\text { through } \\
\text { molybdenum and } \\
\text { phosphorus } \\
\text { limitation or } \\
\text { through smaller } \\
\text { dilution rates. }\end{array}$ \\
\hline Dextran & $\begin{array}{l}\text { Batch or fed- } \\
\quad \text { batch }\end{array}$ & $\begin{array}{l}25^{\circ} \mathrm{C}\left(30^{\circ} \mathrm{C} \text { optimal for }\right. \\
\text { microorganism, } 23^{\circ} \mathrm{C} \text { optimal } \\
\text { for EPS); pH } 6.0 \text { (optimal for } \\
\text { EPS production); No aeration in } \\
\text { the phase of EPS stimulation. }\end{array}$ & $\begin{array}{l}\text { Carbon source: } \\
\text { sucrose }(5-10 \mathrm{~g} / \mathrm{l}) \\
\text { with sucrose } \\
\text { conversion yield } \\
\text { of } 90 \% \text {. High } \\
\text { levels of nitrogen } \\
\text { and } \mathrm{CaCl}_{2} \\
\text { stimulate the } \\
\text { EPS production. }\end{array}$ \\
\hline \multirow[b]{2}{*}{ Xanthan } & Batch & \multirow{2}{*}{$\begin{array}{l}28^{\circ} \mathrm{C} \text {; } \mathrm{pH} 7.0 \text {; Aeration }(0.5-0.75 \\
1 / \mathrm{min} \text {. at the beginning, } 0.751 .5 \\
1 / \mathrm{min} \text {. after } 2 \text { days because of the } \\
\text { increase in viscosity). Agitation. }\end{array}$} & $\begin{array}{l}\text { Carbon } \\
\text { glucose } \\
\text { g/l) }\end{array}$ \\
\hline & Continuous & & $\begin{array}{ll}\text { Dilution } & \text { rate } \\
\text { control. } & \\
\text { Nitrogen, } & \\
\text { sulphur } & \text { or } \\
\text { potassium } & \\
\text { limitation. } & \end{array}$ \\
\hline
\end{tabular}

Fed-batch fermentations may be preferable to the use of high initial sugar concentrations. After pasteurization of the broth, recovery by precipitation with isopropanol is followed by drying and grinding to yield a fine powder. Filtration or centrifugation and other downstream processing add to the final cost (Sutherland, 2002). 
A process for the isolation and purification of pullulan is shown in Figure II.3, the main steps being centrifugation, evaporation, precipitation, ultrafiltration, and drying.

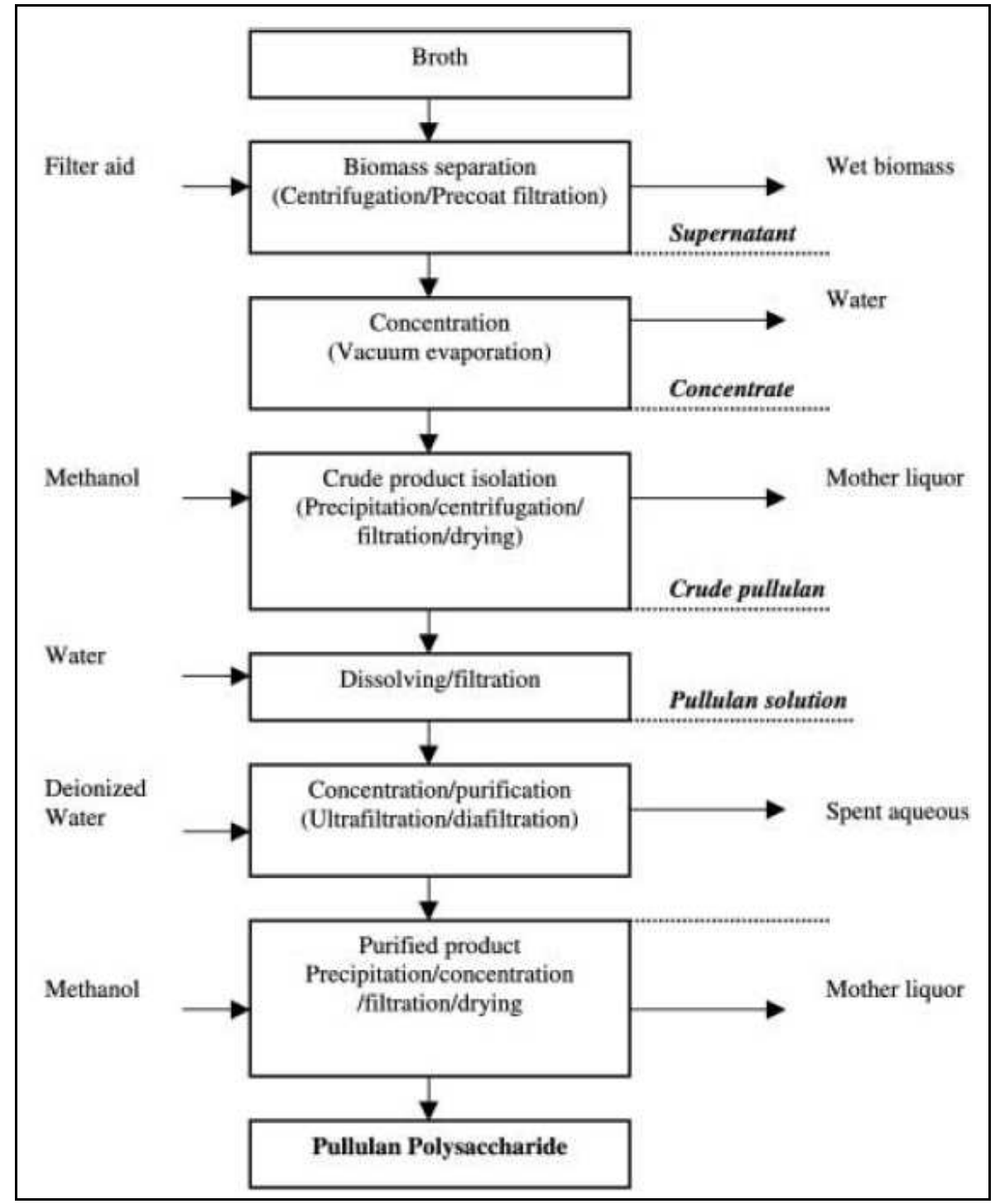

Figure II.3. Downstream process flowsheet for isolation and purification of pullulan.

\section{II.3. IMPORTANT APPLICATIONS OF EPS}

The industrial uses of polysaccharides are based until recently on materials extracted from plants (starch, cellulose, pectins, galactomanans, gums) or algae (carragenan, alginates, agar). In the last 30 years, biotechnologies for the microbial production of extracellular polysaccharides were developed. The polysaccharides of microbial origin are largely used in food industry, biotechnology, medicine and pharmacy. The success is due to their properties and to the diversity of producing microorganisms and synthesized polysaccharides (Mironescu, 2003; Sutherland, 2002). 
Because of their many interesting physico-chemical and rheological properties with novel functionality, the microbial exopolysaccharides (EPS) act as new biomaterials and find wide range of applications in many industrial sectors like textiles, detergents, adhesives, microbial enhanced oil recovery (MEOR), wastewater treatment, dredging, brewing, downstream processing, cosmetology, pharmacology, and food additives (Kumar et al., 2004). Moreover, there are numerous studies on their participation in pathogenic and symbiotic processes in plants and animals and on the general interactions between microorganisms and their environment (Loaëc et al., 1998; Nicolaus et al., 1999). Polysaccharides also contribute to various physiological activities in human beings as anti-tumor, anti-viral, and antiinflammatory agents, and can act as inducers for interferon, platelet aggregation inhibition, and colony stimulating factor synthesis (Kumar et al., 2004).

Many bacteria secrete polysaccharides that can have diverse functions, such as virulence factors, signalling molecules in bacterium-plant interactions, or protective agents. Some of these polymers have unique properties for food applications and are used as viscosifiers, stabilizers, emulsifiers or gelling agents (Table II.2). Commercially, the most important microbial exopolysaccharide (EPS) is xanthan gum, a complex polymer that is very efficiently produced by the phytopathogen Xanthomonas campestris and has been used for decades in food and non-food applications. Acetan is structurally related to xanthan and is produced by Acetobacter xylinum, a strain that is used in the food industry for the production of a sweet confectionery (Nata) and vinegar. Sphingans, capsular polysaccharides secreted by Sphingomonas strains, including gellan, wellan, rhamsan, and sphingan S-88, have special rheological properties and can be used in food as gelling agents, stabilizers or suspending agents. In the dairy industry, EPS-producing lactic acid bacteria (LAB), including the genera Streptococcus, Lactobacillus, and Lactococcus, are used in situ to improve the texture of fermented dairy products such as yoghurt or cheese. This group of food-grade bacteria produces a wide variety of structurally different polymers with potential use for new applications. In addition, for example, replacement of presently applied thickeners produced by non-food-grade bacteria. In addition, it has been suggested that EPSs produced by LAB may confer health benefits as studies with mouse models indicate that EPSs have immunostimulatory, antitumoral, or cholesterol-lowering activity. Furthermore, LAB are used for the 
production of simple polymers such as dextrans, which are used for their rheological properties, by the activity of extracellular glycosyltransferases (van Kranenburg et al., 1999).

Table II.2. Food applications for complex microbial EPSs (van Kranenburg et al., 1999).

\begin{tabular}{|c|c|c|c|}
\hline Polymer & Bacterial source & Use & $\begin{array}{l}\text { In situ } \\
\text { EPS } \\
\text { produ } \\
\text { ction }\end{array}$ \\
\hline Xanthan & $X$. campestris & $\begin{array}{l}\text { Viscosifier, stabilizer, emulsifier } \\
\text { and suspending agent }\end{array}$ & - \\
\hline Acetan & A. xylinum & Viscosifier and gelling agent & - \\
\hline Gellan & Sphingomonas & $\begin{array}{l}\text { Gelling agent, stabilizer and } \\
\text { suspending agent }\end{array}$ & - \\
\hline EPSs of LAB & $\begin{array}{c}\text { S. thermophilus, } \\
\text { Lactobacillus ssp, } \\
\text { L. lactis }\end{array}$ & Viscosifier and hydrating agent & + \\
\hline
\end{tabular}

\section{II.3.1. Emulsifier}

Chemically synthesized and plant derived emulsifiers are used in the food, pharmaceutical, cosmetic and petroleum industries. However, emulsifiers from microbial sources have attracted attention because of the several advantages they offer over the synthetic products such as lower toxicity, higher biodegradability, better environmental compatibility, higher foaming, high selectivity and specific activity at extreme temperature, $\mathrm{pH}$, salinity and ability to be synthesized from renewable feed stocks (Iyer et al., 2006).

Bacteria are capable of making two kinds of polymers, low molecular weight molecules that efficiently lower surface tension and interfacial tensions and high molecular weight polymers that bind tightly to surfaces. These high molecular weight biosurfactants are highly efficient emulsifiers that work at low concentrations and they exhibit considerable substrate specificity, they are produced by a large number of bacteria and they are composed of polysaccharides, proteins, lipopolysaccharides, lipoproteins, etc. (Martínez-Checa et al., 2007).

Dextran, synthesized by certain lactic-acid bacteria such as Leuconostoc mesenteroides and Streptococcus mutans, was the first microbial polysaccharide that 
was approved for its use in food industry and became commercialized in early 1950s (Sutherland 2002). Xanthan gum (the EPS from Xanthomonas campestis pv. campestris bacterium) entered the market in 1967 and then received its approval for food use in 1969. Xanthan is already well established by modern biotechnology and have a sizable market due to its exceptional qualities as a rheology control agent in aqueous systems and as a stabilizer for emulsions and suspensions (Rosalam and England, 2006). Another example is pullulan (the fungal EPS produced by Aureobasidium pullulans) that is used extensively in food industry and as a pharmaceutical bulking agent since more than 20 years.

Numerous studies have been conducted for developing and implementing innovative technology to clean up contamination with petroleum hydrocarbons (King et al., 1998). Bioemulsifiers are able of emulsifying these pollutants much more effectively than do chemical surfactants. Halophilic EPS producers are considered as an interesting source for microbial enhanced oil recovery (MEOR) where polymers act as emulsifiers and mobility controllers. Active emulsification of petroleum has been noted for six strains, close to Halobacterium salinarium, Haloferax volcanii, and Halobacterium distributum (Kulichevskaya et al., 1998).

Martínez-Checa et al. (2007) studied the characteristics of the bioemulsifier V2-7 synthesized by strain F2-7 of Halomonas eurihalina and they found that it has the ability of emulsifying a wide range of hydrocarbons i.e. $n$-tetradecane, $n$ hexadecane, $n$-octane, xylene mineral light and heavy oils, petrol and crude oil.

Iyer et al. (2006) studied the emulsifying ability of the exopolysaccharide, EPS 71a, produced by a marine bacterium, Enterobacter cloaceae. They found that EPS 71a emulsified hexane, benzene, xylene, kerosene, paraffin oil, cottonseed oil, coconut oil, jojoba oil, castor oil, groundnut oil and sunflower oil and the emulsions stabilized by EPS 71a had a good shelf life under standard conditions. In addition, the emulsions were stable under stress conditions like $\mathrm{pH}$ and salinity, similar to those often encountered in the development of food and pharmaceutical formulations.

The emulsifying activitiy of several biopolymers produced from different bacterial isolates were examined comparing with other pure gums by El-Tayeb et al. (2007). The highest biopolymer concentration ( $8.6 \mathrm{~g} / \mathrm{L})$ was obtained by an isolate which was identified as Pseudomonas sp. UBF 2. This biopolymer exhibited the 
highest lipid emulsifying capacity (100\%) when compared with that of xanthan gum (90\%). The minimum concentration of biopolymer solution to obtain a $100 \%$ emulsion stable for 10 days against all oils was $0.2 \%$, while against cotton seed oil was $0.5 \%$.

\section{II.3.2. Bioflocculants}

Flocculating agents are generally categorized into three major groups, namely, inorganic flocculants such as aluminum sulfate and polyaluminum chloride (PAC); organic synthetic polymer flocculants such as polyacrylamide derivatives and polyethylene; and naturally occurring biopolymer flocculants such as chitosan and algin. Among these, organic synthetic polymers are the most widely used flocculants, since they are the most economical and highly effective. However, the use of these flocculants sometimes causes environmental and health problems, because they are not readily biodegradable and some of their degraded monomers, such as acrylamide, are neurotoxic and even potent human carcinogens. On the other hand, naturally occurring biopolymers (bioflocculants), which are produced by microorganisms during their growth, have special advantages such as safety, strong effect, biodegradable and harmlessness to humans and the environment, so they may potentially be applied in drinking and wastewater treatment, downstream processing, and fermentation processes (Lu et al., 2005; Gao et al., 2006). Microbial flocculants have been suggested to replace organic high-polymer flocculants, such as polyacrylamide, which are inexpensive and highly effective but not easily degraded and can be harmful to humans. Among the microbial flocculants reported previously, protein polysaccharide, glycoprotein, polyglutamic acid and xanthan have been investigated (Prasertsan et al., 2008).

In recent years, many bioflocculant-producing microorganisms including bacteria, fungi and actinomyces have been reported to produce extracellular polymeric substances, such as polysaccharides, functional proteins and glycoprotein, which function as bioflocculant. Flocculants produced by a marine dinoflagellate Gyrodinium impudicum KG03, Bacillus subtilis DYU1, Vagococcus sp. W31, Poly$\gamma$-glutamic acid ( $\gamma$-PGA) produced by Bacillus subtilis F-2-01, Enterobacter aerogenes W-23, a haloakalophilic Bacillus sp. I-471, Alcaligenes cupidus KT201 and Bacillus subtilis IFO3335 are polysaccharides. However, only few of these bioflocculants has been practically applied in industry because of their low 
flocculating capability and large dosage requirement. To utilize bioflocculants widely in industrial fields, it is desirable to find various microorganisms with high bioflocculant-producing ability and improve the flocculating efficiency of the bioflocculant (Yükselen et al., 2004).

Li et al. (2008) studied the flocculation behavior and mechanism of the exopolysaccharide secreted by Pseudoalteromonas sp. SM9913 (EPS SM9913). They found that EPS SM9913 could flocculate various suspended solids such as kaolin clay, activated carbon, soil, $\mathrm{MgO}$ and $\mathrm{Al}_{2} \mathrm{O}_{3}$. The flocculating activities of this EPS could be enhanced by the addition of bivalent cations such as $\mathrm{Ca}^{2+}$ and $\mathrm{Fe}^{2+}$ because of these cations' mediating function. Results indicated that EPS SM9913 delivers better flocculation performance than alum at low temperature $\left(5-15^{\circ} \mathrm{C}\right)$ or in high-salinity (5-100\%o) water. Such findings suggested the probable use of this EPS SM9913 as an effective flocculant for wastewater treatment at low temperature and/or salinity.

El-Tayeb et al. (2007) studied the flocculating activitiy of several biopolymers produced from different bacterial isolates comparing with other pure gums such as xanthan, pullulan, dextran, rhizobial exopolysaccharide and arabic gum. The highest flocculating activity was observed with the biopolymer produced by Pseudomonas sp. UBF 2 followed by xanthan gum, biopolymer No. 1, biopolymer No. 5 and pullulan. However, dextran, rhizobial exopolysaccharide and arabic gum showed poor flocculating effect. The unique flocculating activity of the biopolymer produced by Pseudomonas sp. UBF 2 suggested that it has a great potential as a flocculating agent.

\section{II.3.3. Heavy Metal Biosorption Ability}

EPS are metabolic products of bacteria but they also result from organic matter of the effluent and from microbial lysis or hydrolysis and serve as a protective barrier for cells against the harsh external environment. EPS also have the function of sorption of inorganic ions which constitute metabolic elements for bacteria. Their composition is complex but EPS are mainly composed of polysaccharide, protein, humic substances, uronic acid, nucleic acid and lipids, containing ionisable functional groups such as carboxyl, phosphoric, amine, and hydroxyl groups. These functional groups represent potential binding sites for the sequestration of metal ions. It is assumed that metal biosorption involves a physicochemical interaction between 
the metal and functional groups on the cell surface, based on physical adsorption, ion exchange, complexation and precipitation. Moreover, metal biosorption performance depends on external factors, such as $\mathrm{pH}$, other ions in bulk solutions (which may be in competition), organic material in bulk solution and temperature. These properties are potentially of great importance in sewage treatment processes for the removal of toxic heavy metal pollutants (Comte et al., 2008; Liu et al., 2001; Guibaud et al., 2003; Thomas et al, 2003).

\section{II.3.4. EPS in Pharmacy and Medicine}

Polysaccharides constitute a structurally diverse class of biological macromolecules with a wide range of physicochemical properties, which are the basis for the different applications in the broad field of pharmacy and medicine.

A more generally inclusive and descriptive name for the group that are abundant in nature, present in many plant sources are "polysaccharide hydrocolloids"; only a restricted number is of commercial importance of substances. Functional properties of polysaccharide hydrocolloids are; stabilizer (suspending agent), thickener (film-forming agent), coagulant (water retention agent), and colloid (lubricant or friction reducer).

The importance of various polysaccharide hydrocolloids for pharmaceutical purposes has a long historical background and increased considerably during the last decades. Many interesting areas have been opened in the past which include their role in drug delivery, in wound treatment, in cancer therapy, and the diagnosis, prevention, and treatment of bacterial and viral diseases.

Compendial standards and governmental regulations require that even the natural polysaccharides as well as their derivatives meet the strict standards of identity, potency, and purity, in order to define the necessity of drug quality (Table II.3). Some polysaccharides may undergo chemical changes with time, resulting in a loss of biological and therapeutical activity. 
Table II.3. Criteria for the pharmaceutical utilization of polysaccharides.

\begin{tabular}{|l|l|}
\hline Polysaccharides must have: & Polysaccharides must not have: \\
\hline - High purity & - Inactivate enzymes \\
- Chemical, physical, and & - Cause cancer \\
$\begin{array}{l}\text { mechanical properties for the } \\
\text { proposed functions }\end{array}$ & - Produce toxic or allergic \\
- High stability & reactions \\
- Easy fabricability & Deplete electrolytes \\
\hline
\end{tabular}

It is important to note that in almost all commercial products the polysaccharide hydrocolloids never occur alone but are part of a more or less complex formulation with other plant constituents or chemical compounds (Franz, 1989).

Some polysaccharides form integral components of vaccines, usually when coupled to a suitable protein. Thus, meningitis vaccines have been prepared in this way and multivalent polysaccharide vaccines have been formulated against Streptococcus pneumoniae and Klebsiella spp. However, these are expensive to prepare and only use very small amounts of material. Possibly of much greater significance is the role of certain microbial polysaccharides in tumour suppression and immunestimulation. A homopolymer named 'Scleroglucan' or schizophyllan, from several fungal species, appears to be very effective against some cancers when it is applied in the ordered, triple helical form. These $\beta$-linked glucans are therefore the subject of much current study and have already been tested clinically in Japan, proving effective against certain types of tumor. Dextran, although no longer used as a food ingredient, is the base from which the 'Sephadex' range of biochemical adsorbents is prepared. Dextran solutions can also be used as a plasma substitute, being very poorly antigenic and having the correct physical properties (Sutherland, 2002).

Polysaccharides also contribute to various physiological activities in human beings as antitumor, antiviral, and antiinflammatory agents, and can act as inducers for interferon, platelet aggregation inhibition, and colony stimulating factor synthesis (Kumar et al., 2004).

Within the field of pharmacologically active polymers, the area of immunestimulating polysaccharides is a rather new and attractive field of tumor therapy. The interest in polysaccharides as antitumor substances came from the dissatisfaction 
with current cancer chemotherapy. Countless numbers of chemical compounds have been tested as cytostatic agents with possibly a high specificity for the cancer cell. However, unfortunately in many cases, this specificity is rather low, and therefore many chemotherapeutic antitumor substances have considerable side effects. Extensive studies have been carried out on nontoxic antitumor substances and most interestingly, some polysaccharides were shown to be most useful. Mainly fungal polysaccharides have been reported to be active against a series of allogeneic and syngeneic tumors. These antitumor polysaccharides, in most cases, were shown to be glucans with different types of glycosidic linkages. It is interesting to note that besides these very active glucans, several fructans were shown to exhibit pronounced activity against a series of different tumor types (Franz, 1989).

Three examples of polysaccharides in clinical use are Schizophyllan, Lentinan and Krestin. The clinical usefulness of these polysaccharides was demonstrated with patients having head and neck cancer, lung cancer, gastric cancer, and cervical cancer. These polymers were either used alone or in combination with chemotherapy and/or radiotherapy, but in most cases after the surgical removal of the primary tumor (Franz, 1989).

In the past few years, some studies revealed that polysaccharides from mushrooms have shown direct antiproliferative effect on cancer cells. Chen et al. (2008) studied the antitumor effect of a medicinal mushroom Fomes fomentarius isolated from the fruiting body of a wild $F$. fomentarius. To evaluate the effect of growth inhibition, various concentrations of EPS produced by Fomes fomentarius in submerged culture were added to culture medium of SGC-7901 human gastric cancer cells. EPS induced a distinct dose- and time-dependent diminution of cell viability. It was also reported that polysaccharide at low dose could sensitize doxorubicin (Dox) - induced growth inhibition and apoptosis of some cancer cells. Therefore, Chen et al. (2008) evaluated whether EPS at noncytoxic concentration $\left(0.125-0.25 \mathrm{mg} \mathrm{ml}^{-1}\right)$ could sensitize Dox-induced growth inhibition of SGC-7901 cells.

Recently there is an attempt to explore pullulan for various biomedical applications including targeted drug and gene delivery and tissue engineering due to its non-toxic, non-immunogenic, non-mutagenic and non-carcinogenic nature. The early observation on this exopolymer was made by Bauer in 1938 and this exopolysaccharide was named as pullulan by Bender et al in 1959. Pullulan and its derivatives can be used as a denture adhesive. It can also be used for pharmaceutical 
coatings, including sustained release formulations. Novel preparations such as tablets, pills, granules or the like, which contain pullulan in the sugar layer serve the purpose of preventing brownish color change of the composition. Oral care products have been commercialized based on pullulan films. The colorless, transparent and edible pullulan film has also attracted a great deal of interest for other uses such as a non-polluting wrapping material (Singh et al., 2008; Rekha et al., 2007).

Scott et al. (2005) reported pullulan compositions to be used in pharmaceutical products preferably for predosed formulations like soft and hard capsules. Pullulan derivatives are promising as non-toxic conjugates for vaccines. Covalent attachment between the virus and pullulan remarkably enhances the inherent producibility of immunoglobulin $\mathrm{G}$ and immunoglobulin $\mathrm{M}$ antibodies and diminishes the immunoglobulin $\mathrm{E}$ antibody producibility as well as sufficiently inactivating and detoxifying the virus. Pullulan can provide liposome delivery. Sized pullulan fractions having molecular weight 30.000 to $90.000 \mathrm{Da}$ can be used as a blood plasma expander in place of dextran. There have been several attempts to develop plasma substitutes on pullulan.

Shingel (2004) summarized all efforts that have been made so far to understand the pharmacokinetics of intravenously applied pullulan in terms of the molar mass and concentration.

Tissue engineering requires scaffold or artificial extracellular matrix that can accommodate cells and regulate their growth leading to three-dimensional tissue regeneration. Researchers developed carboxymethyl pullulan and conjugated it with heparin and investigated its properties towards tissue engineering applications. Heparin-conjugated pullulan inhibited the proliferation of smooth muscle cells (SMCs) in vitro. Heparin-conjugated pullulan material could thus be used for the proliferation of vascular endothelial cells and to inhibit the proliferation of SMCs (Rekha et al., 2007).

Gene therapy is another area where the application of pullulan is being explored. Gene therapy is thought to be a cure for various inherited disorders and cancer. Gene delivery is usually achieved by endocytic pathway. Efforts for gene therapy using virus have been performed but viruses are known to be immunogenic and can be hazardous. So attempts to develop non-viral vectors are taken and cationic derivatives of natural polymers are investigated towards this purpose. Recently, pullulan being biocompatible and non-toxic is investigated for gene 
delivery application. Researchers developed pullulan-DTPA derivative, which has metal chelating residues and mixed with a plasmid DNA in aqueous solution containing $\mathrm{Zn}^{2+}$ ions to obtain the conjugate of pullulan derivative and plasmid DNA with $\mathrm{Zn}^{2+}$ coordination. Pullulan is also known for its specificity for liver and this property is exploited for liver targeting. The authors observed that the conjugate enhanced the level of gene expression at the liver paranchymal cells and the enhanced gene expression lasted for a period of 12 days after the injection (Rekha et al., 2007).

\section{II.4. EXTREMOPHILES as SOURCES for EPS}

For several decades, interest has been focused on the capacity of microorganisms to produce exopolysaccharides (EPS) because these biopolymers often possess advantageous qualities not shared by many polysaccharides currently in use, which are generally extracted from plants or marine algae (S Bouchotroch et al., 2000). The exopolysaccharides produced by microorganisms are widely used in the food, pharmaceutical and chemical industries, and function as bioflocculants, bioabsorbents, heavy metal removal agents, drug delivery agents, etc (Prasertsan et al., 2008).

The microorganisms used as industrial or technical producers of extracellular polysaccharides are bacteria. Species of Xanthomonas, Leuconostoc, Pseudomonas, Alcaligenes which produce xanthan, dextran, gellan, curdlan are the most known and industrially used. Actually, high attention is accorded to the exopolysaccharides produced by lactic acid bacteria which are already accepted as GRAS (Generally Recognised As Safe) and the most adequate for the food industry. Another group of microorganisms producing of exopolysaccharides are the cyanobacteria. The fungal polysaccharides are limited, pullulan produced by Aureobasidium pullulans and scleroglucan synthesized by Sclerotium glucanicum being the most known and already obtained at technical scale. The newest type of microorganisms, the archeae, are also presented in the literature as polysaccharides producers, as the specie Haloferax mediterranei (Mironescu, 2003; Sutherland, 1990).

Biopolymers produced by diverse groups of microorganisms are rapidly emerging as a new and industrially important source of polymeric materials, which are gradually becoming economically competitive with natural gums produced by a variety of microbes. 
Until now, very few biopolymers have been produced on a commercial basis due to two major facts. Firstly, their production costs are much higher when compared with chemically synthesized polymers that possess similar material characteristics. Consequently, much effort has been devoted to the development of processes for biopolymer production by optimizing the upstream to downstream engineering strategies including the metabolic and cellular engineering of host cells, efficient fermentation and recovery processes, and post-production modification of the biopolymers obtained (Lee et al., 2002). The second fact is that from a variety of microbial polysaccharides characterized so far, only those with physicochemical properties similar to those of plant (cellulose, pectin and starch) and seaweed (alginate and carrageenan) are used in industry (Ruas-Madiedo and Reyes-Gavilan, 2003).

It is widely accepted that extremophiles offer important insights into biology and evolution of many organisms, and they provide a valuable resource for exploitation in novel biotechnological processes.

Although many researchers claim to have found polysaccharides 'of superior viscosity to xanthan', in reality few match the robustness of the Xanthomonas polysaccharide and few can maintain their physical properties in the presence of salts, at higher temperatures or extremes of $\mathrm{pH}$ (Lee et al., 2002). Therefore, most research is focused on the identification of EPS producing extremophiles with the idea that as these microorganisms survive environmental extremes of desiccation, temperature, pressure, salinity, acidity, heavy metals, and radiation, it is to be expected that their biopolymers will also have some unique properties to adapt to such extreme conditions.

A new approach to encountering polysaccharides with novel properties might entail investigating different environments such as hypersaline habitats, since most of the strains used so far for the industrial production of polysaccharides belong to a small number of taxa, which are non-halophilic, soil-dwelling diazotrophs and often plant-associated. Because of the extreme nature of hypersaline environments, they might be expected to harbor unusual microorganisms of biotechnological interest; thus, for the last few years, extensive research is being carried out in examining microorganisms from such habitats in an attempt to find new EPSs with different characteristics (Mata et al., 2006). 
Since 1991, EPS producing extremophilic microorganisms have been isolated from deep-sea hydrothermal vents characterized by extreme pressure and temperature, high concentrations of $\mathrm{H}_{2} \mathrm{~S}$ and heavy metals. These include some bacteria such as Alteromonas macleodii sub spec fijiensis, Vibrio diabolicus, Alteromonas infernos (Raguénès et al., 1997; Roger et al., 2004) and Thermotoga maritime (Rinker et al., 2000) and archaea such as Thermococcus litoralis (Rinker et al., 2000). EPS producing bacteria from marine Mediterranean shallow vents have also been described (Maugeri et al., 2002; Schiano Moriello et al., 2003). EPS produced by moderately halophilic bacteria of the genus Halomonas (Bouchotroch et al., 2000), Halomonas maura (Arias et al., 2003), Halomonas ventosae and Halomonas anticariensis (Mata et al., 2006), Aphanocapsa halophytica (Matsunaga et al., 1996) and recently by haloalkalophilic Bacillus sp. I-450 (Kumar et al., 2004) and Salinivibrio costicola subsp. alcaliphilus (Romano et al., 2005) has also been reported.

\section{II.5. EPS PRODUCTION by Halomonas sp.}

Microorganisms that produce exopolysaccharides are to be found widely in nature and thus, in theory, large numbers of bacterial polysaccharides should be available to industry. Nevertheless, after a great deal of experimental work and examination of their physical properties, only a few have in fact proved to have any real potential for biotechnological purposes. In this category are xanthan and gellan, which have found various applications in the food industry and other fields. Some other EPSs are at different stages of development and may be on the market in the next few years. Nevertheless, industry is constantly looking for EPSs with novel functional properties to satisfy the needs of modern technology and help provide manufacturing with new finished products. Further, there is a pressing demand for industry to resort to non-toxic, biodegradable, environmentally friendly substances.

Extreme environments are proving to be a valuable source of microorganisms that secrete interesting new molecules, including exopolysaccharides. Halophilic bacteria are just such extremophiles and the properties of their extracellular polysaccharides seem to offer numerous applications in various fields of industry (Arias et al., 2003).

Halophilic bacteria are members of the archaebacteria that require extremely high concentrations of $\mathrm{NaCl}$ to grow and survive. Although classically halobacteria 
were considered organisms of very slow growth able to utilize only a restricted range of organic compounds, mostly amino acids, as energy sources, some groups described more recently utilize a wide range of substrates, including sugars, and grow more rapidly.

The genus Halomonas was originally proposed to accommodate one species, Halomonas elongata. It now contains a large number of recently discovered species, as well as already known bacteria which were initially assigned to other genera, such as Deleya, Volcaniella and Halovibrio, but have since been included in Halomonas.

Halomonas species are widely distributed throughout hypersaline environments. Some of them have been recognized for their potential use in biotechnology (Martínez-Checa et al., 2004). They are of great interest, as these bacteria bear great biotechnological potential for the production of compatible solutes, hydrolytic enzymes, bacteriorhodopsin, bioplastic and exopolymer (Lungmann et al., 2007; Yeon et al., 2005).

Moderate halophiles, the group to which Halomonas species belong, already have numerous applications in various fields of industry. The genus Halomonas contains about 30 species of halophilic gram negative bacteria, most of which have been isolated from saline environments and grow best in media containing 0.5 to 2.5 $\mathrm{M} \mathrm{NaCl}$. Four of these species, Halomonas eurihalina, Halomonas maura, Halomonas ventosae and Halomonas anticariensis, all isolated from the rhizosphere of xerophytic plants, have the ability to produce large quantities of EPSs with novel physical and chemical characteristics. Among these, mauran, the EPS produced by strain S-30 of $H$. maura, is notable for its high viscosifying capacity, similar to that of xanthan, and for the pseudoplastic and thixotropic behaviour of its solutions. In addition, the stability of its functional properties under a wide range of $\mathrm{pH}$, saline and freezing-thawing conditions makes this polymer a good candidate for use in foodstuffs, pharmaceutical products and other fields of biotechnology. Although extensive studies have been made into the biotechnological applications of these halophilic EPSs, little is known about the molecular mechanism of their biosynthesis or how they are regulated (Arco et al., 2005). 


\section{PART III}

\section{EXPERIMENTAL WORK}

\section{III.1. MATERIALS}

III.1.1. Microorganism

Halomonas sp AAD6 strain (GenBank accession number DQ131909) used in this study was isolated from Çamaltı Saltern Area in Turkey.

\section{III.1.2. Chemicals}

All chemicals and solutions used in this study were supplied by MERCK (Germany), SIGMA (USA), DIFCO (USA) and FLUKA (Switzerland). All experiments were carried out in the Biotechnology Laboratories of Bioengineering Department at Marmara University.

III.1.3. Culture Media

Culture media used for the growth of microorganisms and for the production of EPS are described below.

\section{$\underline{\text { Minimal Medium }}$}

$\begin{array}{ll}\mathrm{K}_{2} \mathrm{HPO}_{4} & 7 \mathrm{~g} \\ \mathrm{KH}_{2} \mathrm{PO}_{4} & 2 \mathrm{~g} \\ \mathrm{MgSO}_{4} \cdot 7 \mathrm{H}_{2} \mathrm{O} & 0.1 \mathrm{~g} \\ \left(\mathrm{NH}_{4}\right)_{2} \mathrm{SO}_{4} & 1 \mathrm{~g} \\ \text { Pepton } & 0.5 \mathrm{~g} \\ \mathrm{NaCl} & 100 \mathrm{~g} \\ \text { Carbon source } & 10 \mathrm{~g} \\ \mathrm{pH}=7.0 & \end{array}$

per liter of distilled water. 
Optimum Medium

$\begin{array}{lc}\mathrm{K}_{2} \mathrm{HPO}_{4} & 7 \mathrm{~g} \\ \mathrm{KH}_{2} \mathrm{PO}_{4} & 2 \mathrm{~g} \\ \mathrm{MgSO}_{4} \cdot 7 \mathrm{H}_{2} \mathrm{O} & 0.1 \mathrm{~g} \\ \left(\mathrm{NH}_{4}\right)_{2} \mathrm{SO}_{4} & 1 \mathrm{~g} \\ \text { Pepton } & 0.5 \mathrm{~g} \\ \mathrm{NaCl} & 137.2 \mathrm{~g} \\ \text { Sucrose } & 50 \mathrm{~g}\end{array}$

$\mathrm{pH}=7.0$

per liter of distilled water.

The $\mathrm{pH}$ was adjusted to $\mathrm{pH} 7$ by using $1 \mathrm{M} \mathrm{NaOH}$ or with $1 \mathrm{M} \mathrm{HCl}$. While preparing both media, $\mathrm{NaCl}$ and the rest of the medium components were dissolved in $500 \mathrm{~mL}$ and $400 \mathrm{~mL}$ distilled water, respectively and then sterilized separately by autoclaving at 1.06 bar and $121^{\circ} \mathrm{C}$ for 15 minutes. Carbon sources were also sterilized separately in the same manner but for 3 minutes to avoid their degradation. Sterile salt and carbon source solutions were combined to one liter final volume. 18 g/L Agar-Agar was added to both formulations to prepare solid media in petri dishes.

To determine the effects of various carbon sources on growth and EPS yield, Halomonas sp AAD6 was grown in Minimal Medium supplemented with glucose, sucrose, maltose, lactose, raffinose, arabinose, xylose, fructose, galactose, mannose, acetate, glycerol, trisodium citrate, and rhamnose at the concentration of $10 \mathrm{~g} / \mathrm{L}$.

III.1.4. Buffers and Standard Solutions

III.1.4.1. Solutions Used in Phenol/Sulfuric Acid Method

Phenol Solution ( $80 \%$ by weight)

$\begin{array}{ll}\text { Phenol } & 80 \mathrm{~g} \\ \mathrm{dH}_{2} \mathrm{O} & 20 \mathrm{~g}\end{array}$

III.1.4.2. Solutions Used in Preparing Stock Culture

$\underline{\text { Sea Water Stock Solution (30\%) }}$

$\begin{array}{lc}\mathrm{NaCl} & 240 \mathrm{~g} \\ \mathrm{MgSO}_{4} \cdot 7 \mathrm{H}_{2} \mathrm{O} & 35 \mathrm{~g} \\ \mathrm{MgCl}_{2} \cdot 6 \mathrm{H}_{2} \mathrm{O} & 30 \mathrm{~g} \\ \mathrm{KCl} & 7 \mathrm{~g} \\ \mathrm{pH}=7.0 & \end{array}$


After the contents were dissolved in $1000 \mathrm{~mL}$ distilled water, $5 \mathrm{~mL}$ of sterile $\mathrm{CaCl}_{2} \cdot 2 \mathrm{H}_{2} \mathrm{O}(1 \mathrm{M})$ was added to the solution.

$80 \%$ Glycerol, 6\% Sea Water Solution

Glycerol $80 \mathrm{ml}$

Sea Water Stock Solution (30\%) $20 \mathrm{~mL}$

After the solution was sterilized at $121^{\circ} \mathrm{C} 1.06$ bar for 15 minutes, $0.2 \mathrm{~mL}$ of sterile $0.5 \mathrm{M} \mathrm{CaCl}_{2}$ was added to the solution aseptically.

III.1.4.3. Buffers Used for $\mathrm{pH}$ Adjustment

$\underline{\mathrm{NaOH} \text { Buffer }(1 \mathrm{M})}$

$\begin{array}{cc}\mathrm{NaOH} & 40 \mathrm{~g} \\ \mathrm{dH}_{2} \mathrm{O} & 1000 \mathrm{~mL}\end{array}$

$\mathrm{NaOH}$ was dissolved in $1000 \mathrm{~mL}$ distilled water. The buffer was sterilized at $121^{\circ} \mathrm{C} 1.06$ bar for 3 minutes and stored at $+4^{\circ} \mathrm{C}$.

\section{$\underline{\mathrm{HCl} B u f f e r(1 \mathrm{M})}$}

$\begin{array}{lr}\mathrm{HCl}(37 \%) & 83 \mathrm{~mL} \\ \mathrm{dH}_{2} \mathrm{O} & 917 \mathrm{~mL}\end{array}$

$83 \mathrm{~mL}$ of $\mathrm{HCl}(37 \%)$ was added to $917 \mathrm{~mL}$ of distilled water. The buffer was sterilized at $121^{\circ} \mathrm{C} 1.06$ bar for 3 minutes and stored at $+4^{\circ} \mathrm{C}$.

\section{III.2. LABORATORY EQUIPMENT}

Analytic Balances
$(0.1 \mathrm{Mg}, 1 \mathrm{Mg}, 10 \mathrm{Mg})$

Autoclaves

Automatic Pipettor Sets

Centrifuges

\author{
Ab204-S, Pg403-S, Pg40002-S \\ (Mettler Toledo, Sweden)
}

Mod3870 Elv (Systec, Germany)

OT 032 Nüve, Turkey

4500080, (Finipipette, Finland)

4500110, (Finipipette, Finland)

Highspeed Centrifuge 3K30

Benchtop Refrigerated

Centrifuge, 8K10 (Sigma,Germany) 
Deepfreezes

Fermenter

Heating Magnetic Stirrer

Laminar Flow Cabinet

Orbital Shaker

Ovens

pH Meter

Refrigerators

Spectrophotometer

Vortex

Water Purification Systems $-80^{\circ} \mathrm{C}$, (Heto Holten, Denmark)

$-20^{\circ} \mathrm{C}$, (Arçelik, Turkey)

$-20^{\circ} \mathrm{C}$, (Heto Holten, Denmark)

Multi-Fermenter, Biostat Q,

(B.Braun-Sartorious, Germany)

Mr3003s, (Heidolph,Germany)

Class II Safety Cabinet, Safe 2010 0.9,

(Heto Holten, Denmark)

Certomat BS1 (B. Braun, Germany)

New Brunswick Scientific, Excella E24

(Edison, New Jersey, USA)

Oven Bd115

Pasteur Oven, Ed115

(Binder,Germany)

Mp220k, (Mettler Toledo, Germany)

$+4^{\circ} \mathrm{C},($ Arçelik, Turkey)

UV/Vis, Lambda35, (Perkin Elmer,

\section{USA)}

Heidolph, Germany

Primary Grade Water

Purification System, Purelab

Prima 30 Ultrapure Water System,

P.Maxima Ls, (Usf Elga, U.K.) 


\section{III.3. EXPERIMENTAL PLAN and TECHNIQUES}

\section{III.3.1. Sterilization}

Sterilization is the process by which items are rendered free of almost all viable microorganisms. The purpose of sterilization is to provide the end user with a sterile product. Sterilization process must be monitored to ensure that all parameters and specifications have been met to assure sterility of items.

Throughout this study, sterilization was carried out by killing the microorganisms using steam. The culture media used were sterilized in an autoclave. This process, which is known as steam autoclave sterilization, has advantages of short cycle time and good penetration.

Sterilization of Media All media were prepared in Erlenmeyer flasks such that the total volume of the medium was always one fifth of the flask volume. The Erlenmeyer flask was sealed with cotton stopper and wrapped with aluminum foil. The chemical and optimum media were sterilized by autoclaving at 1.06 bar and $121^{\circ} \mathrm{C}$ for 15 minutes before the addition of carbon sources separately sterilized in the same manner but for 3 minutes to avoid their degradation and left to cool before using. All the solutions of media were allowed to cool after sterilization and then they were combined aseptically.

Sterilization of Fermenter Air lines and all probe cables were removed. Jacket and exhaust condenser water lines were disconnected. All the openings of the vessel were wrapped with aluminum foil. Since the vessels should not be sterilized empty, $100 \mathrm{ml}$ of sterile distilled water was placed in the fermenter vessels to allow the probe tips to be moisturized during sterilization. The sterilization of the complete consisting of jar, head plate and components of head plate, was performed at $121^{\circ} \mathrm{C}$ and 1.06 bar for 15 minutes.

Sterilization of Equipments Micropipette tips, eppendorfs and glass equipments were sterilized by autoclaving at 1.06 bar and $121^{\circ} \mathrm{C}$ for 15 minutes.

III.3.2. Cultivation Conditions

Microorganisms were cultured in liquid media. Shake flask cultures were grown in Erlenmeyer flasks with medium volumes up to $1 / 5$ of the flask volume. For optimal aeration, the Erlenmeyer flask cultures were incubated in an orbital shaker at $180 \mathrm{rpm}$. For bioreactor cultivations, a 1L BIOSTAT Q multi-fermenter with an agitation rate of $200 \mathrm{rpm}$ was used and the working volume was $500 \mathrm{~mL}$. 
III.3.3. Preparation of Preculture

$50 \mathrm{~mL}$ of sterile liquid medium in $250 \mathrm{~mL}$ Erlenmeyer flask was inoculated with $1 \%(\mathrm{v} / \mathrm{v})$ frozen glycerol culture and incubated at $37^{\circ} \mathrm{C}$ at $180 \mathrm{rpm}$ for 24 hours until its growth reached the early exponential phase in an orbital shaker (Certomat BS1, B. Braun, Germany). 1\% (v/v) of this preculture was used as an inoculum.

\section{III.3.4. Growth Conditions}

\section{III.3.4.1. Preculture Growth}

The growth of preculture was carried out in an orbital shaker at $37^{\circ} \mathrm{C}$ with an agitation rate of $180 \mathrm{rpm}$ for 24 hours.

\section{III.3.4.2. Batch Experiments}

Shake flask The batch shake flask experiments were carried out in $500 \mathrm{~mL}$ Erlenmeyer flasks. Certomat BS1 and New Brunswick Scientific Excella E 24 orbital shaker incubators were used with the set agitation rate of $180 \mathrm{rpm}$ and the set temperature of $37^{\circ} \mathrm{C}$.

Bioreactor The monitoring of various parameters such as $\mathrm{pH}$, temperature and agitation were performed by the control system of the Multi-Fermenter, BIOSTAT Q. The working volume of the culture medium was kept at $500 \mathrm{~mL}$ in the batch fermenter experiments. The agitation speed was $200 \mathrm{rpm}$ and the temperature was set to $37^{\circ} \mathrm{C}$. The $\mathrm{pH}$ was kept constant at $\mathrm{pH} 7$ by buffering the system either with $1 \mathrm{M}$ $\mathrm{NaOH}$ or with $1 \mathrm{M} \mathrm{HCl}$. Compressed air was sparged into the medium for aeration at a rate of $0.1 \mathrm{vvm}$.

\section{III.3.5. Isolation and Purification of EPS}

For the purification of EPS, cells were harvested by centrifugation at 10000 rpm for $20 \mathrm{~min}$ and the supernatant phases were treated with an equal volume of ethanol at $5^{\circ} \mathrm{C}$ added drop-wise under stirring, held at $-18^{\circ} \mathrm{C}$ overnight, and then centrifuged at $12000 \mathrm{rpm}$ and $4^{\circ} \mathrm{C}$ for $30 \mathrm{~min}$ using a refrigerated centrifuge. The pellets were dissolved in hot distilled water, dialyzed against several changes of distilled water for 3 days, lyophilized and then weighed. The EPS samples were analyzed for total carbohydrate, protein, nucleic acid and uronic acid contents. 
III.3.6. Statistical Optimization of the Medium

Besides important fermentation parameters such as aeration, inoculum density, $\mathrm{pH}$, temperature and incubation time, microbial production of EPS is extremely influenced by media components, the initial sucrose and $\mathrm{NaCl}$ contents.

In this study in order to optimize the initial sucrose and $\mathrm{NaCl}$ contents of the medium, Response Surface Methodology (RSM) was used as a statistical tool. The initial concentrations of sucrose and $\mathrm{NaCl}$ were varied, while the levels of Pepton, $\left(\mathrm{NH}_{4}\right)_{2} \mathrm{SO}_{4}, \mathrm{KH}_{2} \mathrm{PO}_{4}, \mathrm{~K}_{2} \mathrm{HPO}_{4}$ and $\mathrm{MgSO}_{4} .7 \mathrm{H}_{2} \mathrm{O}$ were kept constant in the Minimal Medium. In order to decide on an appropriate initial sucrose and $\mathrm{NaCl}$ contents, the growth profiles were determined. Halomonas sp AAD6 was grown at $\mathrm{pH} 7$ and $37^{\circ} \mathrm{C}$ in an orbital shaker operated at $180 \mathrm{rpm}$ constant speed. At certain time intervals, samples were taken and their cell density was determined.

In accordance with the results of preliminary experiments, a second-order polynomial was used as to model the response variable (maximum biomass yield after 100 hours of fermentation) with respect to the independent factors (initial sucrose and $\mathrm{NaCl}$ concentrations). A $2^{2}$ full factorial central composite design (CCD), with 4 center and 4 star points, was employed to fit this second-order polynomial model. The design contained 12 experiments and two replications of each.

III.3.7. EPS Production in Bioreactor

\section{III.3.7.1. Measurement of Bacterial Growth}

The rate of growth of bacterial cells is usually monitored by measuring the increase in cell number. The optical density (OD) is a measure of the amount of light passing through a cell suspension determined with a spectrophotometer. The growth of the cells was monitored by measuring off-line the optical densities at $660 \mathrm{~nm}$ using Lambda35 UV/Vis spectrophotometer (Perkin Elmer, USA). At the desired time intervals an aliquot of the cell suspension was taken and $\mathrm{OD}_{660 \mathrm{~nm}}$ was measured using cell-free medium as the blank. When necessary, samples were diluted to keep the spectroscopic reading within reliable limits of 0.2-0.8.

In order to convert optical density values to dry cell weight (DCW), a calibration chart was prepared. For this, known volumes of culture samples at varying optical density values were centrifuged at $5000 \mathrm{rpm}$ for $15 \mathrm{~min}$; harvested cells were washed twice with distilled water and then dried at $100^{\circ} \mathrm{C}$ until constant cell dry weight was achieved. Dry weight versus optical density graph was plotted 
and a line was fitted through the data points using least square method. This calibration curve given in Appendix A provides the correlation between the optical measurements obtained from the spectrophotometer and the dry cell weight of the cells that are used in this study.

\section{III.3.7.2. Total Carbohydrate Analysis}

To determine the total carbohydrate concentration, 1-2 mL samples were taken and centrifuged at $10000 \mathrm{rpm}$ for $3 \mathrm{~min}$ to separate biomass. The supernatant was precipitated with three volumes of cold ethanol. This solution was kept at $4^{\circ} \mathrm{C}$ overnight before being centrifuged at $12000 \mathrm{rpm}$ and $4^{\circ} \mathrm{C}$ for $30 \mathrm{~min}$ using a refrigerated centrifuge. The pellet was resuspended in distilled water and subjected to total carbohydrate analysis. Carbohydrate content was determined using phenol/sulfuric acid method using glucose as standard. According to the method; 200 $\mu \mathrm{L}$ of sample was pipetted into an eppendorf, and $0.5 \mu \mathrm{L}$ of $80 \%$ phenol and $1 \mathrm{~mL}$ of concentrated sulfuric acid were added, respectively. They were shaken in order to obtain good mixing and after waiting for 20 minutes at room temperature, optical densities were measured at 490nm. Blanks were prepared by substituting distilled water for the sugar solution (Dubois et al., 1956). The net carbohydrate contents were calculated by subtracting the carbohydrate values of growth media without inoculum.

In order to convert absorbencies to grams per liter, a calibration chart was prepared with known amounts of dried EPS. EPS solutions within a suitable concentration range $(0.25-2.0 \mathrm{~g} / \mathrm{L})$ were subjected to phenol/sulfuric acid method as described above. Optical densities measured at 490nm were plotted against EPS concentration and a line was fitted through the data points using least square analysis. The calibration curves demonstrate a linear relationship between absorbance and EPS concentration, with $\mathrm{R}^{2}$ values greater than 0.98 . This calibration curve given in Appendix B was used to convert the results of phenol/sulfuric assay to carbohydrate concentration in $\mathrm{g} / \mathrm{L}$.

\section{III.3.8. Characterization of EPS}

\section{III.3.8.1. Determination of Protein Concentration}

Protein concentration was determined by the Bradford test using Bovine Serum Albumin (BSA) as standard (Bradford, 1976). The Bradford dye assay is based on the equilibrium between three forms of Coomassie Blue $G$ dye. Under strongly acidic conditions, the dye is most stable as a doubly-protonated red form. 
Upon binding to protein, however, it is most stable as an unprotonated, blue form. To determine the protein concentration of samples, $0.3 \mathrm{~mL}$ of dye stock (BioRad) was added to $1.2 \mathrm{~mL}$ of dilutions of sample to be assayed and vortexed. After incubation at room temperature for at least 5 minutes, absorbance was measured at $595 \mathrm{~nm}$. A standard curve of absorbance versus protein concentration was prepared by using known amounts of Bovine Serum Albumin (BSA).

III.3.8.2. Determination of Quantity and Quality of DNA

Spectrophotometric measurement was used to determine the quantity and quality of DNA. DNA was diluted with distilled water and the UV absorption of DNA was read at $260 \mathrm{~nm}$ using quartz cuvettes.

\section{III.3.8.3 Uronic Acid Assay}

The uronic acid assay of the EPS samples relies on the appearance of a chromagen when uronic acid, heated to $100^{\circ} \mathrm{C}$ in the presence of concentrated sulfuric/tetraborate, is treated with meta-hydroxydiphenyl. To measure the uronic acid content, $1.2 \mathrm{~mL}$ of the sodium tetraborate solution $(0.0125 \mathrm{M}$ sodium tetraborate in concentrated sulfuric acid) was added to $200 \mu \mathrm{L}$ of sample and the mixture vortexed for $45 \mathrm{~s}$ before being heated for $5 \mathrm{~min}$ in a $100{ }^{\circ} \mathrm{C}$ water bath. Samples were then cooled on ice for $3 \mathrm{~min}$ before $20 \mu \mathrm{L}$ of m-hydroxydiphenyl solution $(0.15 \%$ $(\mathrm{v} / \mathrm{v})$ in $0.5 \% \mathrm{NaOH})$ was added. The solution was then mixed gently and the absorbance read at 520nm after 4 min (Blumenkrantz et al., 1973). The concentration of uronic acid is determined by comparison against a calibration curve prepared by similarly assaying calibration standards of a selected uronic acid (e.g., glucuronic acid, galacturonic acid, mannuronic acid, etc) (K. Mojica et al., 2007).

\section{III.3.8.4. Rheological Studies}

Measurements of specific viscosity as a function of concentration of aqueous solutions of EPS were carried out using Cannon-Ubbelohde 75 suspended level viscometers at $25^{\circ} \mathrm{C}$.

\section{III.3.9. Biocompatibility Studies}

\section{III.3.9.1. Inhibition of Toxic Activity}

The inhibition of avarol toxic activity on brine shrimp (Artemia salina) was performed in triplicate using 10 animals, for each dose, in artificial seawater (Meyer et al., 1982). Briefly, $10 \mathrm{ppm}$ of avarol dissolved in DMSO (1\% of final volume) were added to each vial containing the polysaccharides in three different doses (500, 50 , and $5 \mathrm{ppm}$ ) and for each dose survivor shrimps were counted after $24 \mathrm{~h}$ and data 
were statistically analyzed by the Finney program which yields $\mathrm{IC}_{50}$ values (Finney, 1971).

\section{III.3.9.2. Cell Culture}

Osteoblasts were isolated from the calvaria of 1-5 days old neonatal Wistar rats. The calvaria was dissected and freed from soft tissue, cut into small pieces and rinsed in sterile PBS solution (1\%). The calvaria pieces were incubated with $1 \%$ trypsinEDTA for $15 \mathrm{~min}$, followed by four sequential incubations with $2 \%$ collagenase at $37^{\circ} \mathrm{C}$ for $30 \mathrm{~min}$ each. The supernatant of the first collagenase incubation, which contains a high proportion of periosteal fibroblasts, was discarded. The other digestions produced a suspension of cells with high proportion of osteoblasts. After centrifugation at $5000 \mathrm{rpm}$ for $5 \mathrm{~min}$, each pellet were ressuspended in $5 \mathrm{~mL}$ of RPMI medium supplemented with $15 \%$ FBS, $1 \%$ antibiotic-antimycotic. The cells were seeded into $10 \mathrm{~mL}$ tissue culture flasks, and lead to grow in a controlled $5 \%$ $\mathrm{CO}_{2}, 95 \%$ humidified incubator at $37^{\circ} \mathrm{C}$. For experiments, only confluent cells from the $2^{\text {nd }}$ passage were used.

Preparation of EPS Solution EPS was suspended in culture medium RPMI (0.5 $\mathrm{g}$ in $50 \mathrm{ml}$ ), shaked for $5 \mathrm{~h}$ at $37^{\circ} \mathrm{C}$ and sterilized by autoclaving at 1.06 bar and 121 ${ }^{\circ} \mathrm{C}$ for 15 minutes without $15 \%$ of FBS, which was sterilized by filtration $(0.22 \mu \mathrm{m})$. Control medium was subjected to the same process.

Stimulation of Osteoblasts with EPS Solution Osteoblasts were plated $1 \times 10^{5}$ in 24 well plates, and after $2 \mathrm{~h}$, the medium was changed to medium containing EPS. After $48 \mathrm{~h}$ incubation, osteoblasts morphology, viability and secretion capability (alkaline phosphatase) were tested.

Cellular Viability After $48 \mathrm{~h}$ of incubation in the presence of EPS solution, osteoblast viability was evaluated by MTT assay, based on the reduction of tetrazolium salt to formazan crystals by living cells. About $20 \mu \mathrm{L}$ of MTT was added to each well containing $200 \mu \mathrm{L}$ of sample. Four hours later, the cell morphology was analysed by inverted optical microscopy and formazan salts were solubilized with 50 $\mu \mathrm{L}$ of solubulization kit. After incubation, for overnight, in a controlled $5 \% \mathrm{CO}_{2}$, $95 \%$ humidified incubator at $37^{\circ} \mathrm{C}$, the optical density measurement was done at 595 $\mathrm{nm}$.

Alkaline Phosphatase Activity After incubation for the established period the alkaline phosphatase production was evaluated by BCIP-NBT assay. This assay is 
based on a chromagenic reaction initiated by the cleavage of the phosphate group of BCIP by alkaline phosphatase present in the supernatant. This reaction produces a proton, which reduces NBT to an insoluble purple precipitate. Briefly, $50 \mu \mathrm{L}$ of BCIP-NBT solution was added to $50 \mu \mathrm{L}$ of supernatant from each well according to the manufacturer's protocol. After overnight incubation at $37^{\circ} \mathrm{C}$, the optical density measurement was done at $595 \mathrm{~nm}$. Cell cultures were used without samples as control.

\section{III.3.10. Chemical Characterization of EPS}

For the sugar analysis, lyophilized samples obtained under the conditions described above were dissolved in distilled water to give $0.1 \%(\mathrm{w} / \mathrm{v})$ solutions and hydrolyzed with $2 \mathrm{M}$ trifluoroacetic acid (TFA) at $120^{\circ} \mathrm{C}$ for $2 \mathrm{~h}$. The neutral sugar composition of the EPS samples was analyzed by HPAE-PAD using standards for identification and calibration curves (Manca et al., 1996). HPAE-PAD Dionex equipped with Carbopac PA 1 column was eluted isocratically with a) $15 \mathrm{mM} \mathrm{NaOH}$ for neutral sugars; b) buffer $100 \mathrm{mM} \mathrm{NaOH}$ and $150 \mathrm{mM} \mathrm{NaOAc}$ for acidic sugars.

Fourier transform-infrared (FT-IR) spectroscopy spectra of EPS were obtained with Nicolet 6700 FT-IR Spectrometer between 400 and 4000 wave numbers $\left(\mathrm{cm}^{-1}\right)$. Thermogravimetric analysis of EPS was obtained with Mettler TGA apparatus where a known amount of EPS sample $\left(5 \mathrm{mg}\right.$ in $2 \mathrm{~mL} \mathrm{H}_{2} \mathrm{O}$ ) was heated from 30 to $400{ }^{\circ} \mathrm{C}$ at a rate of $20{ }^{\circ} \mathrm{C} \mathrm{min}^{-1}$ under a constant flow of nitrogen.

Molecular size analyses were carried out by Gel filtration on Sepharose Cl6B column using $\mathrm{H}_{2} \mathrm{O} / \mathrm{Pyridine} / \mathrm{AcOH}$ (500/5/2, by vol.) as eluant, with a flux of 3.7 $\mathrm{mL} / \mathrm{h}$, and density gradient centrifugation method, using a sucrose gradient from 0 to $50 \% \mathrm{w} / \mathrm{v}$ at $13000 \mathrm{~g}$ for $16 \mathrm{~h}$ (Pazur et al., 1994). In both methods $10 \mathrm{mg}$ of EPS and a mixture of dextran for calibration curves (10 mg of T-700, MW 670000; T-400, MW 410000; T- 150, MW 154000) were used.

UV spectra of EPS were obtained by reading the absorbance of aqueous solutions from 350 to $210 \mathrm{~nm}$ on a Varian DMS-90 instrument. 


\section{PART IV}

\section{RESULTS AND DISCUSSION}

Considering the widespread use of microbial polysaccharides in various industrial applications, microbial polysaccharide production by the halophilic Halomonas sp AAD6 bacteria isolated from Çamalt1 Saltern Area in Izmir was investigated within the scope of this study. The fermentation conditions were optimized for high-yield biopolymer production by this microorganism. In addition, this novel exopolysaccharide was also produced under controlled bioreactor conditions, purified with high yield and characterized. Finally, preliminary biocompatibility studies were performed by isolating osteoblasts from the calvaria of 1- to 5-day old neonatal wistar rats and incubating the cells in the presence of the EPS. Then, osteoblasts' morphology, viability/proliferation and secretion capability of alkaline phosphatase were tested. Also, the ability of the biopolymer to inhibit the toxic activity of avarol on brine shrimp was analyzed.

\section{IV.1. OPTIMIZATION OF FERMENTATION CONDITIONS}

The yield and quality of microbial exopolysaccharide are greatly affected by the nutritional and environmental conditions and therefore an increase in polymer production is possible by manipulating the culture conditions. Production of most microbial polysaccharides involves growth using media with glucose or sucrose as the carbon and energy source and the biopolymer synthesis is often favored by high $\mathrm{C}: \mathrm{N}$ ratios (Sutherland, 2002).

IV.1.1. Effect of Different Carbon Sources on Growth and Exopolysaccharide Production

The amount of EPS produced by bacterial cultures is often linked to biomass production, but there are exceptions. Attempts have been made to improve yields by manipulating medium composition, such as the carbon source (Macedo et al., 2002).

In this study, the ability of halophilic Halomonas sp AAD6 cells to use different carbon sources for growth and EPS production were analyzed. For this, cells were grown in minimal medium containing 14 different carbon sources, namely, glucose, sucrose, maltose, lactose, raffinose, arabinose, xylose, fructose, 
galactose, mannose, acetate, glycerol, trisodium citrate, and rhamnose at $1 \%$ concentration. Samples were taken from shake flask cultures at certain time periods and analyzed for biomass and EPS production. The results are summarized in Table IV.1.

Table IV.1. The Effect of Carbon Sources (1\% (w/v)) in the Minimal Medium on Growth and EPS Production

\begin{tabular}{|c|c|c|c|}
\hline C - Source & Biomass (g/L) & EPS Production $(\mathbf{g} / \mathbf{L})$ & Yp/x $\mathbf{( g / g})$ \\
\hline Glucose & 1,107998 & 0 & 0 \\
\hline Lactose & 0,103099 & 0,0599 & 0,580994 \\
\hline Sucrose & 0,86346 & 1,0726 & 1,242212 \\
\hline Arabinose & 0,103785 & 0,0273 & 0,263044 \\
\hline Xylose & 0,096111 & 0,2665 & 2,77285 \\
\hline Maltose & 1,37422 & 0,1893 & 0,137751 \\
\hline Raffinose & 0,134516 & 0,2059 & 1,530678 \\
\hline Fructose & 1,548088 & 0 & 0 \\
\hline Galactose & 1,199438 & 0 & 0 \\
\hline Mannose & 0,607132 & 0 & 0 \\
\hline Rhamnose & 0,084974 & 0 & 0 \\
\hline Acetate & 0,051141 & 0 & 0 \\
\hline Glycerol & $-0,00091$ & 0 & 0 \\
\hline Trisodium citrate & 0,003102 & & 0 \\
\hline
\end{tabular}

Halomonas sp AAD6 cells grown in the presence of sucrose were found to reach highest EPS production levels of $1.0726 \mathrm{~g} / \mathrm{L}$. Although higher biomass concentrations were observed when glucose, maltose, fructose and galactose were used as carbon source, their EPS production levels (which were 0, 0.1893, 0 and 0 $\mathrm{g} / \mathrm{L}$, respectively) were very low when compared with sucrose. Acetate, trisodium citrate, rhamnose and glycerol were most probably not utilized by the microorganism metabolism resulting in very poor growth and biopolymer production levels. The product yield on biomass $(\mathrm{Yp} / \mathrm{x})$ of the cultures was calculated by dividing the net produced EPS amounts by the biomass concentration. High $\mathrm{Yp} / \mathrm{x}$ value of xylose $(2.77285 \mathrm{~g} / \mathrm{g})$ is due to the very low steady state biomass concentration of the 
culture. Arabinose reached almost the same biomass concentrations like xylose but the cells' biopolymer production yields were about ten-fold lower than xylose.

In the light of these results, sucrose was chosen as the best carbon source for both biomass and EPS production.

In literature, there are numerous reports on the influence of various carbon sources on the biomass and EPS production.

Shih et al. (2005) studied production of levan by Bacillus subtilis (natto) Takahashi. A large amount of the levan was produced when the bacteria were cultivated using sucrose, but the yields varied with the sucrose concentration. The maximum levan productivity $(49.4 \mathrm{~g} / \mathrm{L})$ was obtained on the medium containing 200 $\mathrm{g} / \mathrm{L}$ of sucrose, whereas the yield decreased at the higher or the lower sucrose concentrations. A small amount of polysaccharide (alcohol precipitate) was also produced when the bacteria were grown on lactose and maltose, but no polysaccharide was produced using glucose or fructose.

Prasertsan et al. (2008) investigated factors affecting the production of exopolysaccharide from Enterobacter cloacae WD7 cultivated in basal medium. The influence of different carbon sources (glucose, fructose, galactose, sucrose and maltose at $1 \% \mathrm{w} / \mathrm{v})$ and concentrations $(0-4.0 \% \mathrm{w} / \mathrm{v})$ of the selected carbon sources were studied. Sucrose and galactose gave similar EPS yields $(2.45$ and $2.50 \mathrm{~g} / \mathrm{L}$, respectively) $(\mathrm{p}<0.05)$ and higher than those from using maltose, fructose and glucose $(2.34,2.32$ and $2.23 \mathrm{~g} / \mathrm{L}$, respectively). Sucrose was chosen due to its lower cost than galactose. Increase of the sucrose concentration (testing at 1\%, 2\%, 3\%, 4\% $\mathrm{w} / \mathrm{v}$ ) resulted in increase in EPS yields of $2.23,2.24,2.72$, and $2.52 \mathrm{~g} / \mathrm{L}$, respectively. The optimal sucrose concentration for EPS production from E. cloacae WD7 was 3\% w/v while it was $2.5 \% \mathrm{w} / \mathrm{v}$ for Agrobacterium tumefaciens (Stredansky et al., 1999), 10\% for Lactobacillus strain LB 80 (van Geel-Schutten et al., 1998) and 2\% w/v for Lactobacillus casei CG11 (Cerning et al., 1994), giving the maximum EPS yields of 2.72, 23.5, 21.0 and $0.05 \mathrm{~g} / \mathrm{L}$, respectively.

Huang H. C. and Liu H. C (2008) studied the effects of cultural condition on the mycelial growth and exopolysaccharide (EPS) production by Grifola umbellata (Fries). To select the best carbon sources for mycelial growth and EPS production, various carbohydrates $(2 \%, \mathrm{w} / \mathrm{v})$ such as sucrose, soluble starch, lactose, molasses and xylose were added into the basal medium, respectively. It is obvious that the highest mycelia dry cell weight and EPS production were obtained when glucose was 
used. In contrast, very low cell and polysaccharide productions were observed when using lactose and xylose as carbon sources. Base on this result, glucose was selected as the carbon source for the subsequent experiments. 1-5\% glucose was added to the medium to search for the optimal glucose concentration. Both mycelia and EPS productions increased with the increase of glucose concentration from 1 to $3 \%$. Whereas, further increasing glucose concentration from 3 to $5 \%$ exerted a negative effect on the production.

Çelik et al. (2008) investigated the cultivation of Pseudomonas aeruginosa G1 and Pseudomonas putida G12 strains in the PAP medium containing various carbon sources (glucose, mannose, fructose and xylose) to find a suitable carbon source for the EPS production. When strains G1 and G12 were grown in the xylose containing medium, the EPS productions $(335,262 \mathrm{mg} / \mathrm{L}$, respectively) were the highest among those tested. The EPS produced (267 mg/L) from fructose and other carbon sources by strain G11 was much lower than that from xylose. Similarly, the EPSs produced $(208,196,242 \mathrm{mg} / \mathrm{L})$ from glucose, mannose, fructose by strain G12 were lower than that from xylose.

E. Arsköld et al. (2007) studied the effect of several environmental conditions on the growth and EPS production in the L. reuteri strain ATCC 55730. The strains were grown in batch mode using a semi-defined medium with sucrose or glucose as carbon and energy source under anaerobic conditions, in 1-L fermentors. To study the influence of glucose on growth and EPS production, L. reuteri ATCC 55730 was grown with either sucrose or glucose and with a combination of the two sugars. The growth rate declined from the cultures on sucrose $\left(0.72 \mathrm{~h}^{-1}\right)$, sucrose plus glucose $\left(0.66 \mathrm{~h}^{-1}\right)$ to glucose $\left(0.53 \mathrm{~h}^{-1}\right)$. However, in the presence of glucose the EPS production $(0.14 \mathrm{~g} / \mathrm{g} \mathrm{CDW})$ dropped by about $50 \%$ compared to the fermentation with sucrose only $(0.27 \mathrm{~g} / \mathrm{g} \mathrm{CDW})$. In the culture on glucose no EPS was produced, confirming that EPS is only formed when sucrose is present.

Poli et al. (2004) studied the influence of various carbon sources on the biomass and EPS production with newly isolated Halomonas strain CRSS by using batch fermentation in complex media $\mathrm{A}$ and $\mathrm{B}$ containing trisodium citrate $(3 \mathrm{~g} / \mathrm{L})$ and maltose $(20 \mathrm{~g} / \mathrm{L})$ respectively as carbon source and minimal medium with $1 \%$ (w/v) sodium acetate, D-glucose, D-galactose, lactic acid, D-maltose, D-fructose, Dcellobiose, D-ribose, D-trehalose, glycerol or sucrose. The strain CRSS grew aerobically in enrichment medium a yielding $0.5 \mathrm{~g}$ dry cells/Land in medium B 0.45 
$\mathrm{g}$ dry cells/L. Among several carbon sources tested using minimal medium, the isolated CRSS utilised acetate $(0.25 \mathrm{~g}$ dry cells/L) better than galactose, glucose, ribose, fructose sucrose or trehalose. The maximum yield of EPS for all media was reached after $48 \mathrm{~h}$ of incubation. The isolate grew well in complex media A and B and minimal medium plus sodium acetate producing (g EPS/g dry cells) 2.2, 2.9, 1.23 , respectively.

Tallon et al. (2003) studied the influence of carbon source to improve EPS production by L. plantarum EP56. Five carbon sources (glucose, galactose, fructose, lactose and sucrose) were tested. Lower growth and EPS production rates, which were $0.36 \mathrm{~h}^{-1}$ and $46.3 \mathrm{mg} / \mathrm{L}$, respectively, were observed when fructose was used as the carbon source. Although higher growth rates were observed when glucose, galactose and sucrose were used as the carbon source, their EPS production levels (which were 114.5, 121.1 and $129.2 \mathrm{mg} / \mathrm{L}$, respectively) were low. Fructose and lactose were less favorable carbon sources for growth of L. plantarum EP56. However, lactose, which is a poor carbon source in regard to the growth, resulted in the best EPS production: $140.2 \mathrm{mg} / \mathrm{L}$ EPS.

Cerning et al. (1994) used Lactobacillus casei in basal minimum medium (BMM) supplemented with galactose, glucose, sucrose, maltose, or melibiose at different concentrations $(2-20 \mathrm{~g} / \mathrm{L})$ to determine the effects of various carbon sources and concentrations on the yield of EPS produced. They reported that, increasing the sugar concentrations from 2 to $20 \mathrm{~g} / \mathrm{L}$ did not affect growth. The lowest growth of cells was obtained with galactose and lactose, while slightly higher growth was observed with glucose, sucrose, and maltose. Even at concentrations of $20 \mathrm{~g} / \mathrm{L}$, galactose and lactose gave the lowest EPS yields (20-45 mg/L of EPS, respectively). With melibiose, the EPS yield increased dramatically from 15 to $100 \mathrm{mg} / \mathrm{L}$ of EPS when the sugar concentration was increased from 2 to $20 \mathrm{~g} / \mathrm{L}$. With glucose, sucrose, and maltose the EPS yield increased when the sugar concentration in the medium increased. The EPS yield obtained with $2 \mathrm{~g} / \mathrm{L}$ of sucrose was $35 \mathrm{mg} / \mathrm{L}$, and the EPS yield obtained with $20 \mathrm{~g} / \mathrm{L}$ of sucrose was $50 \mathrm{mg} / \mathrm{L}$. When the maltose concentration was increased from 2 to $20 \mathrm{~g} / \mathrm{L}$, the EPS yield increased from 15 to $60 \mathrm{mg} / \mathrm{L}$. With 2 $\mathrm{g} / \mathrm{L}$ of glucose, the EPS yield was $70 \mathrm{mg} / \mathrm{L}$, which was greater than the yield obtained with any other carbon source at the same concentration. When the medium contained $20 \mathrm{~g} / \mathrm{L}$ of glucose, the amount of EPS produced was $160 \mathrm{mg} / \mathrm{L}$; thus, glucose was by far the most efficient carbon source in terms of EPS production. 
To produce large quantities of an extracellular, highly viscous polysaccharide, Manresa et al. (1987) studied with Pseudomonas sp. GSP-910 in a simple salt medium. They tested alternative carbon sources; glucose, sucrose, manose, galactose, fructose, xylose, lactose, maltose. Among the carbon sources provided, glucose, sucrose and xylose allowed maximum EPS production (4.81, 4.43, $3.72 \mathrm{~g} / \mathrm{L}$, respectively). High yield production (g EPS/g cell dry weight) could be detected with manose and galactose as well $(2,2.15 \mathrm{~g}$ EPS/g cell dry weight, respectively); however, these sugars were not satisfactory as growth substrates.

IV.1.2. Statistical Optimization of the Medium

To achieve high product yields in a fermentation process, it is a prerequisite to design an optimal production medium and a set of optimal process operating conditions (Desai et al., 2006).

As the physico-chemical property of polysaccharide is influenced by culture conditions, it is very important to optimize culture conditions for the production of a specific type of polysaccharides (Lee et al., 2007).

The use of statistical instruments, such as factorial experimental planning associated to the surface-response methodology, has been used by various authors in biotechnology. Experimental planning permits product and process implementation and optimization, reducing development and production costs, because it promotes decrease in the number of experiments at the development stage, so that a considerable number of factors can be studied at the same time. The interaction among these factors can be assessed and optimum production levels obtained and hence greater precision in the results and production optimization. The responsesurface methodology is a set of experiment planning and analysis techniques used in the mathematical modeling of responses that can be applied, for example, in pharmacology, food sciences and optimization of fermentative processes (de Oliveira et al., 2007).

In this study, Response Surface Methodology (RSM) was used as a statistical tool in order to optimize the initial sucrose and $\mathrm{NaCl}$ contents of the medium. The initial concentrations of sucrose and $\mathrm{NaCl}$ were varied, while the levels of other components were kept constant in the Minimal Medium. To determine the range of parameters, preliminary experiments were performed where the Halomonas sp AAD6 cells were cultivated in minimal medium containing different concentrations of sucrose (from $10 \mathrm{~g} / \mathrm{L}$ to $50 \mathrm{~g} / \mathrm{L}$ ). The observed increase in EPS production with 
increasing sucrose concentration was in agreement with the similar behavior reported by Prasertsan et al. (2008) for exopolysaccharide production from Enterobacter cloacae WD7 cultivated in basal medium. Hence the initial sucrose concentration was varied within the range of $5-50 \mathrm{~g} / \mathrm{L}$. Considering the halophilic nature of the microorganism, a $\mathrm{NaCl}$ concentration range of $50-200 \mathrm{~g} / \mathrm{L}$ was chosen for the optimization experiments.

The design contained 12 experiments and two replications of each. The details of the design, values of the actual parameters, and results of the experiments are shown in Table IV.2.

Table IV.2. Maximum Biomass yields by shake flask cultures of Halomonas sp AAD6 strain grown in different media. Coded values were used during the calculations. The real values in $\mathrm{g} / \mathrm{l}$ are given in parenthesis. Intermediate values are calculated assuming linear interpolation.

\begin{tabular}{|c|c|c|}
\hline Sucrose (g/L) & $\mathrm{NaCl}(\mathrm{g} / \mathrm{L})$ & Biomass (g DCW/L) \\
\hline $\begin{array}{ll}0 & (27.5)\end{array}$ & $0 \quad(125)$ & 0.8544 \\
\hline $1 \quad(43.41)$ & $-1 \quad(71.96)$ & 0.5139 \\
\hline$-1.414 \quad(5)$ & $0 \quad(125)$ & 0.7561 \\
\hline $1 \quad(43.41)$ & $1 \quad(178.04)$ & 0.7117 \\
\hline$-1 \quad(11.59)$ & $1 \quad(178.04)$ & 0.7463 \\
\hline $0 \quad(27.5)$ & $0 \quad(125)$ & 0.8978 \\
\hline$-1 \quad(11.59)$ & $-1 \quad(71.96)$ & 0.6794 \\
\hline $0 \quad(27.5)$ & $0 \quad(125)$ & 0.8571 \\
\hline $0 \quad(27.5)$ & $0 \quad(125)$ & 0.7917 \\
\hline $0 \quad(27.5)$ & $-1.414 \quad(50)$ & 0.2805 \\
\hline $0 \quad(27.5)$ & 1.414 (200) & 0.4798 \\
\hline $1.414 \quad(50)$ & $0 \quad(125)$ & 1.3442 \\
\hline
\end{tabular}

A second-order polynomial was constructed with the experimental results using regression analysis. The model equation obtained is given in Equation 1:

Ln Biomass $=-0,163+0,147 \times \mathrm{NaCl}+0,06087 \times$ Suc $-0,401 \times \mathrm{NaCl}^{2}+0,05792 \times$ $\mathrm{NaCl} \times \mathrm{Suc}+0,105 \times \mathrm{Suc}^{2}$ 
where $\mathrm{NaCl}$ and Suc refer to the coded values of $\mathrm{NaCl}$ and sucrose, respectively.

The coefficient of multiple determination, $\mathrm{R}^{2}$ was found to be 0.881 , which means that the model could explain $88.1 \%$ of the total variation in the system. The relatively high value of $\mathrm{R}^{2}$ indicates that the second-order polynomial equation is capable of representing the system under the given experimental regime. Therefore, the model equation was used for studying the effects of the medium components on the biomass yield. Figure IV.1 depicts the interactions of sucrose with $\mathrm{NaCl}$, and the combined effect on the amount of biomass produced. The model equation was optimized using Nelder-Mead simplex method to maximize the biomass production within the experimental range studied. The optimum medium composition was found to be $50 \mathrm{~g} / \mathrm{L}$ and $137.2 \mathrm{~g} / \mathrm{L}$ for sucrose and $\mathrm{NaCl}$, respectively.

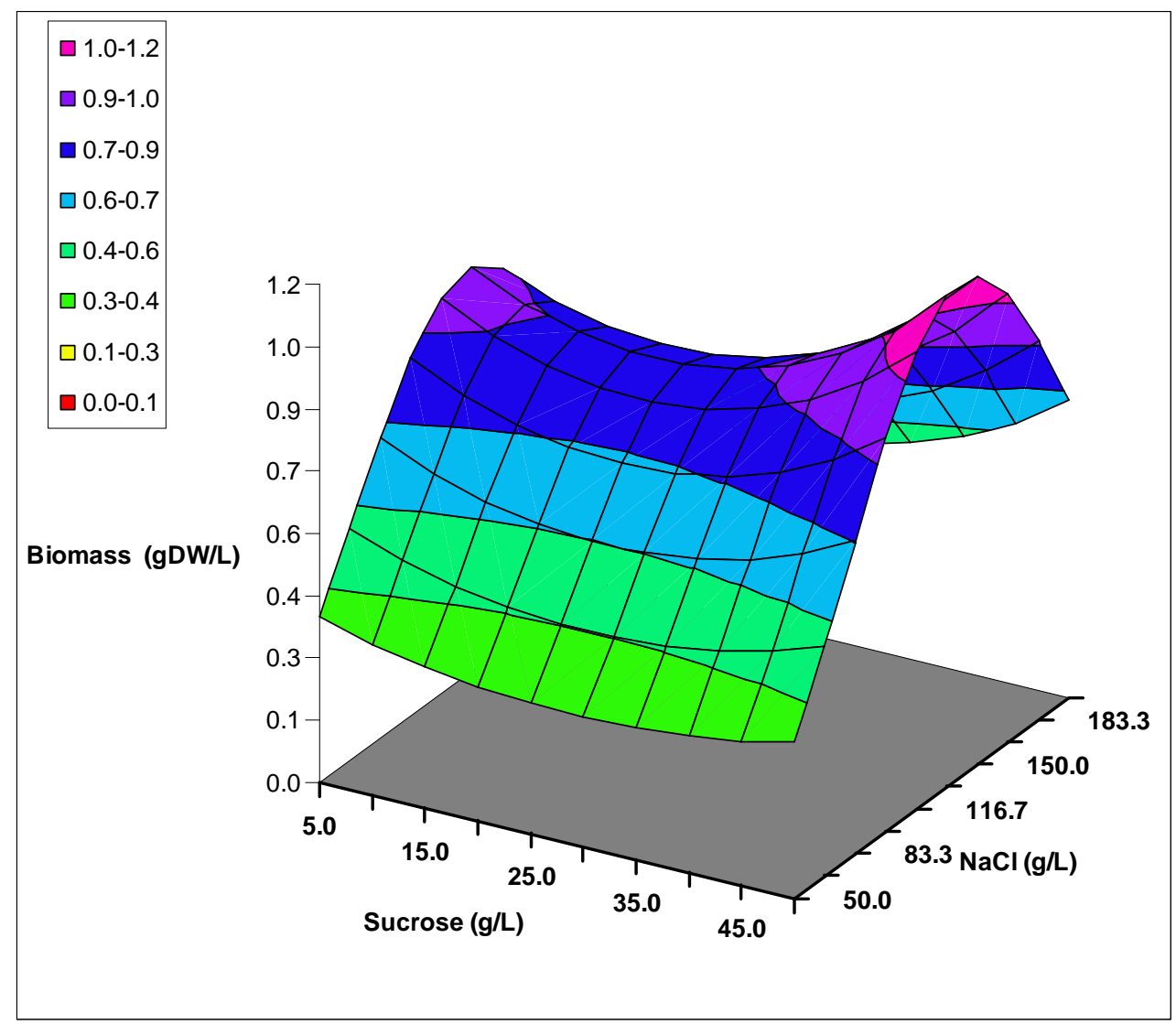

Figure IV.1. The interaction of sucrose and $\mathrm{NaCl}$ on maximum biomass yields by shake flask cultures of Halomonas sp AAD6 strain.

In literature, there are numerous reports on optimization of culture conditions for the production of a specific type of polysaccharides. 
Calazans et al. (2007) studied with Zymomonas mobilis strain ZAG-12 for optimization of levan production employing a $2^{4-1}$ fractional factorial design to analyze the influence of the temperature $\left(20,25,30^{\circ} \mathrm{C}\right)$ agitation $(50,75,100 \mathrm{rpm})$, and the initial concentrations of both sucrose $(150,200,250 \mathrm{~g} / \mathrm{L})$ and yeast extract $(2.0,3.5,5.0 \mathrm{~g} / \mathrm{L})$ on final levan concentration. The experiments showed that the final levan concentration depended on initial sucrose concentration, temperature and agitation velocity and that the initial concentration of yeast extract did not influence levan production. The best conditions for levan production occurred at $100 \mathrm{rpm}$ agitation, $20{ }^{\circ} \mathrm{C}$ and $250 \mathrm{~g} / \mathrm{L}$ of initial sucrose resulting in $14.67 \mathrm{~g} / \mathrm{L}$ of levan.

Lungmann et al. (2007) studied on medium optimization for production of exopolymer by a newly isolated bacterium, Halobacterium sp. SM5, using the mixture design and response surface method. They designed the mixture by setting five parameters (glucose, yeast extract, $\mathrm{MgSO}_{4} \cdot 7 \mathrm{H}_{2} \mathrm{O}$, vitamin casamino and $\mathrm{KCl}$ ). For optimization of this product, the mixture design experiment with the observed responses of the 30 formulations and the original point were determined. The results showed that the exopolymer yields varied within the range of 1.22-2.25 g/L. The exopolymer production was highest in media which contained $7.43 \mathrm{~g} / \mathrm{L}$ glucose, $12.38 \mathrm{~g} / \mathrm{L}$ yeast extract, $17.33 \mathrm{~g} / \mathrm{L} \mathrm{MgSO}_{4} \cdot 7 \mathrm{H}_{2} \mathrm{O}, 9.9 \mathrm{~g} / \mathrm{L}$ vitamin casamino acid and $2.48 \mathrm{~g} / \mathrm{L} \mathrm{KCl}$.

de Oliveira et al. (2007) used the complete factorial $3^{2}$ design to determine the optimal concentration of sucrose and fermentation time for levan production by $Z$. mobilis ATCC 31821, where the sucrose concentration $\left(x_{1}\right)$ and the fermentation time $\left(x_{2}\right)$ were assessed. The temperature of the fermentative process was fixed at $25^{\circ} \mathrm{C}$. The optimum conditions for levan production were $250 \mathrm{~g} / \mathrm{L}$ sucrose concentration and a fermentation time of $24 \mathrm{~h}$. Under these conditions production reached 21.685 $\mathrm{g} / \mathrm{L}$. The results show that an increase in fermentation time caused an increase in the levan production at all concentrations of sucrose tested. However, the sucrose concentration at its upper $(350 \mathrm{~g} / \mathrm{L})$ and lower $(150 \mathrm{~g} / \mathrm{L})$ limits reduced levan production. An increase in fermentation time leads to an increase in consumption of the sugar present in the medium and to an increase in the levan production in all the experiments.

Cui et al. (2006) used a three-level Box-Behnken factorial design for optimizing mycelial biomass and exopolymer produced by Grifola frondosa GF 9801. The model estimated that, a maximal yield of mycelia biomass $(17.61 \mathrm{~g} / \mathrm{L})$ 
could be obtained when the concentrations of glucose, $\mathrm{KH}_{2} \mathrm{PO}_{4}$, peptone were set at $45.2 \mathrm{~g} / \mathrm{L}, 2.97 \mathrm{~g} / \mathrm{L}, 6.58 \mathrm{~g} / \mathrm{L}$, respectively; while a maximal exopolymer yield (1.326 $\mathrm{g} / \mathrm{L}$ ) could be achieved when setting concentrations of glucose, $\mathrm{KH}_{2} \mathrm{PO}_{4}$, peptone at $58.6 \mathrm{~g} / \mathrm{L}, 4.06 \mathrm{~g} / \mathrm{L}$ and $3.79 \mathrm{~g} / \mathrm{L}$, respectively.

Hsieh et al. (2005) used RSM for optimizing polysaccharide produced by Cordyceps sinensis. The maximum polysaccharide of $3.17 \mathrm{~g} / \mathrm{L}$ was predicted from the regression model of RSM in the medium containing $6.17 \%$ sucrose, $0.53 \%$ corn steep powder, $0.5 \%\left(\mathrm{NH}_{4}\right)_{2} \mathrm{HPO}_{4}$ and $0.15 \% \mathrm{KH}_{2} \mathrm{PO}_{4}$. When applying this optimal medium, the maximum polysaccharide production was 3.05 and $3.21 \mathrm{~g} / \mathrm{L}$ in a shake flask and a 2-L jar fermentor, respectively.

$\mathrm{Xu}$ et al. (2003) used one-factor-at-a time and orthogonal matrix method for optimizing exobiopolymer produced by Paecilomyces tenuipes C240. The exopolymer $1.89 \mathrm{~g} / \mathrm{L}$ was produced in the medium containing $3 \mathrm{~g} / \mathrm{L}$ glucose, $0.4 \mathrm{~g} / \mathrm{L}$ $\mathrm{KNO}_{3}, 0.1 \mathrm{~g} / \mathrm{L} \mathrm{K}_{2} \mathrm{HPO}_{4}$, and $0.1 \mathrm{~g} / \mathrm{L} \mathrm{MgSO}_{4} \cdot 7 \mathrm{H}_{2} \mathrm{O}$ in shake flask.

Grothe et al. (1999) used central composite experimental design for optimizing poly ( $\beta$ - hydroxybutyric acid) (PHB) produced by Alcaligenes latus. The poly PHB $2.97 \mathrm{~g} / \mathrm{L}$ was produced in the optimized medium containing $20 \mathrm{~g} / \mathrm{L}$ sucrose and 1.5 $\mathrm{g} / \mathrm{L}$ ammonium sulfate, which was 1.8 fold greater than the yield in the screening experiment.

From the survey of literature, it can be seen that the application of statistical experimental design techniques in fermentation process development can result in improved product yield, reduced process variability, closer confirmation of the output response (product yield or productivity) in relation to nominal and target requirements, and reduced development time overall costs (Lungmann et al., 2007).

\section{IV.2. EPS PRODUCTION IN BIOREACTOR}

Although the production yields, compositions, structures and properties of bacterial EPS are genetically determined, it is possible to influence these factors by modifying culture conditions, such as temperature, dissolved oxygen tension, and growth medium composition (i.e., the concentration of cations and the carbon source used) (Fialho et al., 1999).

In our study, bioreactor cultivations were performed in a $1 \mathrm{~L}$ BIOSTAT $Q$ multi-fermenter with well-controlled environment of $\mathrm{pH}$ and temperature. In each run, the working volume was $500 \mathrm{~mL}$, the fermentation temperature and $\mathrm{pH}$ were 
kept constant at $37^{\circ} \mathrm{C}$ and $\mathrm{pH} 7$, respectively. Aeration was provided at a rate of 0.1 vvm and agitation was set to $200 \mathrm{rpm}$. Optimum medium composition was used for the cultivations. Samples were taken at certain time periods to determine the growth and amount of EPS. Biomass concentration was measured in terms of $\mathrm{OD}_{660 \mathrm{~nm}}$ and carbohydrate concentration of the samples was determined using phenol/sulfuric acid method using glucose as standard. Optical densities for carbohydrate concentration were measured in terms of $\mathrm{OD}_{490 \mathrm{~nm}}$. The net carbohydrate contents were calculated by subtracting the carbohydrate values of growth media without inoculum. In order to convert $\mathrm{OD}_{660 \mathrm{~nm}}$ and $\mathrm{OD}_{490 \mathrm{~nm}}$ absorbencies to grams per liter, calibration charts were prepared (Appendix A, Appendix B, respectively). Figure IV.2 shows the time course of the growth and EPS production of Halomonas sp AAD6cells. Results are averages of dublicate runs for four different experiments.

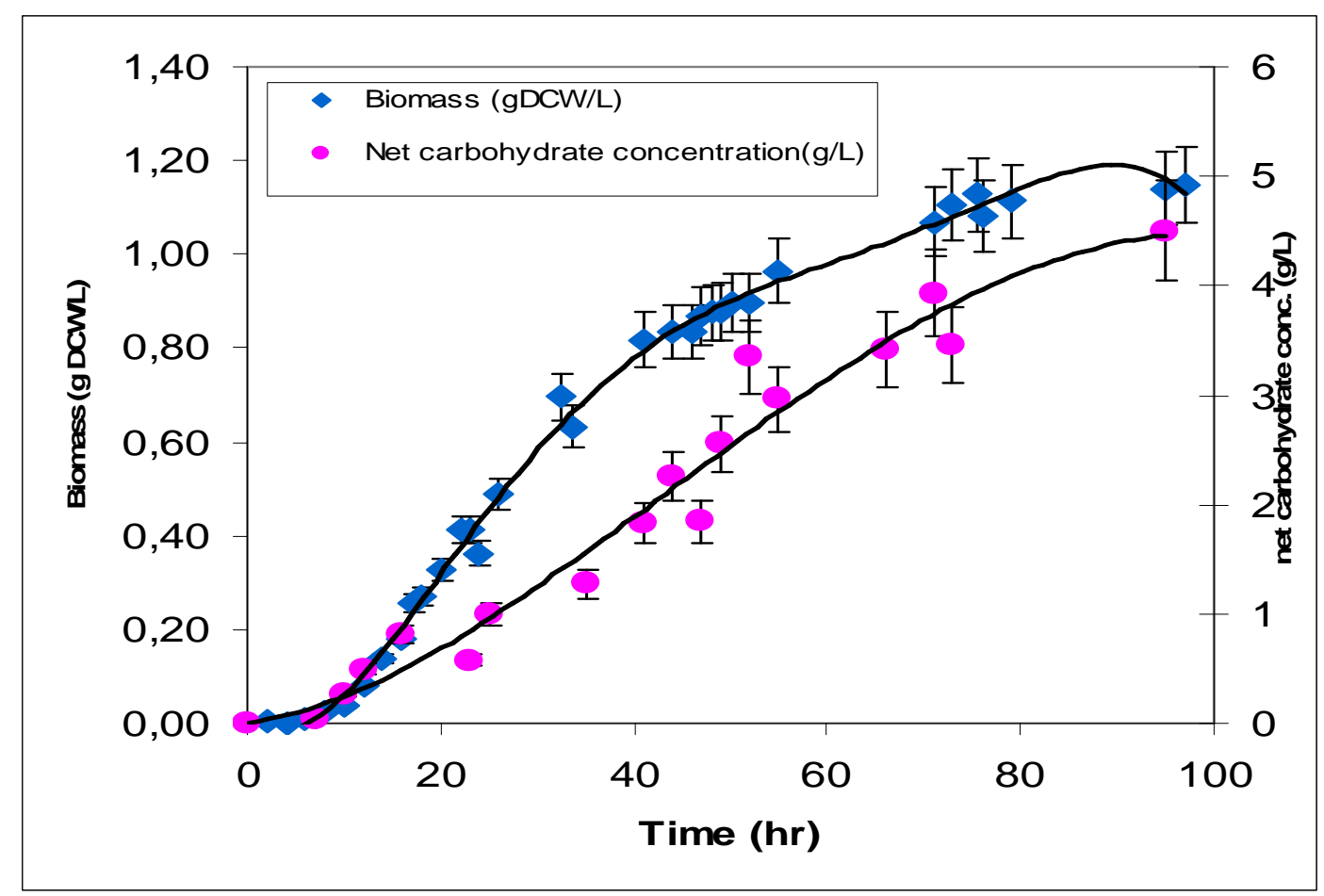

Figure IV.2 Time Course of Growth and EPS Production of Halomonas sp AAD6

As can be seen in Fig. IV.2, biomass and EPS yields reached by the bioreactor culture after 95 hours of fermentation period were $1.1407 \mathrm{~g} / \mathrm{L}$ and $4.5024 \mathrm{~g} / \mathrm{L}$, respectively. 
From the survey of literature, it can be seen that bioreactor cultivations with different biomass and EPS yields were studied by several researchers who used different process conditions.

Chi et al. (2007) studied exopolysaccharide production by marine Cyanothece sp. 113 in 5-L fermentor under the optimal conditions; $29^{\circ} \mathrm{C}, \mathrm{pH} 7.2$ and at an aeration rate of $7.01 / \mathrm{min}$ but with no agitation. Under these conditions, $22.34 \mathrm{~g} / \mathrm{L}$ of exopolysaccharide was released into the medium in 11 days when cell growth reached the late stationary phase. This was the highest exopolysaccharide yield by cyanobacteria reported so far. After purification, the spectra of UV, IR, ${ }^{1} \mathrm{H} N M R,{ }^{13} \mathrm{C}$ NMR and GC-MS analysis showed that the purified exopolysaccharide was $\alpha-\mathrm{D}-1,6$ homoglucan.

Shene and Bravo (2007) studied on the continuous culture fermentations of the strain of Lactobacillus delbrueckii subsp. bulgaricus in the whey-based media at dilution rates between 0.06 and $0.8 \mathrm{~h}^{-1}$ in a laboratory fermentor (Biostat M, B. Braun, Melsungen, Germany). Temperature and $\mathrm{pH}$ were kept at $37^{\circ} \mathrm{C}$ and 6 , respectively. Stirring was set to $150 \mathrm{rpm}$. They used lactose from deproteinized whey as the carbon source. The highest biomass concentration $(3.03 \mathrm{~g} / \mathrm{L})$ was obtained at a dilution rate of $0.21 \mathrm{~h}^{-1}$. EPS were isolated and quantified from culture samples with (EPS-1) and without (EPS-2) the biomass. Highest EPS-1 (0.83 g/L) and EPS-2 (0.39 $\mathrm{g} / \mathrm{L}$ ) concentrations were obtained at dilution rates of 0.36 and $0.29 \mathrm{~h}^{-1}$, respectively.

In order to determine the phase that EPS production is maximum, bioreactor cultivations were performed with well-controlled environment. In these experiments, EPS was purifed after cells were harvested by centrifugation in certain time periods. EPS production yields obtained in exponantial and stationary phases are summarized in Table IV.3.

As shown in Table IV.3, the data obtained from our experiments demonstrated that the maximum EPS yield reached by the bioreactor culture was $1.844 \mathrm{~g} / \mathrm{L}$ after 41 hours of fermentation period.

Table IV.3. EPS yields in different phases in bioreactor cultivations

\begin{tabular}{|c|c|c|c|c|}
\hline & $17 \mathrm{~h}$ & $21.5 \mathrm{~h}$ & $41 \mathrm{~h}$ & $47 \mathrm{~h}$ \\
\hline Biomass (gDCW/L) & 0.395 & 0.492 & 0.911 & 1.069 \\
\hline EPS (g/L) & 0.368 & 0.502 & 1.844 & 1.718 \\
\hline EPS yield (g EPS/g biomass) & 0.931 & 1.021 & 2.024 & 1.608 \\
\hline
\end{tabular}


Halomonas sp AAD6 cells entered the logarithmic growth phase after 8 hours of lag time. The maximum specific growth rate $\left(\mu_{\max }\right)$ of the culture was determined from the slope of the $\ln x$ versus time plots in the exponential phase using linear regression as $0.3162 \pm 0.005 \mathrm{~h}^{-1}$. The related graph is given in the Appendix C.

\section{IV.3. CHARACTERIZATION of EPS}

Protein Concentration Protein concentration was determined by the Bradford test using Bovine Serum Albumin (BSA) as a standard (Bradford, 1976). Absorbance was measured at $595 \mathrm{~nm}$. A standard curve of absorbance versus protein concentration was prepared by using known amounts of Bovine Serum Albumin (BSA). This calibration curve is given in Appendix D.

Analytical determinations carried out in this study was showed that EPS produced by Halomonas sp AAD6 in a 1L BIOSTAT Q multi-fermenter with wellcontrolled environment of $\mathrm{pH}$ and temperature has low content of proteins $(0.5125$ $\%)$. Result is averages of dublicate runs for four different experiments.

Quantity and Quality of DNA Spectrophotometric measurement was used to determine the quantity and quality of DNA. DNA was diluted with distilled water and the UV absorption of DNA was read at 260nm using quartz cuvettes.

The data obtained from our experiments demonstrated that nucleic acid content of the EPS was $1.8 \%$. Result is averages of dublicate runs for four different experiments.

Uronic Acid Concentration The concentration of uronic acid was determined as described in Blumenkrantz (1973) by using the comparison against a calibration curve prepared by similarly assaying calibration standards of a selected uronic acid (e.g., glucuronic acid, galacturonic acid, mannuronic acid, etc) (K. Mojica et al., 2007).

In order to convert $\mathrm{OD}_{520 \mathrm{~nm}}$ absorbencies to percentage values, the following data points were considered:

- Glucuronic acids 6 micrograms read 0.6 (at $\mathrm{OD}_{520 \mathrm{~nm}}$ ).

- Galacturonic acids 10 micrograms read 0.8 (at $\mathrm{OD}_{520 \mathrm{~nm}}$ ).

As a result, uronic acid concentration of EPS from Halomonas sp AAD6 was found as $4.4 \%$. Result is averages of dublicate runs for four different experiments. 
Rheological Studies The specific viscosity ( $\eta$ ) of aqueous solution of exopolysaccharide at different concentration values was determined using CannonUbbelohde 75 suspended level viscometer at $25{ }^{\circ} \mathrm{C}$. As concentration increases coils start to overlap and become entangled, with viscosity showing a more marked dependence on concentration reaching $\eta=0.710$ at $2 \%(w / v)$ of concentration.

Martínez-Checa et al. (2007) studied characteristics of exopolysaccharide V2-7 produced by strain F2-7 of Halomonas eurihalina in MY medium supplemented with various hydrocarbons. The viscosity of solutions was measured with a Bohlin Rheometer CSR-10 at $25{ }^{\circ} \mathrm{C}$. Rheological behavior was studied at neutral $\mathrm{pH}$ and at $\mathrm{pH}$ 3. Solutions were acidified with $1 \mathrm{M} \mathrm{HCl}$. With respect to the rheological behavior, all the EPS synthesized on hydrocarbon media originated solutions with very low viscosity and they were unable to form high viscosity solutions at $\mathrm{pH} 3$, as it happens when $H$. eurihalina strain F2-7 produces the EPS with glucose as carbon source (Calvo et al., 1995; Quesada et al., 1993). As a result, only the EPS from glucose MY medium exhibit pseudoplastic behavior indicated when the viscosity decreases as shear rate is increased. All biopolymers synthesized in presence of the hydrocarbons originated non-viscous solutions. This is a profitable characteristic required in several industrial fields, as the cleaning of oil tankers or the recovery of solid wastes.

Dlamini et al. (2007) characterized physical, chemical and rheological properties of a polysaccharide produced by an isolate of Klebsiella oxytoca in whey based media. Viscosity was measured using a Wells-Brookfield cone and plate viscometer at $25^{\circ} \mathrm{C}$. The rheological properties of the $K$. Oxytoca polysaccharide (KOP) were compared with those of gellan and xanthan gums. The results indicated that at lower gum concentrations, 0.1 to $0.5 \%(\mathrm{w} / \mathrm{v})$, gellan had comparatively lower apparent viscosities than either KOP or xanthan. However, at higher concentrations $(1.2 \%, \mathrm{w} / \mathrm{v})$, gellan gave very high apparent viscosities. It reached over $2000 \mathrm{cP}$ at 6 $\mathrm{s}^{-1}$ compared to 1400 and $1100 \mathrm{cP}$ reached by KOP and xanthan, respectively, at the same shear rate. The rheological behavior of the KOP resembled that of xanthan more than gellan gum. The KOP formed non newtonian fluids. The viscosity increased as the shear rates were decreased. This indicated that KOP is a pseudoplastic biopolymer and has a shear thinning effect.

Mata et al. (2006) studied exopolysaccharides produced by the strains of Halomonas ventosae $\left(\mathrm{A} 112^{\mathrm{T}}\right.$ and $\left.\mathrm{Al16}\right)$ and Halomonas anticariensis $\left(\mathrm{FP} 35^{\mathrm{T}}\right.$ and 
FP36), under optimum environmental and nutritional conditions. They made rheological measurements at $25^{\circ} \mathrm{C}$ in a controlled-stress Bohlin CSR10 rheometer. All EPSs produced solutions of low viscosity and pseudoplastic behaviour. For comparison's sake the viscosities of the four polymers at a shear rate of $59.5 \mathrm{~s}^{-1}$ are $3.13 \times 10-3,2.79 \times 10^{-3}, 3.92 \times 10^{-3}$ and $2.85 \times 10^{-3}$, respectively.

\section{IV.4. BIOCOMPATIBILITY STUDIES}

\section{IV.4.1. Inhibition of Toxic Activity}

The inhibitory effect of EPS on the toxic activity of the sesquiterpene hydroquinone avarol ( $\mathrm{LD}_{50} 0.18 \mathrm{ppm}$ ) on brine shrimp (Artemia salina) was tested. With decreasing doses of EPS solution (500 ppm, 50 ppm, 5 ppm, respectively), survivor shrimps increased $(2,13,16$, respectively). Activity for EPS isolated from Halomonas sp AAD6 strain was found that increased the value of $\mathrm{LD}_{50}$ of Avarol from $0.18 \mathrm{ppm}$ up to $10 \mathrm{ppm}$.

\section{IV.4.2. Cell Culture Results}

To asses the biocompatibility of EPS, basic in vitro tests were performed with osteoblast cells isolated from the calvaria of Wistar rats. Osteoblast cell cultures were stimulated with EPS and after $48 \mathrm{~h}$ incubation, osteoblasts morphology, viability and secretion capability (alkaline phosphatase) were tested. No evident change in cell morphology was detected when stimulated cells were analysed by inverted optical microscopy. As shown in Figure IV.3, comparing to control, there was no significant difference in viability and alkaline phosphatase production when the osteoblasts were incubated in the presence of EPS. 


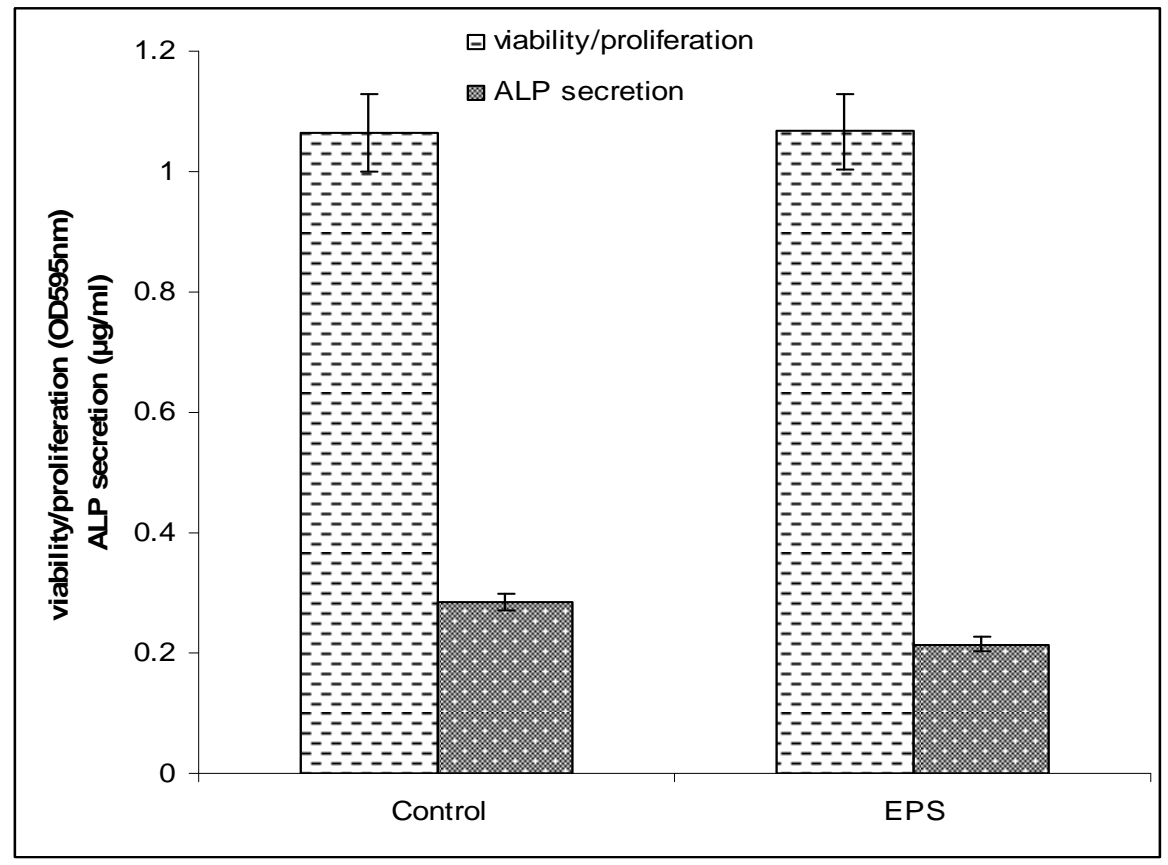

Figure IV.3. Biocompatibility results of EPS

The polysaccharide, that we produced, did not affect cellular viability and proliferation on osteoblasts, supporting the high biocompatibility of this EPS. Moreover in the Brine shrimp test the polymer, at low concentration (5 ppm), showed a protective effect against the toxic activity of Avarol, suggesting a potential anti-cytotoxic role of this polysaccharide. In the light of the results of this study, it can be concluded that the EPS produced by the Halomonas sp. AAD6 strain can be considered quite promising for industrial exploitation and is worthy of further investigation to determine the most suitable fields of application.

\section{IV.5. CHEMICAL CHARACTERIZATION RESULTS}

Sugar Analysis Most EPS are composed of the neutral sugars glucose, galactose and/or rhamnose. Some of them also consist of (acetylated) amino sugars. The strain, the culture conditions, and the type of carbon source influence the amount and the composition of microbial EPS that is produced by a certain species. Read and Costerton (1987) found that with glucose as a carbon source, $P$. putida and Pseudomonas fluorescens synthesized an EPS composed of glucose, galactose and pyruvate. Hung et al. (2005) found that EPS produced by P. fluorescens Biovar II was composed of galactose, mannose, rhamnose, glucose, fucose, ribose, arabinose and xylose. Kachlany et al. (2001) revealed that the purified EPS from P. putida G7 contained the monosaccharides, glucose, rhamnose, ribose, $\mathrm{N}$-acetylgalactosamine and glucuronic acid. Similarly, some researches showed that EPS were isolated from 
Pseudomonas caryophylli CFR 1705 grown on lactose containing medium was composed of rhamnose, mannose and glucose in the ratio 1:3.26:4.97, respectively. Also, EPS production and its monomeric sugar composition were dependent on the carbon source, nitrogen source and carbon/nitrogen ratio of the growth medium (Çelik et al., 2008).

In our study, sugar analysis was performed by hydrolysis of EPS with $0.5 \mathrm{M}$ trifluoroacetic acid (TFA) at $120{ }^{\circ} \mathrm{C}$ for $1.5 \mathrm{~h}$ and was identified by HPAE-PAD using standards for identification and calibration curves. Hydrolysis of EPS showed a peak attributable to fructose presence (RT $7.8 \mathrm{~min}$ ).

Poli et al. (2004) studied with a haloalkalophilic Halomonas strain CRSS, isolated from salt sediments in Antarctica. The growth was tested in two complex media (Medium A and B) and in the minimal medium $\mathrm{C}$ with $1 \%(\mathrm{w} / \mathrm{v})$ sodium acetate, D-glucose, D-galactose, lactic acid, D-maltose, D-fructose, D-cellobiose, Dribose, D-trehalose, glycerol or sucrose. The maximum yield of EPS for all media was reached after $48 \mathrm{~h}$ of incubation. The isolate grew well in the media $\mathrm{A}, \mathrm{B}$, and $\mathrm{C}$ plus sodium acetate producing (g EPS/g dry cells) 2.2, 2.9, 1.23, respectively. The sugar composition of EPS was performed by TLC and HPAE-PAD using standards for identification and calibration curves. It was yielded as principal constituents: mannose, glucose, galactose, glucosamine and galactosamine in relative proportion of 1:0.1:trace:trace:trace in the EPS from medium A; mannose, xylose, glucose, galactosamine, fructose, rhamnose and unknown component (UK 3) in a relative proportion of 1:0.7:0.3:0.2:trace:trace: 0.3 in the EPS from medium B; glucose, fructose, glucosamine and galactosamine in relative proportion of 1:0.7:0.3:trace in the EPS from medium $\mathrm{C}$ plus sodium acetate. Two different polymers, a mannan and a xylo-mannan, were obtained from the culture supernatants using complex media A and $\mathrm{B}$, respectively, while strain CRSS produced a new polysaccharide, a fructoglucan, when it was grown on acetate medium.

Thermogravimetric analysis of EPS in this study indicated a degradation temperature (Td) of $253{ }^{\circ} \mathrm{C}$ (Fig. IV.4.a). Moreover, the infrared spectrum of this biopolymer showed the characteristic peak signals of polysaccharides: broad stretching peak at around $3300 \mathrm{~cm}^{-1}$, (OH stretching), a weak $\mathrm{C}-\mathrm{H}$ band at around $2900 \mathrm{~cm}^{-1}, \mathrm{C}=\mathrm{O}$ stretching at $1660 \mathrm{~cm}^{-1}$ and several sharp peaks around $1000 \mathrm{~cm}^{-1}$ typical of carbohydrates (Fig. IV.4.b). 
a)

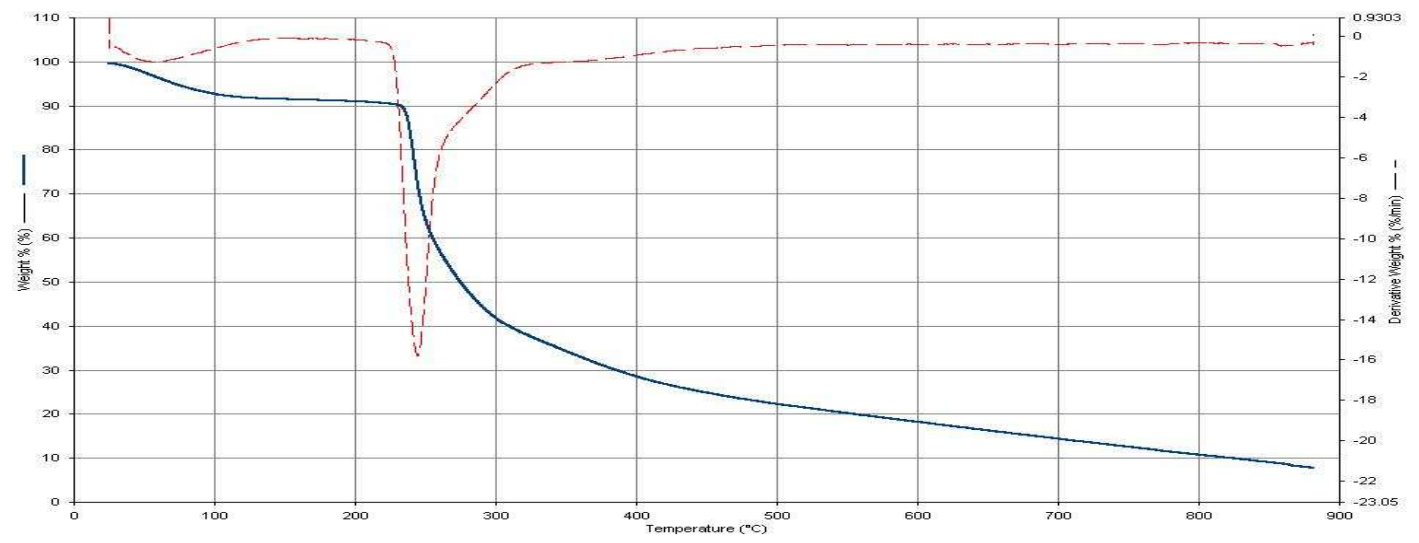

b)

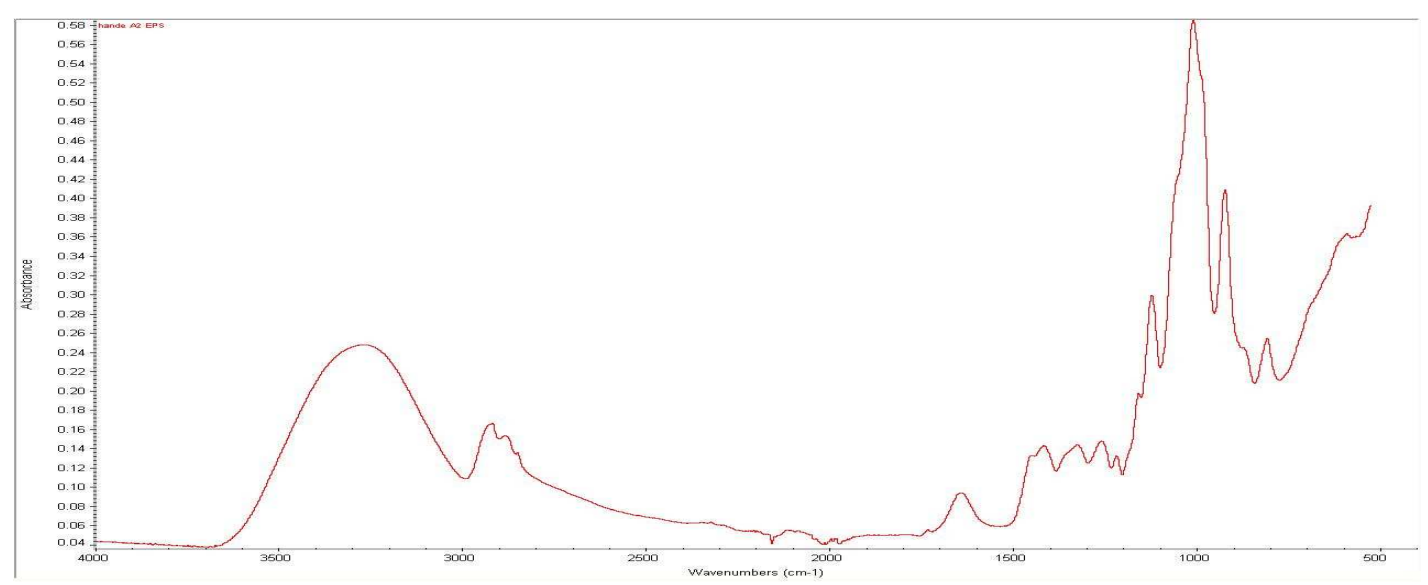

Figure IV.4. TGA thermogram (a) and Fourier transform-infrared spectroscopy spectrum (b) of the EPS from Halomonas sp. AAD6.

Molecular Size Analysis The molecular size of EPS, estimated using a calibration curve of standard dextrans obtained by gel filtration on Sepharose CL-6B and also by density gradient centrifugation, was greater than 1,000,000 Da.

$\boldsymbol{U V}$ Spectra Results The UV spectra of EPS, obtained by reading the absorbance of aqueous solutions from 350 to $210 \mathrm{~nm}$ on a Varian DMS-90 instrument, did not indicate any strong absorption peaks in that range. 


\section{PART V}

\section{CONCLUDING REMARKS AND RECOMMENDATIONS}

In the light of this study, several recommendations can be drawn for future work related to the EPS production by halophilic Halomonas sp AAD6.

Although it is possible to influence the production yields, compositions, structures and properties of bacterial EPS by modifying culture conditions, these factors can be genetically determined. It is possible that the levels of production of exopolysaccharides by Halomonas $s p$. can be improved by metabolic modeling of exopolysaccharide production. On the other hand, composition of the EPS can be modified by metabolic engineering.

There is no published research on the use of bioflocculants of halophilic origin in high-salinity biotreatment processes. Therefore, it is of utmost importance to explore the potential of the EPS isolated from the halophilic Halomonas sp AAD6 as a bioflocculant agent under different conditions. Flocculating capabilitiy of this EPS should be studied. On the other hand, halophilic EPS producers are considered as an interesting source for microbial enhanced oil recovery (MEOR) where polymers act as emulsifiers and mobility controllers. It's important to study the emulsifying capacity of this EPS for future work.

The potential of this EPS in various pharmaceutical applications need to be investigated. The real potential of this biopolymer in pharmaceutical industry should be clarified.

The use of alternative regional low-cost substrates has become very interesting because in addition to the ease of acquisition it presents a relatively low cost. With the ultimate goal of developing a cost-effective and environmentally friendly biopolymer production process, the potential use of different waste streams as fermentation substrates should be evaluated for the production of EPS from Halomonas sp AAD6. In order to make the production process of this novel EPS cost-competitive with petrochemical-derived polymers, studies should be conducted on the potential use of cheaper fermentation substrates. 


\section{REFERENCES}

[1] Arakawa, Y.; Wacharotayankun, R.; Nagatsuka, T.; Ito, H.; Kato, N.; Ohta, M.: "Genomic organization of the Klebsiella pneumoniae cps region responsible for serotype K2 capsular polysaccharide synthesis in the virulent strain Chedid", $J$. Bacteriol., 177 (1995) 1788-1796.

[2] Arco, Y.; Llamas, I.; Martinez-Checa, F.; Argandona, M.; Quesada E.; del Moral, A.: "epsABCJ genes are involved in the biosynthesis of the exopolysaccharide mauran produced by Halomonas maura", Microbiology, 151 (2005) 2841-2851.

[3] Arias, S.; Ferrer, M.R.; del Moral, A.E; Quesada V Béjar Mauran: “An exopolysaccharyde produced by the halophilic bacterium Halomonas maura, with a novel composition and interesting properties for biotechnology", Extremophiles 7, (2003) 319-324.

[4] Årsköld, E.; Svensson, M.; Grage, H.; Roos,S.; Rådström, P.; van Niel, Ed W.J.: "Environmental influences on exopolysaccharide formation in Lactobacillus reuteri ATCC 55730”, International Journal of Food Microbiology, 116 (2007) $159-167$.

[5] Bauer, R.: "Physiology of Dematium pullulans de Bary", Zentralbl Bacteriol Parasitenkd Infektionskr Hyg Abt2, 98 (1938)133-167.

[6] Bender, H.; Lehmann, J.; Wallenfels, K.: "Pullulan, an extracellular glucan from Pullularia pullulans", Biochimica et Biophysica Acta, 36 (1959) 309-316.

[7] Blumenkrantz, N.; Asboe-Hansen, G.: "New method for quantitative determination of uronic acids", Anal Biochem, 54 (1973) 484-489.

[8] Bock, K.; Pedersen, C.: "Carbon-13 nuclear magnetic resonance spectroscopy of monosaccharides", Adv Carbohyd Chem Biochem, 41 (1983) 27-66.

[9] Boels, I.C.; van Kranenburg, R.; Hugenholtz, J.; Kleerebezem, M.; de Vos, W.M.: "Sugar catabolism and its impact on the biosynthesis and engineering of exopolysaccharide production in lactic acid bacteria", International Dairy Journal, 11 (2001) 723-732.

[10]Bouchotroch, S.; Quesada, E.; Izquierdo, I.; Rodriguez, M.; Bejar, V.: "Bacterial exopolysaccharides produced by newly discovered bacteria belonging to the 
genus Halomonas, isolated from hypersaline habitats in Morocco", J Indust Microbiol Biotechnol, 24 (2000) 374-378.

[11]Bradford, M.M.: "A rapid and sensitive method for the quantification of microgram quantities of protein utilizing the principle of protein-dye binding", Anal Biochem, 72 (1976) 248-254.

[12]Bugert, P.; Geider, K.: "Molecular analysis of the ams operon required for exopolysacchaide synthesis of Erwinia amylovora", Mol. Microbiol., 15 (1995) 917-933.

[13]Calvo, C.; Ferrer, M.R.; Béjar, V.; Martínez-Checa, F.; Quesada, E.: "Some Rheological properties of the extracellular polysaccharide produced by Volcaniella eurihalina F2-7”, Appl. Biochem. Biotechnol., 55 (1995) 45-54.

[14]Cerning, J.; Renard, C.M.G.C.; Thibault, J.F.; Bouillanne, C.; Landon, M.; Desmazeaud, M.; Topisirovic, L.: "Carbon source requirements for exopolysaccharide production by Lactobacillus casei CG11 and partial structure analysis of the polymer", Applied and Environmental Microbiology, 60 (1994) 3914-3919.

[15]Chen, W.; Zhao, Z.; Chen, S.F.; Li, Y.Q.: "Optimization for the production of exopolysaccharide from Fomes fomentarius in submerged culture and its antitumor effect in vitro", Bioresource Technology, 99 (2008) 3187-3194.

[16]Chi, Z.; Su, C.D.; Lu, W.D.: “A new exopolysaccharide produced by marine Cyanothece sp. 113”, Bioresource Technology, 98 (2007) 1329-1332.

[17]Comte, S.; Guibaud, G.; Baudu, M.: "Biosorption properties of extracellular polymeric substances (EPS) towards $\mathrm{Cd}, \mathrm{Cu}$ and $\mathrm{Pb}$ for different $\mathrm{pH}$ values", Journal of Hazardous Materials, 151(1) (2008) 185-193.

[18]Cui, F.J.; Li, Y.; Xu, Z.H.; Xu, H.Y.; Sun, K.; Tao, W.Y.: “Optimization of the medium composition for production of mycelial biomass and exo-polymer by Grifola frondosa GF9801 using response surface methodology", Bioresource Technology, 97 (2006) 1209-1216.

[19]Çelik, G.Y.; Aslim, B.; Beyatli, Y.: "Characterization and production of the exopolysaccharide (EPS) from Pseudomonas aeruginosa G1 and Pseudomonas putida G12 strains", Carbohydr Polym, 73 (2008) 178-182.

[20]de Oliveira, M.R.; da Silva, R.S.S.F.; Buzato, J.B.; Colabone Celligoi, M.A.P.: "Study of levan production by Zymomonas mobilis using regional low-cost carbohydrate sources", Biochem Eng J, 37 (2007) 177-183. 
[21]Desai, K.M.; Akolkar, S.K.; Badhe, Y.P.; Tambe, S.S.; Lele, S.S.: “Optimization of fermentation media for exopolysaccharide production from Lactobacillus plantarum using artificial intelligence-based techniques", Process Biochemistry, 41 (2006) 1842-1848.

[22]Dlamini, A.M; Peiris, P.S.; Bavor, J.H.; Kailasapathy. K.: "Characterization of the exopolysaccharide produced by a whey utilizing strain of Klebsiella oxytoca", African J Biotechnol, 6(22) (2007) 2603-2611.

[23]Dubois, M.A.; Gilles, K.A.; Hamilton, J.K.; Robers, P.A.; Smith, F.: "Colorimetric method for determination of sugars and related substances", Anal Chem, 28 (1956) 350-356.

[24]El-Tayeb, T.S. and Khodair, T.A.: "Production and Purification of a Bioemulsifier and Flocculating Agent Produced by Pseudomonas sp.UBF 2", J Appl Sci Res, 3(11) (2007) 1564-1570.

[25]Fett, W.F.: "Naturally occurring biofilms on alfalfa and other types of sprouts", J. Food Prot., 63 (2000) 625-632.

[26]Fialho, A.M.; Martins, L.O.; Donval, M.L.; Leitao, J.H.; Ridout, M.J.; Jay, A.J.; Morris, V.J.; Sa-Correia, I.: "Structures and Properties of Gellan Polymers Produced by Sphingomonas paucimobilis ATCC 31461 from Lactose Compared with Those Produced from Glucose and from Cheese Whey", Applied And Environmental Microbiology, 65(6) (1999) 2485-2491.

[27]Finney, D.J.: "Probit analysis", $3^{\text {rd }}$ Edition.; Cambridge University Press, Cambridge (1971).

[28]Franz, G.: "Polysaccharides in Pharmacy: Current Applications and Future Concepts", Planta Medica, 55 (1989) 493-497.

[29]Gao, J.; Bao, H.Y.; Xin, M.X.; Liu, Y.X.; Li, Q.; Zhang, Y.F.: “Characterization of a bioflocculant from a newly isolated Vagococcus sp. W31”, J. Zhejiang Univ. Sci. B., 7(3) (2006) 186-192.

[30]González-Domenech, C.M.; Martínez-Checa, F.; Quesada, E.; Béjar, V.: "Halomonas cerina sp. nov., a moderately halophilic, denitrifying, exopolysaccharide-producing bacterium”, Int. J. Syst. Evol. Microbiol., 58 (2008) 803-809.

[31]Grothe, E.; Moo-Young, M.; Chisti, Y.: "Fermentation optimization for the production of poly( $\beta$-hydroxybutyric acid) microbial thermoplastic", Enzyme and Microbial Technology, 25 (1999) 132-141. 
[32]Guibaud, G.; Tixier, N.; Bouju, A.; Baudu, M.: "Relation between extracellular polymer' composition and its ability to complex $\mathrm{Cd}, \mathrm{Cu}$ and $\mathrm{Pb}$ ", Chemosphere, 52 (2003) 1701-1710.

[33]Hsieh, C.; Tsai, M.J.; Hsu, T.H.; Chang, D.M.; Lo, C.T.: "Medium optimization for polysaccharide production of Cordyceps sinensis", Appl. Biochem. Biotechnol., 120 (2005) 145-157.

[34]Huang, H.C.; Liu, Y.C.: "Enhancement of polysaccharide production by optimization of culture conditions in shake flask submerged cultivation of Grifola umbellata", Journal- Chinese Institute of Chemical Enginners, 39( 4) (2008) 307-311.

[35]Hugenholtz, J.; Looijesteijn, E.; Starrenburg, M.; Dijkema, C.: "Analysis of sugar metabolism in an EPS producing Lactococcus lactis by 31P NMR", Journal of Biotechnology, 77 (2000) 17-23.

[36]Hung, C.C.; Santschi, P.H.; Gillow, J.B.: "Isolation and characterization of extracellular polysaccharides produced by Pseudomonas fluorescens Biovar II", Carbohydrate Polymers, 61 (2005) 141-147.

[37]Iyer, A.; Mody Kaplana; Bhavanath Jha: "Emulsifying properties of a marine bacterial exopolysaccharide”, Enzyme Microb Technol, 38 (2006) 220-222.

[38]Kachlany, S.C.; Levery, S.B.; Kim, J.S.; Reuhs, B.L.; Lion, L.W.; Ghiorse, W.C.: "Structure and carbohydrate analysis of the exopolysaccharide capsule of Pseudomonas putida G7”, Environmental Microbiology, 3 (2001) 774-784.

[39]Katzen, F.; Ferreiro, D.U.; Oddo, C.G.; Ielmini, M.V.; Becker, A.; Pühler, A.; Ielpi, L.: "Xanthomonas campestris pv. Campestris gum mutants: effects on xanthan biosynthesis and plant virulence”, J. Bacteriol., 180 (1998) 1607-1617.

[40]King, R.B.; Long, G.M.and Sheldon, J.K.: "Practical Environmental Bioremediation", The Field Guide, CRC Press LLC, (1998) Florida.

[41]Koçer, E.; Tükel, Ç.; Akçelik, M.: "Conjugal Transfer and Stability of the Plasmids Determining Exopolysaccharide Production in Lactococcus lactis Strains", Turk. J. Vet. Anim. Sci., 28 (2004) 481-487.

[42]Kolkman, M.A.; Wakarchuk, W.; Nuijten, P.J.; van der Zeijst, B.A.: “Capsular polysaccharide synthesis in Streptococcus pneumoniae serotype 14: molecular analysis of the complete cps locus and identification of genes encoding glycosyltransferases required for the biosynthesis of the tetrasaccharide subunit", Mol. Microbiol., 26 (1997) 197-208. 
[43]Kulichevskaya, I.S.; Milekhina, E.I.; Borzenkov, I.A.; Zvyagintseva, I.S.; Belyaev, S.S.: "Oxidation of petroleum hydrocarbons by extremely halophilic archaeabacteria", Microbiology, 60 (1998) 596-601.

[44]Kumar, C.G.; Joo, H.; Choi, J.; Koo, Y.; Chang, C.: "Purification and characterization of an extracellular polysaccharide from haloalkalophilic Bacillus sp. I-450”, Enzyme Microb Technol, 34 (2004) 673-681.

[45]Lambo-Fodje, A.M.; Leeman, M.; Wahlund, K.G.; Nyman, M.; Öste, R.; Larsson, H.: "Molar mass and rheological characterisation of an exopolysaccharide from Pediococcus damnosus 2.6", Carbohydr Polym, 68 (2007) 577-586.

[46]Lee, S.Y.; Park, S.J.; Park, J.P.; Lee, Y.; Lee, S.H.: "Economic aspects of biopolymer production", Biopolymers, VCH-Wiley, Weinheim, Germany, Vol. 10, Ch. 2 (2002) 307-337.

[47]Lee, W.Y.; Park, Y.; Ahn, J.K.; Ka, K.H.; Park, S.Y.: "Factors influencing the production of endopolysaccharide and exopolysaccharide from Ganoderma applanatum”, Enzyme and Microbial Technology, 40 (2007) 249-254.

[48]Levander, F.; Svensson, M.; Rådström, P.: "Enhanced exopolysaccharide production of Streptococcus thermophilus", Appl. Environ. Microbiol, 68 (2002) 784-790.

[49]Li, W.W.; Zhou, W.Z.; Zhang, Y.Z.; Wang, J.; Zhu, X.B.: "Flocculation behavior and mechanism of an exopolysaccharide from the deep-sea psychrophilic bacterium Pseudoalteromonas sp. SM9913", Bioresource Technology, 99(15) ( 2008) 6893-6899.

[50]Lin, W.S.; Cunneen, T.; Lee, C.Y.: "Sequence analysis and molecular characterization of genes required for the biosynthesis of type 1 capsular polysaccharide in Staphylococcus aureus”, J. Bacteriol., 176 (1994) 7005-7016.

[51]Liu, Y.; Lam, M.C.; Fang, H.H.P.: "Adsorption of heavy metal by EPS of activated sludge", Water. Sci. Technol., 43 (2001) 59-66.

[52]Loaëc, M.; Olierb, R.; Guezenneca, J.: "Chelating properties of bacterial exopolysaccharides from deep-sea hydrothermal vents", Carbohydrate Polymers, 35 (1998) 65-70.

[53]Lu, W.; Zhang, T.; Zhang, D.Y.; Li, C.H.; Wen, J.P.; Du, L.X.: "A novel bioflocculant produced by Enterobacter aerogenes and its use in defecating the trona suspension", Biochemical Engineering Journal, 27(1) (2005) 1-7. 
[54]Lungmann, P.; Choorit, W.; Prasertsan, P.: “Application of statistical experimental methods to optimize medium for exopolymer production by newly isolated Halobacterium sp. SM5”, Electronic Journal of Biotechnology, 10(1) (2007).

[55]Macedoa, M.G.; Lacroixa, C.; Gardnerb, N.J.; Champagne, C.P.: "Effect of medium supplementation on exopolysaccharide production by Lactobacillus rhamnosus RW-9595M in whey permeate", International Dairy Journal, 12 (2002) 419-426.

[56]Mahmoud M Nour El-Dein; Amira A El-Fallal; El-Shahat A Toson; Faten E Hereher: "Exopolysaccharides Production by Pleurotus pulmonarius: Factors Affecting Formation and Their Structures", Pak J Biol Sci, 7(6) (2004) 10781084.

[57]Manca, M.C.; Lama, L.; Improta, R.; Esposito, E.; Gambacorta, A.; Nicolaus, B: "Chemical composition of two exopolysaccharides from Bacillus thermoantarcticus", Appl Environ Microbiol, 62 (1996) 3265-3269.

[58]Mancuso Nichols, C.A.; Guezennec, J.; Bowman, J.P.: "Bacterial Exopolysaccharides from Extreme Marine Environments with Special Consideration of the Southern Ocean, Sea Ice, and Deep-Sea Hydrothermal Vents: A Review”, Marine Biotechnology, 7(4) (2005) 253-271.

[59]Manresa, A.; Espuny, M.J.; Guinea, J.; Comelles, F.: "Characterization and production of a new extracellular polymer from Pseudomonas sp. GSP-910”, Applied Microbiology and Biotechnology, 26 (1987) 347-351.

[60]Martinez-Cánovas, M.J.; Quesada, E.; Martinez-Checa, F.; Béjar, V.: “A taxonomic study to establish the relationship between exopolysaccharideproducing bacterial strains living in diverse hypersaline habitats", Current Microbiol, 48 (2004) 348-353.

[61]Martínez-Checa, F.; Toledo, F.L.; El Mabrouki, K; Quesada , E.; Calvo, C.: "Characteristics of bioemulsifer V2-7 synthesized in culture media added of hydrocarbons: Chemical composition, emulsifying activity and rheological properties", Bioresource Technology, 98 (2007) 3130-3135.

[62]Mata, J.A.; Béjar, V.; Llamas, I.; Arias, S.; Bressollier, P.; Tallon, R.; Urdaci, M.C.; Quesada, E.: "Exopolysaccharides produced by the recently described halophilic bacteria Halomonas ventosae and Halomonas anticariensis", Res Microbiol, 157 (2006) 827-835. 
[63]Matsunaga, T.; Sudo, H.; Takemasa, H.; Wachi, Y.: "Sulfated extracellular polysaccharide production by the halophilic cyanobacterium Aphanocapsa halophytica immobilized on light-diffusing optical fibers", Appl Microbiol Biotechnol, 45 (1996) 24-27.

[64]Maugeri, T.L.; Gugliandolo, C.; Caccamo, D.; Panico, A.; Lama, L.; Gambacorta, A.; Nicolaus, B.: "A halophilic thermotolerant Bacillus isolated from a marine hot spring able to produce a new exopolysaccharide", Biotechnology Letter, 24 (2002) 515-519.

[65]Melo, I.R.; Pimentel, M.F.; Lopes, C.E.; Calazans, G.M.T.: "Application of Fractional Factorial Design to Levan Production by Zymomonas Mobilis", Brazilian Journal of Microbiology, 38 (2007) 45-51.

[66]Meyer, B.N.; Ferrigni, N.R.; Putnam, J.E.; Jacobsen, L.B.; Nichols, D.E.; McLaughlin, J.L.: "Brine shrimp: a convenient general bioassay for active plants constituents", Planta Med, 45 (1982) 31-34.

[67]Mironescu, M.: "Microbial Polysaccharides. Production, Characterisation And Properties", Food Technology, 7(2) (2003) 26-38.

[68]Mojica, K.; Elsey, D.; Cooney, J.M.: "Quantitative analysis of biofilm EPS uronic acid content", J Microbiol Methods, 71 (2007) 61-65.

[69]Morona, J.K.; Morona, R.; Paton, J.C.: "Characterization of the locus encoding the Streptococcus pneumoniae type 19F capsular polysaccharide biosynthetic pathway", Mol. Microbiol., 23 (1997) 751-763.

[70]Mossman, T.: "Rapid colorimetric assay for cellular growth and survival: application to proliferation and cytotoxic assays", Journal of Immunology Methods, 65 (1983) 55-63.

[71]Nicolaus, B.; Lama, L.; Manca, M.C.; Gambacorta, A.: "Extremophiles: polysaccharides and enzymes degrading polysaccharides", Recent. Res. Devel. Biotech. Bioeng., 2 (1999) 37-64.

[72]Nicolaus, B.; Panico, A.; Manca, M.C.; Lama, L.; Gambacorta, A.; Maugeri, T.L.; Gugliandolo, C.; Caccamo, D.: “A thermophilic Bacillus isolated from an Eolian shallow hydrothermal vent, able to produce exopolysaccharides", System Appl Microbiol, 23 (2000) 426-432.

[73]Pazur, J.H.: "In Carbohydrate analysis", $2^{\text {nd }}$ Edition,; Chaplin, M.F.; Kennedy, J.F.Editors.; IRL Press, Oxford, (1994) 73-124. 
[74]Poli, A.; Manca, M.C.; De Giulio, A.; Strazzullo, G.; De Rosa, S.; Nicolaus, B.: "Bioactive exopolysaccharides from the cultured cells of tomato, Lycopersicon esculentum var. San Marzano", J Na. Prod, 69(4) (2006) 658-661.

[75]Poli, A.; Moriello, V.S.; Esposito, E.; Lama, L.; Gambacorta, A.; Nicolaus, B.: "Exopolysaccharide production by a new Halomonas strain CRSS isolated from saline lake Cape Russell in Antarctica growing on complex and defined media”, Biotechnol Lett, 26 (2004) 16351638.

[76]Prasertsan, P.; Wichienchot, S.; Doelle, H.; Kennedy, J.F.: "Optimization for biopolymer production by Enterobacter cloacae WD7", Carbohydr Polym, 71 (2008) 468-475.

[77]Quesada, E.; Béjar, V.; Calvo, C.: "Exopolysaccharide production by Volcaniella eurihalina”, Experientia, 49 (1993) 1037-1041.

[78]Raguénès, G.H.C.; Peres, A.; Ruimy, R.; Pignet, P.; Christen, R.; Loaec, M.; Rougeaux, H.; Barbier, G.; Guezennec, J.G.: "Alteromonas infernus sp. nov., a new polysaccharide-producing bacterium isolated from a deep-sea hydrothermal vent”, J Appl Microbiol, 82 (1997) 422-430.

[79]Rahn, A.; Drummelsmith, J.; Whitfield, C.: "Conserved organization in the cps gene clusters for expression of Escherichia coli group $1 \mathrm{~K}$ antigens: relationship to the colanic acid biosynthesis locus and the cps genes from Klebsiella pneumoniae”, J. Bacteriol., 181(1999) 2307-2313.

[80]Read, R.R.; Costerton, J.W.: "Purification and characterisation of adhesive exopolysaccharides from Pseudomonas putida and Pseudomonas fluorescens", Canadian Journal of Microbiology, 33 (1987) 1080-1090.

[81]Rekha, M.R.; Sharma, C.P.: "Pullulan as a Promising Biomaterial for Biomedical Applications: A Perspective", Trends Biomater. Artif. Organs, 20(2) (2007).

[82]Reuber, T.L.; Walker, G.C.: "Biosynthesis of succinoglycan, a symbiotically important exopolysaccharide of Rhizobium meliloti”, Cell, 74 (1993) 269-280.

[83]Rinker, K.D.; Kelly, R.M.: "Effect of carbon and nitrogen sources on growth dynamics and exopolysaccharide production of the hyperthermophilic archaeon Thermococcus litoralis and bacterium Thermotoga maritima", Biotechnol Bioeng, 69 (2000) 537-547. 
[84]Roger, O.; Kervarec, N.; Ratiskol, J.; Colliec-Jouault, S.; Chevolot, L.: "Structural studies of the main exopolysaccharide produced by the deep-sea bacterium Alteromonas infernus", Carbohydr Res, 339(14) (2004) 2371-2380.

[85]Romano, I.; Gambacorta, A.; Lama, L.; Nicolaus, B.; Giordano, A.: "Salinivibrio costicola subsp. alcaliphilus subsp. nov., a haloalkaliphilic aerobe from Campania Region (Italy)", Systematic and Applied Microbiology, 28(1) (2005) 34-42.

[86]Rosalam S. and England R.: "Review of xanthan gum production from unmodified starches by Xanthomonas comprestris sp.", Enzyme and Microbial Technology, 39( 2) (2006) 197-207.

[87]Ruas-Madiedo, P.; de los Reyes-Gavilan, C.G.: "Methods for the screening, Isolation, and Characterization of Exopolysaccharides Produced by Lactic Acid Bacteria”, J. Dairy Sci., 88 (2003) 843-856.

[88] Schiano Moriello, V.; Lama, L.; Poli, A.; Gugliandolo, C.; Maugeri, T.L.; Gambacorta, A.; Nicolaus, B.: "Production of exopolysaccharides from a thermophilic microorganism isolated from a marine hot spring in flegrean areas", J Ind Microbiol Biotechnol, 30 (2003) 95-101.

[89]Scott, R.; Cade, D.; He, X.: "Pullulan film compositions”, US Patent 6887 307, (2005).

[90]Shih, I.L.; Yu, Y.T.; Shieh, C.J.; Hsieh, C.Y.: "Selective Production and Characterization of Levan by Bacillus subtilis (Natto) Takahashi”, J. Agric. Food Chem., 53 (2005) 8211-8215.

[91] Shingel, K.I.: "Current knowledge on biosynthesis, biological activity, and chemical modification of the exopolysaccharide, pullulan", Carbohdrate Research, 339 (2004) 447-460.

[92] Shene, C.; Bravo, S.: "Whey fermentation by Lactobacillus delbrueckii subsp. bulgaricus for exopolysaccharide production in continuous culture", Enzyme and Microbial Technology, 40 (2007) 1578-1584.

[93]Simms, P.J.; Boyko, W.J.; Edwards, J.R.: "The structural analysis of a levan produced by Streptococcus salivarius SS2”, Carbohydr Res, 208 (1990) 193198.

[94]Singh, R.S.; Saini, G.K.; Kennedy, J.F.: "Pullulan: Microbial sources, production and applications", Carbohydrate Polymers, 73 (2008) 515-531. 
[95]Stingele, F.J.R.; Neeser, J.R.; Mollet, B.: "Identification and characterization of the EPS (exopolysaccharide) gene cluster from Streptococcus thermophilus Sfi6”, Journal of Bacteriology, 178 (1996)1680-1690.

[96] Stingele, F.; Newell, J.W.; Neeser, J.R.: "Unraveling the Function of Glycosyltransferases in Streptococcus thermophilus Sfi6", Journal of Bacteriology, 181( 20) (1999) 6354-6360.

[97]Stredansky, M.; Conti, E.; Navarini, L.; Bertocchi, C.: "Production of bacterial exopolysaccharides by solid substrate fermentation", Process Biochemistry, 34 (1999) 11-16.

[98] Sutherland, I.W.: “The exopolysaccharides of Klebsiella serotype 2 strains as substrates for phage-induced polysaccharide depolymerases", Journal of general microbiology, 70(2) (1972) 331-8.

[99]Sutherland, I.W.: "Biotechnology of Microbial Exopolysaccharides", Cambridge University Press, (1990), Cambridge.

[100] Sutherland, I.W.: "Novel and established applications of microbial polysaccharides", Tibtech., 16 (1998) 41-46.

[101] Sutherland, I.: "A sticky business. Microbial polysaccharides: current products and future trends", Microbiol Today, 29 (2002) 70-71.

[102] Tallon, R.; Bressollier, P.; Urdaci, M.: "Isolation and characterization of two exopolysaccharides produced by Lactobacillus plantarum EP56", Res Microbiol, 154 (2003) 705-712.

[103] Thomas, A.D.; Volesky, B.; Mucci, A: "A review of the biochemistry of heavy metal biosorption by brown algae”, Water Res., 37 (2003) 4311-4330.

[104] Xu, C.P.; Kim, S.W.; Hwang, H.J.; Choi, J.W.; Yun, J.W.: "Optimization of submerged culture conditions for mycelial growth and exo-biopolymer production by Paecilomyces tenuipes C240”, Process Biochemistry, 38 (2003) 1025-1030.

[105] van Geel-Schutten, G.H.; Flesch, F.; ten Brink, B.; Smith, M.R.; Dijkhuizen, L.: "Screening and characterization of Lactobacillus strains producing large amounts of exopolysaccharides", Appl. Microbiol. Biotechnol., 50 (1998) 697703.

[106] van Geel-Schutten, G.H.; Faber, E.J.; Smit, E.; Bonting, K.; Smith, M.R.; Ten Brink, B.; Kamerling, J.P.; Vliegenthart, J.F.; Dijkhuizen, L.: "Biochemical and structural characterization of the glucan and fructan exopolysaccharides 
synthesized by the Lactobacillus reuteri wild-type strain and by mutant strains", Appl Environ Microbiol, 65(7) (1999) 3008-3014.

[107] van Kranenburg, R.J.; Marugg, D.; van Swam, I.I.; Willem, N.; de Vos, W.M.: "Molecular characterization of the plasmid-encoded eps gene cluster essential for exopolysaccharide biosynthesis in Lactococcus lactis", Mol. Microbiol., 24 (1997) 387-397.

[108] van Kranenburg, R.; Boels, I.C.; Kleerebezem, M.; de Vos, W.M.: "Genetics and engineering of microbial exopolysaccharides for food: approaches for the production of existing and novel polysaccharides", Current Opinion in Biotechnology, 10(5) (1999) 498-504.

[109] Welman, A.D; Maddox, I.S.: "Exopolysaccharides from lactic acid bacteria: perspectives and challenges", Trends in Biotechnology, 21(6) (2003) 269-274.

[110] Yang, B.Y.; Brand, J.M.; Gray, J.S.S.; Montgomery, R.: "Extracellular polysaccharides of modified strains of Erwinia spp.", Carbohydrate Research, 333 (2001) 295-302.

[111] Yeon, S.H.; Jeong, W.J.; Park, J.S.: "The Diversity of Culturable Organotrophic Bacteria from Local Solar Salterns", The Journal of Microbiology, 43(1) (2005) 1-10.

[112] Yoshida, T.; Ayabe, T.; Yasunaga, M.; Usami, Y.; Habe, H.; Nojiri, H.; Omori, T.: "Genes involved in the synthesis of the exopolysaccharide methanolan by the obligate methylotroph Methylobacillus sp. strain 12S", Microbiology, 149 (2003) 431-444.

[113] Yükselen, M.A.; Gregory, J.: "The reversibility of floc breakage", International Journal of Mineral Processing, 73(2-4) (2004) 251-259. 


\section{APPENDIX A}

\section{BIOMASS CALIBRATION CHART}

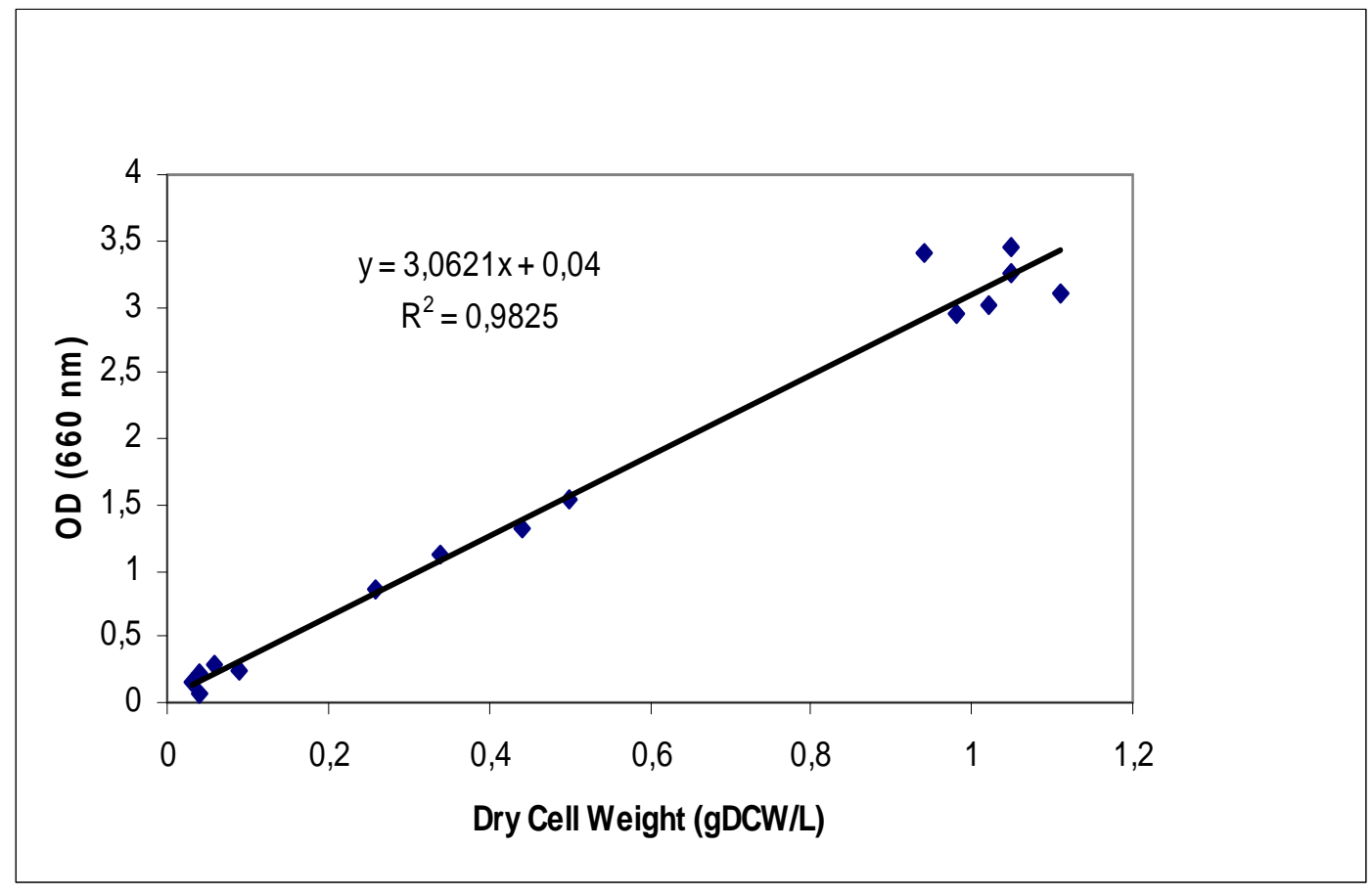

Figure A.1 Dry Cell Weight Calibration Chart 


\section{APPENDIX B}

\section{CARBOHYDRATE CALIBRATION CHART}

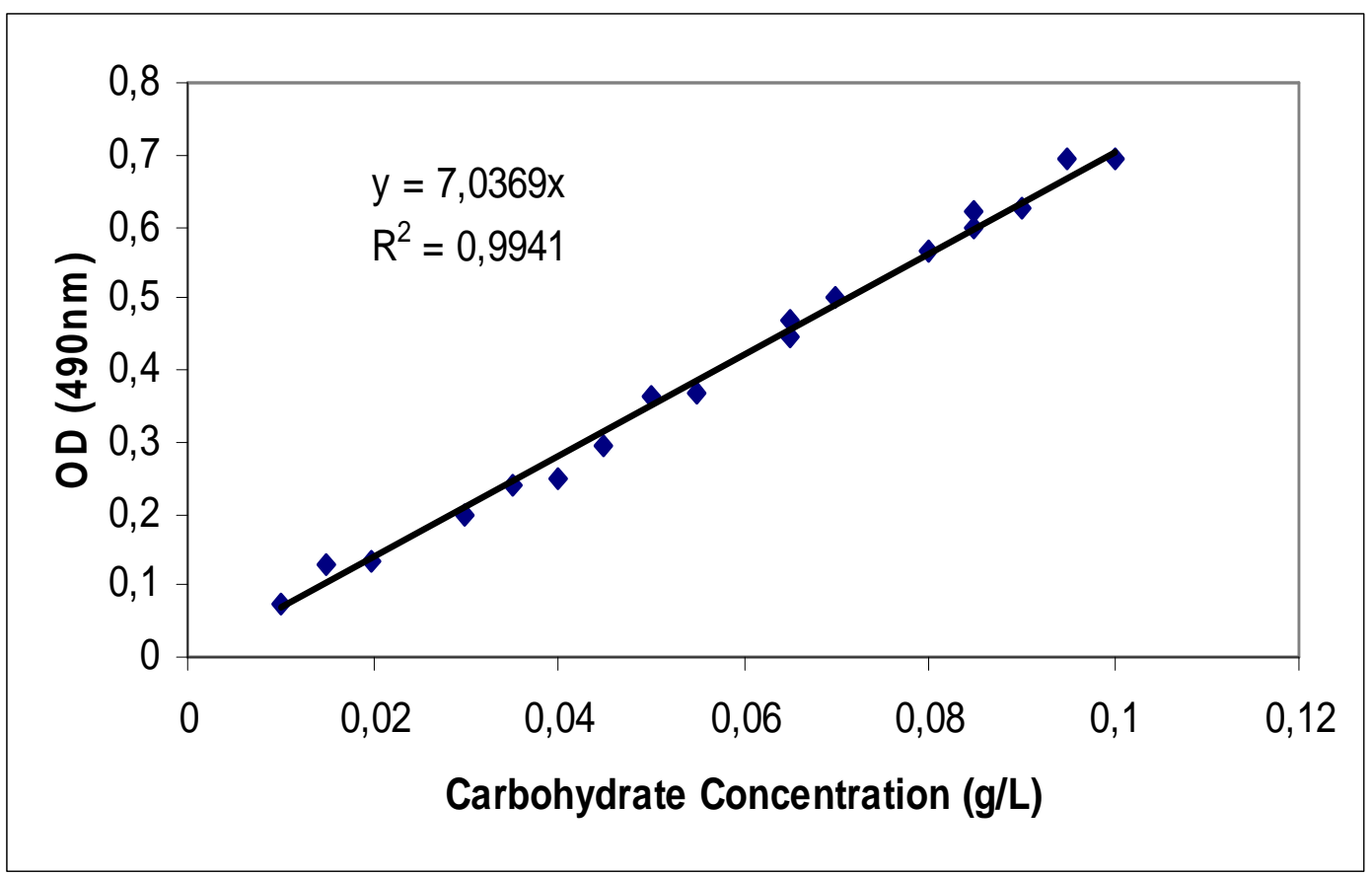

Figure B.1 Carbohydrate Calibration Chart 


\section{APPENDIX C}

\section{MAXIMUM SPECIFIC GROWTH RATE $\left(\mu_{\text {MAX }}\right)$ CHART}

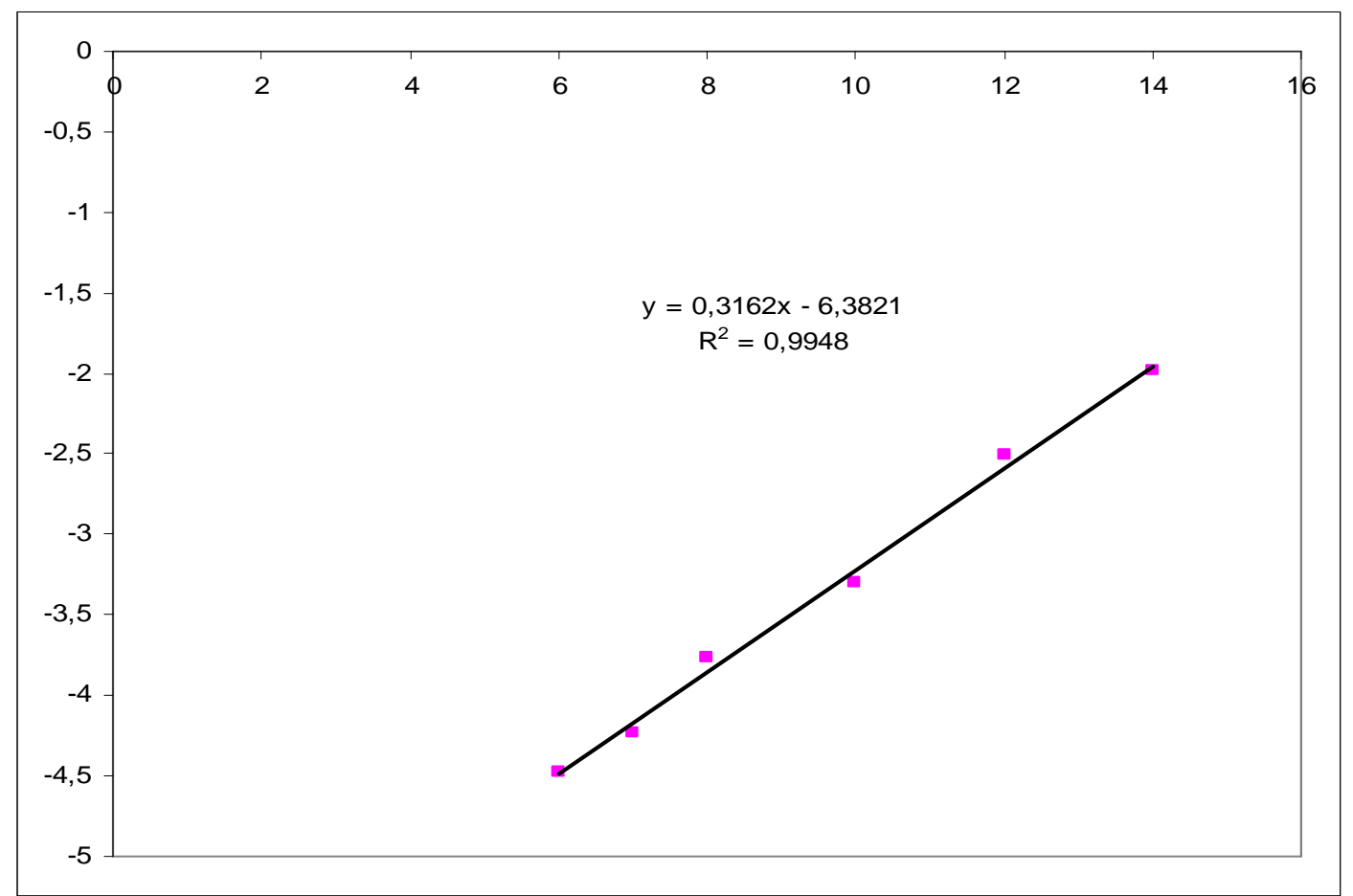

Figure C.1 Maximum Specific Growth Rate $\left(\mu_{\max }\right)$ Chart 


\section{APPENDIX D}

\section{ABSORBANCE OD $_{595}$ VERSUS PROTEIN CONCENTRATION CALIBRATION CHART}

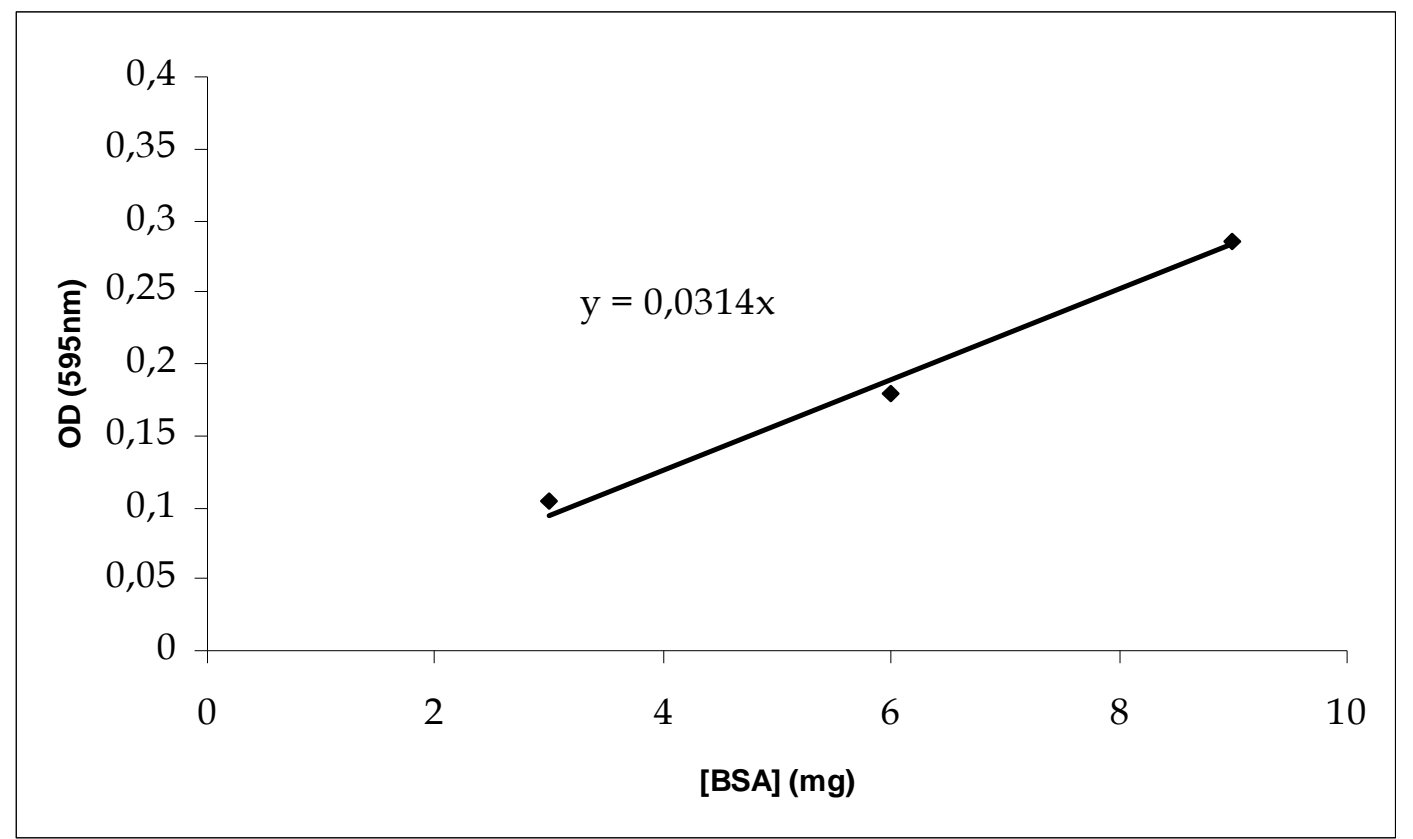

Figure D.1 Protein Calibration Chart 


\section{AUTOBIOGRAPHY}

I was born on 27 July 1983 in Izmir. I gratuated from Atakent Anatolian High School and I started on my undergraduate education in Ege University, Faculty of Engineering, Bioengineering Department in 2001. I graduated from Ege University Bioengineering Programme in 2006. I started master of science at Marmara University Biongineering Deparment in 2006.

\section{Presented Announcements}

- Hande Kazak, Bahar Gürleyendag, Annarita Poli, Ebru Toksoy Öner, Barbara Nicolaus, "Exopolysaccharide production by Halomonas strains isolated from Turkey", 13 $^{\text {th }}$ European Congress on Biotechnology (ECB 13), September 16-19, 2007, Barcelona, Spain, Poster Presentation

- Hande Kazak, Bahar Gürleyendag, Annarita Poli, Ebru Toksoy Öner, Barbara Nicolaus, "Ekstremofilik Mikroorganizmalardan Ekzopolisakkarit Üretimi", 15 $^{\text {th }}$ National Biotechnology Congress, October 28-31, 2007, Antalya, Turkey, Oral Presentation

- Ates, Ö., Kazak, H., Arga, K., Y., Toksoy Öner, E., "EPS Production from Proteomics Perspective", ICGEB International Center for Genetic Engineering and Biotechnology; Proteomic Approaches in Molecular Biology: Theory and Practice Course, March 03-14, 2008, Buenos Aires, Argentina, Poster Presentation

- Ateş, Ö., Kazak, H., Arga, K. Y., Toksoy Öner, E., "Metabolic Reconstruction and Modeling of Microbial Biopolymer Production", $9^{\text {th }}$ International Conference on Systems Biology (ICSB2008), August 22-28, 2008, Gothenburg, Sweden, Poster Presentation 


\section{MARMARA UNIVERSITY \\ THE INSTITUTE FOR}

GRADUATE STUDIES IN PURE AND APPLIED SCIENCES

\section{ACCEPTANCE AND APPROVAL DOCUMENT}

The jury established by the Executive Board of the INSTITUTE FOR GRADUATE STUDIES IN PURE AND APPLIED SCIENCES on 1.2... 01.2009..(Resolution no:2009/.02-26) has accepted Ms Hande KAZAK's thesis titled "EXOPOLYSACCHARIDE PRODUCTION BY HALOMONAS STRAINS ISOLATED FROM TURKEY" as Master of Science in Bioengineering.

Advisor : Assoc. Prof Ebru TOKSOY ÖNER

1. Member of the jury: Prof. Jülide AKBUĞA
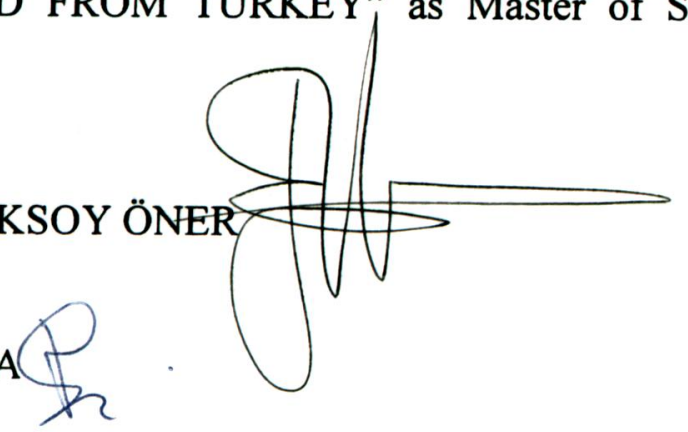

2. Member of the jury: Assist. Prof. Kazım Yalçın ARĞA

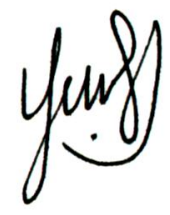

Date $: 19 \cdot 01.2009$

\section{APPROVAL}

Ms. Hande KAZAK has satisfactorily completed the requirements for the degree of Master of Science in Bioengineering at Marmara University. The Executive Commitee approves that

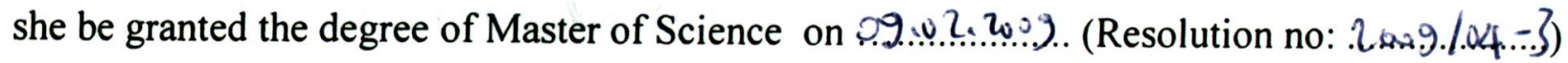

DIRECTOR OF THE INSTITUTE Prof. Dr. Sevil ÜNAL

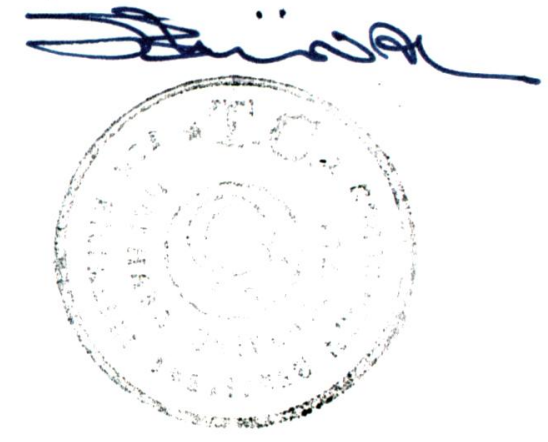

